\title{
Clinical Practice Guideline for the Treatment of Obstructive Sleep Apnea and Snoring with Oral Appliance Therapy: An Update for 2015
}

\author{
An American Academy of Sleep Medicine and American Academy of Dental Sleep Medicine \\ Clinical Practice Guideline
}

Kannan Ramar, MBBS, MD; Leslie C. Dort, DDS²; Sheri G. Katz, DDS³; Christopher J. Lettieri, MD; Christopher G. Harrod, MS5; Sherene M. Thomas, $\mathrm{PhD}^{5}$; Ronald D. Chervin, $\mathrm{MD}^{6}$

${ }^{1}$ Mayo Clinic, Rochester, MN; ${ }^{2}$ University of Calgary, Calgary, Alberta, Canada; ${ }^{3}$ Atlanta, GA; ${ }^{4}$ Walter Reed National Military

Medical Center, Bethesda, MD; ${ }^{5}$ American Academy of Sleep Medicine, Darien, IL; ${ }^{6}$ University of Michigan, Ann Arbor, MI

\begin{abstract}
Introduction: Since the previous parameter and review paper publication on oral appliances (OAs) in 2006, the relevant scientific literature has grown considerably, particularly in relation to clinical outcomes. The purpose of this new guideline is to replace the previous and update recommendations for the use of OAs in the treatment of obstructive sleep apnea (OSA) and snoring.
\end{abstract}

Methods: The American Academy of Sleep Medicine (AASM) and American Academy of Dental Sleep Medicine (AADSM) commissioned a seven-member task force. A systematic review of the literature was performed and a modified Grading of Recommendations Assessment, Development, and Evaluation (GRADE) process was used to assess the quality of evidence. The task force developed recommendations and assigned strengths based on the quality of the evidence counterbalanced by an assessment of the relative benefit of the treatment versus the potential harms. The AASM and AADSM Board of Directors approved the final guideline recommendations.

\section{Recommendations:}

1. We recommend that sleep physicians prescribe oral appliances, rather than no therapy, for adult patients who request treatment of primary snoring (without obstructive sleep apnea). (STANDARD)

2. When oral appliance therapy is prescribed by a sleep physician for an adult patient with obstructive sleep apnea, we suggest that a qualified dentist use a custom, titratable appliance over non-custom oral devices. (GUIDELINE)

3. We recommend that sleep physicians consider prescription of oral appliances, rather than no treatment, for adult patients with obstructive sleep apnea who are intolerant of CPAP therapy or prefer alternate therapy. (STANDARD)

4. We suggest that qualified dentists provide oversightrather than no follow-up - of oral appliance therapy in adult patients with obstructive sleep apnea, to survey for dentalrelated side effects or occlusal changes and reduce their incidence. (GUIDELINE)

5. We suggest that sleep physicians conduct follow-up sleep testing to improve or confirm treatment efficacy, rather than conduct follow-up without sleep testing, for patients fitted with oral appliances. (GUIDELINE)

6 . We suggest that sleep physicians and qualified dentists instruct adult patients treated with oral appliances for obstructive sleep apnea to return for periodic office visitsas opposed to no follow-up - with a qualified dentist and a sleep physician. (GUIDELINE)

Conclusions: The AASM and AADSM expect these guidelines to have a positive impact on professional behavior, patient outcomes, and, possibly, health care costs. This guideline reflects the state of knowledge at the time of publication and will require updates if new evidence warrants significant changes to the current recommendations.

Keywords: obstructive sleep apnea, snoring, oral appliance, mandibular advancement, positive airway pressure

Citation: Ramar K, Dort LC, Katz SG, Lettieri CJ, Harrod CG, Thomas SM, Chervin RD. Clinical practice guideline for the treatment of obstructive sleep apnea and snoring with oral appliance therapy: an update for 2015. J Clin Sleep Med 2015;11(7):773-827.

\section{SUMMARY}

Since the publication of the initial position statement by the American Academy of Sleep Medicine (AASM) in 1995, the clinical use of oral appliances (OAs) for the treatment of snoring and obstructive sleep apnea (OSA) has markedly increased. The most recent AASM practice parameters on the treatment of snoring and OSA with oral appliances was published in

2006 as "Practice Parameters for the Treatment of Snoring and Obstructive Sleep Apnea with Oral Appliances: An Update for 2005" with the accompanying systematic review paper "Oral Appliances for Snoring and Obstructive Sleep Apnea: A Review." Since these publications, the scientific literature on OAs has grown considerably, particularly related to clinical outcomes after use of OAs. The purpose of this guideline is therefore to replace the recommendations in the 
2006 guideline for the use of OAs in the treatment of OSA and snoring.

\section{Methods}

To develop this guideline, the AASM and American Academy of Dental Sleep Medicine (AADSM) commissioned a task force of seven members, three sleep medicine physicians and two dentists, with expertise in the use of OAs, and two AASM research staff members experienced in guideline development. None of the task force members had any conflicts that would preclude participation in this effort. Eleven PICO (patient, population or problem, intervention, comparison, and outcomes) questions were developed based on both the questions raised in the 2006 AASM review paper and practice parameter and review of systematic reviews, meta-analyses, and guidelines published since then (Table 1). The AASM Board of Directors approved the final list of PICO questions before the targeted literature search was performed.

The literature search was performed by the AASM research staff using the PubMed and Embase databases. Though the search yielded all types of articles with various study designs, for most PICO questions the analysis was limited to only randomized controlled trials (RCTs). The RCTs that were cited in the 2006 AASM review paper and 2006 practice parameter paper were included for data analysis if they met the study inclusion criteria. For PICO questions 7 and 11, due to lack of RCTs, we relied on prospective observational studies. The PubMed database was searched from January 1, 2004, through July 31, 2012, and was updated again on February 28, 2013, to capture the latest literature. A total of 324 citations were identified in PubMed and supplemented by pearling. A total of 53 citations were identified in Embase, yielding a total of 377 citations from both databases.

Meta-analysis was performed with Review Manager 5.2 software to compare various types of OAs used to treat snoring and OSA. Oral appliances were categorized into the following types: custom, titratable; custom, non-titratable; non-custom, titratable; and non-custom, non-titratable. Meta-analysis was performed for each PICO question by pooling data across studies for each outcome measure. All analyses were performed using the random effects model. The result of each meta-analysis is shown as a forest plot.

The assessment of evidence quality was performed according to a modified Grading of Recommendations Assessment, Development, and Evaluation (GRADE) process. The final assessment, as defined in Table 3, was determined for each treatment and outcome measure. The results are reported as evidence profiles for each PICO question that include the number of studies, study design, limitations, inconsistency, indirectness, imprecision, and other considerations that went into determining the quality of evidence for each outcome of interest. The task force then developed recommendations for the efficacy of OA treatment for snoring and OSA. Strengths of recommendation were assigned to these statements based on the quality of the evidence and counterbalanced by an assessment of the relative benefits of the treatment versus the potential risks as delineated in Table 4.

This guideline refers to a "qualified dentist" as the dental provider of choice to provide oral appliance therapy. The successful delivery of oral appliances requires technical skill, acquired knowledge, and judgment regarding outcomes and risks of these therapies. The need to append the word "qualified" stems from two things: (1) all of the studies conducted to evaluate the efficacy and risks of oral appliances were conducted by dentists with considerable experience in dental sleep medicine, and (2) the unfortunate fact that training in dental sleep medicine is uncommon. Therefore, not all dentists have the training or experience required to deliver knowledgeable care, and application of the literature to practice dental sleep medicine.

The American Academy of Dental Sleep Medicine (AADSM) is one of several organizations that has begun to address this issue over the past decade via the development and delivery of educational programs in dental sleep medicine along with the development of a certifying examination in dental sleep medicine that is now administered and maintained by the American Board of Dental Sleep Medicine (ABDSM). As physicians diagnose and subsequently refer patients with OSA to select dentists to evaluate for delivery of oral appliance therapy, they should seek qualified dentists who have a valid state license and proof of liability coverage and possess additional training or experience in this area of care. Although not all-inclusive, desirable qualifications include that the dentist have at least one of the following: certification in dental sleep medicine by a non-profit organization, designation as the dental director of a dental sleep medicine facility accredited by a non-profit organization, or a minimum of 25 hours of recognized continuing education in dental sleep medicine (e.g., American Dental Association Continuing Education Recognition Program [ADA CERP] or Academy of General Dentistry Program Approval for Continuing Education [AGD PACE]) provided by a dental sleep medicine focused non-profit organization or accredited dental school in the last two years.

OSA is a chronic disorder and therefore would be best diagnosed and followed by a sleep physician in cooperation with any other healthcare providers the patient may be going to for treatment (their primary care physician, a qualified dentist, ENT, etc.). For the purposes of this guideline, a sleep physician is defined as a physician who is either sleep board-certified or sleep board-eligible. A multicenter, prospective, comparative effectiveness study showed that board-certified sleep physicians and accredited centers improved patient-centered outcomes for OSA patients. Also, most of the RCTs that were reviewed to develop the recommendations in this current guideline were conducted by sleep physicians and investigators as defined by the above criteria.

\section{Results}

Our assessment of the efficacy of different OAs, as compared to each other and to PAP for different levels of OSA severity (mild, moderate, and severe), was based on very limited evidence. Most of the studies accepted for inclusion in this guideline did not provide sub-analyses of results based on different levels of OSA severity. Therefore, the recommendations presented below do not provide guidance for treating OSA patients with specific levels of severity. Meta-analyses performed using the limited available evidence indicates that OAs can significantly reduce the apnea hypopnea index/ 
respiratory disturbance index/respiratory event index (AHI/ RDI/REI) across all levels of OSA severity in adult patients. There was no statistically significant difference in the mean reduction in AHI before and after treatment using OAs versus CPAP across all levels of OSA severity. Moreover, there was no significant difference between OAs and CPAP in the percentage of mild OSA patients achieving their target AHI/RDI/ REI $(<5,<10,>50 \%$ reduction) after treatment. For patients with moderate to severe OSA, however, the odds of achieving the target AHI were significantly greater with CPAP than with OAs.

Our assessment of factors that may be used to predict treatment success in adults with OSA was also based on very limited evidence. We found that treatment success was usually defined as a reduction in the AHI/RDI/REI to a specific level (e.g., posttreatment $\mathrm{AHI} / \mathrm{RDI} / \mathrm{REI}<5,>50 \%$ reduction in $\mathrm{AHI} / \mathrm{RDI} /$ REI). However, there were no reported factors that consistently predicted treatment success. Specifically, there was conflicting evidence for the use of age, gender, neck circumference, body mass index (BMI), and cephalometric measurements to predict treatment success. Patient preference for OA versus CPAP should be considered by the treating sleep physician before therapy is prescribed. The strength of each recommendation was not only made based on the quality of evidence, but also incorporated patient preference along with other factors such as cost, value, and other patient-related factors.

\section{Summary of Recommendations}

1. We recommend that sleep physicians prescribe oral appliances, rather than no therapy, for adult patients who request treatment of primary snoring (without obstructive sleep apnea). (STANDARD)

\section{Quality of Evidence: High}

Values and Trade-Offs: Oral appliances (OAs) reduce the frequency and intensity of snoring, improve sleep quality for both patients who snore and their bed partners, and improve quality of life (QOL) measures. Though the available evidence on these outcomes is limited, we gave this a STANDARD strength of recommendation, as the possible benefits from treatment of primary snoring clearly outweigh the risk. Insufficient evidence exists to conclude that treatment of primary snoring improves other health-related outcomes, or to compare objective sleep quality during use of oral appliances versus other treatments. Therefore, OAs should be recommended for patients who snore who fail conservative measures (such as weight loss, positional therapy, and avoiding alcohol) and request further treatment. Diagnosis of primary snoring should be rendered by a sleep physician and not a dentist, as snoring is frequently accompanied by OSA, and misdiagnosis can have serious implications for the patient.

2. When oral appliance therapy is prescribed by a sleep physician for an adult patient with obstructive sleep apnea, we suggest that a qualified dentist use a custom, titratable appliance over non-custom oral devices. (GUIDELINE)

Quality of Evidence: Low

Values and Trade-Offs: The overall grade for the body of evidence exploring the impact of custom vs. non-custom OAs to treat OSA varies between low and moderate depending on the physiologic sleep outcome measures. A systematic review of the evidence has shown that custom, titratable OAs reduce the AHI, arousal index, and oxygen desaturation index, and increase oxygen saturation to a greater extent than do non-custom OAs. The evidence supports the use of custom, titratable OAs over other types of appliances. Although the reduction in AHI and ODI are similar for both custom, titratable and custom, non-titratable OAs, the confidence interval for the effect of the custom, titratable OAs is considerably smaller than for the custom, non-titratable appliances. Both types of custom appliances are more effective than non-custom OAs.

Neither custom nor non-custom OAs have been shown to significantly affect sleep architecture and sleep efficiency. However, the overall improvement in other physiologic sleep parameters with the use of custom OAs in adult patients with OSA should result in an improvement in daily function and quality of life.

The available data also suggest that OAs effectively improve daytime sleepiness. The mean change in the Epworth Sleepiness Scale (ESS) with custom, titratable OAs is moderate. The reduction in subjective daytime sleepiness achieved with custom titratable OAs is not inferior to that reported with CPAP therapy. In contrast, very limited data suggest that custom, non-titratable OAs do not produce a significant change in ESS. Insufficient data are available to assess objective measures of sleepiness or wakefulness following OA therapy.

The evidence indicates that OAs are also effective in improving QOL. Specifically, custom, titratable OAs provide moderate improvement in QOL outcomes. The data on QOL is very limited for custom, non-titratable OAs, and therefore their use cannot be recommended to improve QOL.

3. We recommend that sleep physicians consider prescription of oral appliances, rather than no treatment, for adult patients with obstructive sleep apnea who are intolerant of CPAP therapy or prefer alternate therapy. (STANDARD)

Quality of Evidence: Moderate

Values and Trade-Offs: A review of the evidence suggests that adherence rates using OAs are greater than those observed with CPAP. However, no randomized controlled trials have assessed objective OA adherence rate as compared with CPAP. The subjective reporting of adherence rate is prone to bias, and needs to be interpreted with caution as patients may overestimate their OA use. However, a patient whose OSA does not improve with the use of CPAP or is intolerant to CPAP may benefit from the use of an OA. Overall, the discontinuation of therapy due to side effects occurs less when using OAs versus CPAP to treat adult patients with OSA.

The overall grade for the body of evidence on the impact of OAs to treat obstructive sleep apnea (OSA) varies between low and moderate depending on the physiologic sleep outcome measures. A systematic review of the evidence has shown that OAs reduce AHI, arousal index, and oxygen desaturation index, and increase oxygen saturation. However, OAs have shown no significant effect on sleep architecture and sleep efficiency. The overall improvement in physiologic sleep parameters with the use of OAs in adult patients with OSA should result in an improvement in daily function and quality of life. 
Although OAs have been shown to improve physiologic sleep parameters, continuous positive airway pressure (CPAP), in our meta-analyses, was found to be superior to OAs in reducing the AHI, arousal index, and oxygen desaturation index and improving oxygen saturation, and therefore, should still generally be the first-line option for treating OSA. The improvement in QOL produced by custom, titratable OAs is not inferior to that reported with CPAP therapy. The quality of evidence for the use of these OAs to improve QOL is moderate, whereas the quality of evidence comparing OAs to CPAP is low. The custom, titratable OAs improve QOL, but as with CPAP, reduced QOL may persist despite otherwise adequate therapy.

The available data regarding the impact of OAs on blood pressure are more limited (overall grade for the body of evidence is low) than the data addressing blood pressure change with CPAP. For example, the role of OAs in patients with resistant hypertension has not yet been evaluated. However, the available data suggest that OAs may be as effective as CPAP in at least select patient populations to lower blood pressure and therefore should not preclude the use of either therapy or diminish the other established benefits that accrue from treatment of OSA. Of note, no RCTs have assessed the impact of OA therapy on other cardiovascular endpoints.

In summary, OAs may be effective in improving sleep parameters and outcomes of OSA, and there is little likelihood of harm. Although they are not as efficacious as PAP therapy, the benefits of using OAs outweigh risks of not using OAs. Thus, a STANDARD strength of recommendation to use OAs was provided.

4. We suggest that qualified dentists provide oversightrather than no follow-up-of oral appliance therapy in adult patients with obstructive sleep apnea, to survey for dental-related side effects or occlusal changes and reduce their incidence. (GUIDELINE)

Quality of Evidence: Low

Values and Trade-Offs: Beneficial treatment effects may be reduced by treatment-related side effects, and most OA therapy side effects are dental. A wide range of devices made from a variety of materials and having different characteristics are utilized in clinical practice. Literature on dentists performing interventions to prevent failure of OA therapy is limited, although the topic is mentioned in the results and discussion sections of some publications. Therefore, the overall evidence in support of the above recommendation was considered low. Nevertheless, minimization of side effects may improve adherence and thereby patient outcomes. Several studies demonstrated dental interventions to mitigate side effects. Additionally, knowledge of dental materials and a variety of dental devices including the knowledge of the patients' dental status will likely ensure fewer side effects. A qualified dentist will be able to screen for many problems and choose and/or build the OA with features to minimize the side effects of the therapy. A qualified dentist will have the skills to choose the proper OA and make necessary modifications to accommodate patients who, among other things, may have allergies to metals or acrylics, are strong teeth grinders, or have anatomical deviations. The patient's history and exam, appliance preference, and review of any side effects should be taken into account to avoid device breakage, allergic reactions, or discomfort that leads to frustration or discontinuation of the therapy.

5. We suggest that sleep physicians conduct follow-up sleep testing to improve or confirm treatment efficacy, rather than conduct follow-up without sleep testing, for patients fitted with oral appliances. (GUIDELINE)

Quality of Evidence: Low

Values and Trade-Offs: The overall grade of evidence for support of follow-up evaluations and testing by sleep physicians is low due to a lack of evidence. However, the discussion sections in most research studies report significant improvement in OA efficacy when changes were made to the appliances based on data obtained either during or after the sleep studies. While insufficient evidence exists to produce a meta-analysis, the available data suggest that subjective feedback is not sufficient to determine the optimal setting of the OA in the management of OSA. Without objective data the patient may, unnecessarily, remain sub-optimally treated. Follow-up sleep testing by sleep physicians should also be considered for OA-treated patients who develop recurrent symptoms, show substantial weight changes, or receive diagnoses of comorbidities relevant to OSA.

6. We suggest that sleep physicians and qualified dentists instruct adult patients treated with oral appliances for obstructive sleep apnea to return for periodic office visitsas opposed to no follow-up-with a qualified dentist and a sleep physician. (GUIDELINE)

Quality of Evidence: Low

Values and Trade-Offs: A review of the evidence suggests that patients may benefit from periodic follow-up visits with a physician and with a qualified dentist. Several studies have demonstrated that adjustments made to the OA by a dentist, based on data obtained from PSGs and home sleep apnea tests conducted by a physician, may result in greater long-term improvement in OSA. The absence of periodic follow-up visits may result in suboptimal improvement in OSA or side effects that increase risk for discontinuation of therapy. 


\subsection{INTRODUCTION}

Snoring and obstructive sleep apnea (OSA) are common sleep disorders resulting from repetitive narrowing and collapsing of the upper airway. Untreated OSA is associated with multiple adverse health outcomes including systemic hypertension, coronary artery disease, stroke, atrial fibrillation, increased motor vehicle accidents, congestive heart failure, daytime sleepiness, decreased quality of life, and increased mortality. ${ }^{1}$ Snoring is also a significant social problem and contributes to decreased quality of life for bed partners through disrupted sleep. ${ }^{2}$ Snoring itself may have a negative health impact, such as increased risk for cardiovascular disease. ${ }^{3}$

In recent years, oral appliances (OAs) have become an increasingly common treatment modality for OSA and snoring. Although positive airway pressure (PAP) remains the most common and most efficacious treatment for sleep disordered breathing, OAs offer effective therapy for many patients with OSA. These devices offer advantages over PAP in that they do not require a source of electricity and are less cumbersome, especially with travel. Oral appliances are well tolerated in most patients, and therapeutic adherence may be better than CPAP. ${ }^{4}$

Since the publication of the initial position statement by the American Academy of Sleep Medicine (AASM) in 1995, the clinical use of OAs for the treatment of snoring and obstructive sleep apnea has markedly increased. The most recent AASM practice parameters on the treatment of snoring and OSA with oral appliances was published in 2006 as "Practice Parameters for the Treatment of Snoring and Obstructive Sleep Apnea with Oral Appliances: An Update for 2005" with the accompanying systematic review paper "Oral Appliances for Snoring and Obstructive Sleep Apnea: A Review." 5,6 Since the publication of the previous review paper and practice parameters, the scientific literature on oral appliances has grown considerably, particularly related to clinical outcomes after use of OAs, and hence the recommendations in this guideline will replace the recommendations in the 2006 guideline for the use of OAs in the treatment of OSA and snoring.

This guideline refers to a "qualified dentist" as the dental provider of choice to provide oral appliance therapy. The successful delivery of oral appliances requires technical skill, acquired knowledge, and judgment regarding outcomes and risks of these therapies. The need to append the word "qualified" stems from two things: (1) all of the studies conducted to evaluate the efficacy and risks of oral appliances were conducted by dentists with considerable experience in dental sleep medicine, and (2) the unfortunate fact that training in dental sleep medicine is uncommon. Therefore, not all dentists have the training or experience required to deliver knowledgeable care, and application of the literature to practice dental sleep medicine.

The American Academy of Dental Sleep Medicine (AADSM) is one of several organizations that has begun to address this issue over the past decade via the development and delivery of educational programs in dental sleep medicine along with the development of a certifying examination in dental sleep medicine that is now administered and maintained by the American Board of Dental Sleep Medicine (ABDSM). As physicians diagnose and subsequently refer patients with
OSA to select dentists to evaluate for delivery of oral appliance therapy, they should seek qualified dentists who have a valid state license and proof of liability coverage and possess additional training or experience in this area of care. Although not all-inclusive, desirable qualifications include that the dentist have at least one of the following: certification in dental sleep medicine by a non-profit organization, designation as the dental director of a dental sleep medicine facility accredited by a non-profit organization, or a minimum of 25 hours of recognized continuing education in dental sleep medicine (e.g., American Dental Association Continuing Education Recognition Program [ADA CERP] or Academy of General Dentistry Program Approval for Continuing Education [AGD PACE]) provided by a dental sleep medicine focused non-profit organization or accredited dental school in the last two years.

OSA is a chronic disorder and, therefore, would be best diagnosed and followed by a sleep physician in cooperation with any other healthcare providers the patient may be going to for treatment (their primary care physician, a qualified dentist, ENT, etc.). For the purposes of this guideline, a sleep physician is defined as a physician who is either sleep boardcertified or sleep board-eligible. A multicenter, prospective, comparative effectiveness study showed that board-certified sleep physicians and accredited centers improved patient-centered outcomes for OSA patients. ${ }^{7}$ Also, most of the RCTs that were reviewed to develop the recommendations in this current guideline were conducted by sleep physicians and investigators as defined by the above criteria.

\subsection{BACKGROUND}

\subsection{Nomenclature, Types, and Definition of an Effective Oral Appliance}

Oral appliances are devices intended to protrude and stabilize the mandible to maintain a patent airway during sleep. ${ }^{8}$ A custom OA is "fabricated using digital or physical impressions and models of an individual patient's oral structures. As such, it is not a primarily prefabricated item that is trimmed, bent, relined, or otherwise modified. It is made of biocompatible materials and engages both the maxillary and mandibular arches." " Non-custom OAs, commonly known as "boil and bite devices," are primarily prefabricated and usually partially modified to an individual patient's oral structures. There are also custom-made and non-custom-made OAs that hold the tongue forward and are called tongue retaining devices (TRDs), and these have to be distinguished from the OAs. There was insufficient evidence to assess the efficacy of TRDs for the treatment of adult patients with OSA.

In addition to being custom- or non-custom-made, OAs are either titratable or non-titratable. Titratable OAs have a mechanism that allows for varying amounts of mandibular protrusion. The increasing protrusion of the mandible is considered analogous to the titration of continuous positive airway pressure (CPAP). Non-titratable OAs hold the mandible in a single protrusive position, and no changes are possible over the course of treatment.

The American Academy of Dental Sleep Medicine (AADSM) published a definition of an effective OA in March 
Table 1-PICO Questions.

1. In adult patients with primary snoring, do oral appliances (OAs) improve snoring, sleep quality, including the bed partner's sleep quality, and/or quality of life measures compared to other therapies or no treatment?

2. In adult patients with obstructive sleep apnea (OSA) (irrespective of underlying severity of OSA, and for each mild, moderate, or severe OSA), do oral appliances improve the apnea hypopnea index (AHI)/respiratory disturbance index (RDI)/respiratory event index (REI), oxygen saturation, arousal index, and/or sleep architecture compared to other therapies or no treatment?

3. In adult patients with OSA, do OAs improve cardiovascular endpoints, such as hypertension, coronary artery disease, myocardial infarction, and/or arrhythmias, as compared to other therapies or no treatment?

4. In adult patients with OSA, do OAs improve quality of life measures, and/or objective and subjective daytime sleepiness, as compared to other therapies or no treatment?

5. In adult patients with OSA, do titratable OAs improve AHI/RDI/REI, oxygen saturation, arousal index, and/or sleep architecture and do they improve long-term management of OSA with outcome measures such as AHI/RDI/REI, sleep quality, quality of life measures, cardiovascular endpoints, and/ or subjective/objective measures of sleepiness compared to non-titratable OAs?)

6. In adult patients with OSA, do OAs lead to mild or serious side effects compared to those treated with other therapies or no treatment?

7. In adult patients with OSA, do follow-up oximetries, home sleep apnea tests, polysomnograms, or follow-up with a sleep physician improve long-term management with OAs as compared to no follow-up?

8. In adult patients with OSA, does follow-up with dentists/sleep specialists improve adherence and reduce side effects associated with OAs compared to those who do not have follow-up?

9. In adult patients with OSA, does OA use show better adherence than that reported by subjective or objective measures for PAP therapy?

10. In adult patients with OSA, do different types of OAs have variable effectiveness in controlling sleep-disordered breathing as measured by the $\mathrm{AHI} / \mathrm{RDI} / \mathrm{REI}$ and/or other outcome measures such as sleep quality, quality of life measures, cardiovascular endpoints, and/or objective/subjective daytime sleepiness?

11. In adult patients with OSA, what are the factors that predict success with OAs compared to other therapies or no treatment?

2013, focusing on custom-titratable OAs. ${ }^{8}$ This definition was developed at a consensus conference attended by a group of experienced dental sleep medicine researchers and clinicians using a modified RAND Appropriateness Method. The definition was unanimously approved by the conference attendees and then subsequently approved by the AADSM Board of Directors. A manuscript detailing the conference, the process, the literature search, grading, and review has also been published. ${ }^{8}$

Currently, there is no universal terminology to describe oral appliances that are used to treat OSA. The plethora of terms is potentially confusing. Commonly used terms include, but are not limited to: mandibular advancement device (MAD), mandibular repositioning device (MRD), mandibular advancement splint (MAS), and mandibular advancement appliance (MAA). Throughout this guideline paper, we use the term "oral appliance (OA)" to refer to all of these different types. We will, however, specify whether they are custom or non-custom made and whether they are titratable or non-titratable OAs. A preferred term chosen by the AADSM may lead to less confusion in the field.

\subsection{METHODS}

\subsection{Expert Task Force}

To develop this guideline, the AASM and AADSM commissioned a Task Force of seven members, three sleep medicine physicians and two dentists with expertise in the use of oral appliances, and two AASM research staff members experienced in guideline development. Prior to being appointed to the Task Force, the content experts were required to disclose all potential conflicts of interest (COI) according to the AASM's COI policy. None of the task force members had any conflicts that would preclude participation in this effort. The Task Force members performed an extensive review of the scientific literature to draft recommendations and supporting text for the use of OAs in the treatment of snoring and OSA.

\subsection{PICO Questions}

PICO (patient, population or problem, intervention, comparison, and outcomes) questions were developed based on both the questions raised in the 2006 AASM review paper ${ }^{5}$ and practice parameter ${ }^{6}$ and review of systematic reviews, meta-analyses, and guidelines published since then (Table 1). The PICO format is an established framework for subsequently guiding literature searches targeted at addressing the PICO questions and developing evidence-based clinical practice recommendations. After a thorough review, editing, and approval of these questions by the task force members, the AASM Board of Directors approved the final list of PICO questions before the targeted literature search was performed.

\subsection{Literature Search}

The Task Force members performed an extensive review of the scientific literature to retrieve articles which addressed at least one of the eleven PICO questions. The literature search was performed by the AASM research staff using the PubMed and Embase databases. Though the search yielded all types of articles with various study designs, for most PICO questions the analysis was limited to only randomized controlled trials (RCTs) as RCTs are considered a higher quality of evidence than observational, nonrandomized, or before-after interventional studies. The RCTs that were cited in the 2006 AASM review paper ${ }^{5}$ and 2006 practice parameter paper ${ }^{6}$ were 
included for data analysis if they met the study inclusion criteria. For PICO questions 7 and 11, due to lack of RCTs, we relied on prospective observational studies. The literature search in PubMed was conducted using a combination of MeSH terms and keywords. The MeSH terms were: Sleep Apnea Syndromes, Snoring, Orthodontic Appliances, and Mandibular Advancement/Instrumentation. The keywords were: sleep apnea, sleep apnoea, sleep-related breathing disorders, sleep-disordered breathing, oral, intraoral, dental, orthodontic, mandibular, tongue-retaining, tongue-stabilizing, occlusal, titratable, titrated, appliance(s), splint(s), device(s), OA, or snoring. The limits of the search (criteria that all had to be met) were: humans, English, all adults (no pediatrics), and RCTs. The RCT limitation was not used for PICO questions 7 and 11. The PubMed database was searched from January 1, 2004, through July 31, 2012, for any relevant literature published since the last guideline. This search was updated again on February 28, 2013, to capture the latest literature. A total of 324 citations were identified in PubMed and supplemented by pearling (i.e., checking the reference sections of search results for articles otherwise missed). The literature search in Embase was performed using a combination of disorder and treatment terms. The disorder terms were: sleep apnea, sleep apnoea, sleep apnea syndrome, sleep-related breathing disorders, or sleep-disordered breathing. The treatment terms were: orthodontic device, mandible reconstruction, oral, intraoral, dental, orthodontic(s), mandibular, tongue retaining, tonguestabilizing, occlusal, titratable, or titrated. The presence of any one of these terms in the title or abstract of a publication would identify a potentially relevant article for inclusion in data analysis. The limits of the search were: humans, English, adults, and RCTs. The RCT limitation was not used for PICO questions 7 and 11. The Embase database was searched from January 1, 2004, through August 31, 2012. This search was updated again on February 28, 2013, to capture the latest literature and cross-checked with the results from the PubMed search to find any previously unidentified articles. A total of 53 citations were identified in Embase, yielding a total of 377 citations from both databases.

Abstracts from these articles were assessed by two task force members to determine whether they met inclusion criteria. However, if there were any questions on whether the abstract met the inclusion criteria, the article was reviewed in detail to determine whether to accept or reject. Articles were included for evaluation if they focused on treatment of snoring and/or OSA with OAs, and included only adult subjects. Included articles also had to address at least one of the eleven "PICO" questions identified ahead of the review process. Articles were accepted if they used either the apnea hypopnea index (AHI) or the respiratory disturbance index (RDI) as determined by an overnight polysomnogram (PSG) or the respiratory event index (REI) as determined by a home sleep apnea test. However, there were 3 articles that did not necessarily meet the above criteria, but were still included in our analysis. $^{9-11}$ In two studies by Gauthier et al., RDI was defined as the combination of apneas, hypopneas and arousals per hour of sleep, ${ }^{9,10}$ while Gotsopoulos et al. defined AHI as the combination of apneas, hypopneas, and arousals per hour of sleep. ${ }^{11}$ The Task Force acknowledges that there are limitations to the direct comparisons made in this guideline due to the variety of ways AHI, RDI, and REI are defined and scored among the studies included. Articles were excluded if they focused on diagnosis, described the use of OAs to treat central or complex sleep apnea, or if they were studies on pediatric patients. A total of 51 articles met these criteria and were used for data extraction, meta-analysis, and grading.

\subsection{Meta-Analysis}

Meta-analysis was performed with Review Manager 5.2 software to compare various types of OAs used to treat snoring and OSA. Oral appliances were categorized into the following types: custom, titratable; custom, non-titratable; non-custom, titratable; and non-custom, non-titratable. Meta-analysis was performed for each PICO question by pooling data across studies for each outcome measure. All analyses were performed using the random effects model. The result of each meta-analysis is shown in a forest plot. Individual studies in the meta-analysis are identified in a table that includes the mean and standard deviation (SD) of the outcome measure and the number of patients. The pooled results are expressed as the total number of patients and mean difference between the experimental treatment and the control or between the baseline and final values of the outcome measure. The center of the black diamond at the bottom of the plot indicates the mean difference (i.e., average response or magnitude of effect) across all studies. The width of the black diamond represents the $95 \%$ confidence interval of the mean difference. The zero line represents no effect. If the black diamond does not touch the zero line, and lies beyond the clinical decision threshold, the treatment is considered either effective or ineffective depending on which side of the zero line the diamond lies.

It should be noted that for a number of PICO questions there was insufficient evidence to perform meta-analyses for certain comparisons and outcome measures. For example, the efficacy of OAs was only compared with CPAP, as there was insufficient evidence to compare OAs to other therapies, such as conservative treatment or surgery. Therefore, the content of this guideline includes comparisons, outcome measures, and recommendations for which there was sufficient evidence. It should also be noted that meta-analysis of head-to-head studies was only performed when comparing the efficacy of OAs to CPAP. Due to insufficient head-to-head studies comparing different types of OAs (e.g., custom, titratable vs. custom, nontitratable), data on the efficacy of specific device types were pooled across studies and compared side by side. The metaanalyses are presented in the Appendix.

\subsection{Quality of Evidence}

The assessment of evidence quality was performed according to a modified Grading of Recommendations Assessment, Development, and Evaluation (GRADE) process. ${ }^{12}$ The GRADE system differs from other grading systems in that each study is not only evaluated for study design and risk of bias, but, additionally, an estimate of effect is generated for each outcome. The quality of evidence reflects the degree of confidence that the estimates of the effects are correct, and the quality of a body of evidence for each outcome is assessed as opposed to evaluating individual studies. Multiple aspects of 
Table 2-A summary of GRADE's approach to rating quality of evidence.

\begin{tabular}{|c|c|c|c|c|}
\hline Study Design & $\begin{array}{l}\text { Initial Quality of a } \\
\text { Body of Evidence }\end{array}$ & Downgrade if & Upgrade if & Quality of a Body of Evidence \\
\hline \multirow[t]{2}{*}{ Randomized trials } & \multirow[t]{2}{*}{ High $\rightarrow$} & $\begin{array}{l}\text { Risk of bias } \\
-1 \text { Serious } \\
-2 \text { Very serious }\end{array}$ & $\begin{array}{l}\text { Large effect } \\
\quad+1 \text { Large } \\
\text { +2 Very large }\end{array}$ & High (four plus: $\oplus \oplus \oplus \oplus$ ) \\
\hline & & $\begin{array}{l}\text { Inconsistency } \\
\text {-1 Serious } \\
-2 \text { Very serious }\end{array}$ & $\begin{array}{l}\text { Dose response } \\
+1 \text { Evidence of a } \\
\text { gradient }\end{array}$ & Moderate (three plus: $\oplus \oplus \oplus \Theta$ ) \\
\hline \multirow[t]{3}{*}{ Observational studies } & \multirow[t]{3}{*}{ Low $\rightarrow$} & $\begin{array}{l}\text { Indirectness } \\
\text {-1 Serious } \\
-2 \text { Very serious }\end{array}$ & $\begin{array}{l}\text { All plausible residual } \\
\text { confounding } \\
\quad+1 \text { Would reduce }\end{array}$ & Low (two plus: $\oplus \oplus \Theta \Theta$ ) \\
\hline & & $\begin{array}{l}\text { Imprecision } \\
\text {-1 Serious } \\
\text {-2 Very serious }\end{array}$ & $\begin{array}{l}\text { a demonstrated } \\
\text { effect } \\
+1 \text { Would suggest } \\
\text { a spurious }\end{array}$ & Very Low (one plus: $\oplus \ominus \ominus \ominus$ ) \\
\hline & & $\begin{array}{l}\text { Publication bias } \\
-1 \text { Serious } \\
-2 \text { Very serious }\end{array}$ & $\begin{array}{l}\text { effect if no } \\
\text { effect was } \\
\text { observed }\end{array}$ & \\
\hline
\end{tabular}

Table 3-Final assessments of level of bodies of evidence.

High: We are very confident that the true effect lies close to that of the estimate of the effect.

Moderate: We are moderately confident in the effect estimate. The true effect is likely to be close to the estimate of effect, but there is a possibility that it is substantially different.

Low: $\quad$ Our confidence in the effect estimate is limited. The true effect may be substantially different from the estimate of effect.

Very low: We have very little confidence in the effect estimate. The true effect is likely to be substantially different from the estimate of effect.

quality are assessed including study limitations, imprecision, inconsistency of results, indirectness of evidence, and likeliness of publication bias.

A risk of bias analysis was performed on all RCTs. Analyzing risk of bias includes reviewing aspects of conduct such as blinding, allocation concealment, loss to follow-up, or selective outcome reporting that could affect the quality of evidence. The GRADE process allows for the downgrading of the quality of evidence due to risk of bias. The grading of evidence also includes an analysis of imprecision, indirectness, and inconsistency. Imprecision refers to wide confidence intervals around the estimate of effect when there are relatively few patients and few events. Indirectness occurs when the question being addressed is different than the available evidence in terms of population, intervention, comparator, or outcome. There is inconsistency when there is unexplained heterogeneity of the results. A summary of the GRADE approach to rating quality of evidence is presented in Table 2.

All studies were assessed for study design and limitations to validity (bias) for each outcome of interest. Subsequently, the body of evidence for each outcome was assessed and graded, taking into account the results of the meta-analysis (if applicable) and other factors as described above. The final assessment, as defined in Table 3, was determined for each treatment and outcome measure. The results are reported as evidence profiles, for each PICO question, that include the number of studies, study design, limitations, inconsistency, indirectness, imprecision, and other considerations that went into determining the quality of evidence for each outcome of interest. Also reported are the number of patients that were studied, the overall effect that was calculated in the meta-analysis (reported as the mean difference $[\mathrm{MD}]$ ), and a qualitative assessment of the relative importance of the outcome. Task force members and AASM staff extracted the data and graded the studies. The GRADE summary of findings reports, along with the meta-analyses, are presented in the Appendix.

\subsection{Strength of Recommendations}

The task force then developed recommendations for the efficacy of OA treatment for snoring and OSA. Strengths of recommendation were assigned to these statements based on the strength of evidence and counterbalanced by an assessment of the relative benefits of the treatment versus the potential risks as delineated in Table 4. Particularly noteworthy on this table is that when the harm or burden clearly outweighs the benefit, a STANDARD strength of recommendation against the proposed therapy is given regardless of the overall quality of evidence.

Sections titled "Values and Trade-offs" appear under each individual recommendation to explain the rationale leading to each recommendation. These sections are an integral part of the GRADE system and offer transparency to the process.

\subsection{Approval and Interpretation of Recommendations}

A draft of the guideline was available for public comment for a two-week period on the AASM and AADSM websites. The 
Table 4-AASM strengths of recommendations.

\section{Assessment of Benefits versus Harms/Burdens}

Benefits clearly outweigh harms/burdens

Benefits closely balanced with harms/burdens OR

Uncertainty in the estimates of benefits versus harms/burdens

Harms/burdens clearly outweigh benefits

\begin{tabular}{cccc}
\multicolumn{4}{c}{ Overall Quality of Evidence } \\
\hline High & Moderate & Low & Very Low \\
STANDARD & STANDARD & GUIDELINE & OPTION \\
GUIDELINE & GUIDELINE & OPTION & OPTION
\end{tabular}

$\begin{array}{lll}\text { STANDARD } & \text { STANDARD } & \text { STANDARD } \\ \end{array}$

Table 5-Summary of recommendation statements.

Recommendation Statement

\section{Strength of Quality of Benefits versus Harms/ Recommendation Evidence}

\section{The Use of Oral Appliances for Treatment of Primary Snoring in Adults}

We recommend that sleep physicians prescribe oral appliances, rather than no therapy, for adult patients who request treatment of primary snoring (without obstructive sleep apnea).

STANDARD High $\quad \begin{aligned} & \text { Benefits clearly } \\ & \text { outweigh harms }\end{aligned}$

\section{The Use of Oral Appliances for Treatment of Obstructive Sleep Apnea in Adults}

When oral appliance therapy is prescribed by a sleep physician for an adult patient with obstructive sleep apnea, we suggest that a qualified dentist use a custom, titratable appliance over non-custom oral devices.

We recommend that sleep physicians consider prescription of oral appliances, rather than no treatment, for adult patients with obstructive sleep apnea who are intolerant of CPAP therapy or prefer alternate therapy.

We suggest that qualified dentists provide oversight—rather than no follow-up—of oral appliance therapy in adult patients with obstructive sleep apnea, to survey for dentalrelated side effects or occlusal changes and reduce their incidence.

We suggest that sleep physicians conduct follow-up sleep testing to improve or confirm treatment efficacy, rather than conduct follow-up without sleep testing, for patients fitted with oral appliances.

We suggest that sleep physicians and qualified dentists instruct adult patients treated with oral appliances for obstructive sleep apnea to return for periodic office visits-as opposed to no follow-up-with a qualified dentist and a sleep physician.

GUIDELINE Low $\quad \begin{aligned} & \text { Benefits clearly } \\ & \text { outweigh harms }\end{aligned}$

STANDARD Moderate Benefits clearly outweigh harms

GUIDELINE Low $\quad \begin{aligned} & \text { Benefits clearly } \\ & \text { outweigh harms }\end{aligned}$

GUIDELINE Low Benefits clearly
outweigh harms

GUIDELINE Low Benefits clearly task force took into consideration all the comments received and made decisions about whether to revise the draft based on the comments. The revised guideline was submitted to the AASM and AADSM Board of Directors who subsequently approved these recommendations.

The recommendations in this guideline define principles of practice that should meet the needs of most patients in most situations. This guideline should not, however, be considered inclusive of all proper methods of care or exclusive of other methods of care reasonably expected to obtain the same results. The ultimate judgment regarding propriety of any specific care must be made by the clinician (sleep physician and dentist), in light of the individual circumstances presented by the patient, available diagnostic tools, accessible treatment options, and resources.

The AASM expects this guideline to have an impact on professional behavior, patient outcomes, and, possibly, health care costs. This clinical practice guideline reflects the state of knowledge at the time of publication and will be reviewed every few years and updated if new evidence warrants significant changes to the recommendations.

\subsection{RECOMMENDATIONS}

All figures, including meta-analyses and GRADE profile reports, are presented in the Appendix. Table 5 shows a summary of the recommendation statements organized by strength of recommendation, including the quality of evidence and the assessment of the harm/benefit balance of the recommendation.

Our assessment of the efficacy of different OAs, as compared to each other and to PAP for different levels of OSA severity (i.e., mild, moderate, and severe), was based on very limited evidence. Most of the studies accepted for inclusion in this guideline did not provide sub-analyses of results based on different levels of OSA severity. Therefore, the recommendations presented below do not provide guidance for treating OSA patients with specific levels of severity. Meta-analyses performed using the limited available evidence indicate that both OAs and CPAP can significantly reduce the apnea hypopnea index/respiratory disturbance index/respiratory event index (AHI/RDI/REI) across all levels of OSA severity in adult patients (see Figures 1-6). There were 
statistically significant differences in the mean reduction in AHI before and after treatment using OAs versus CPAP for mild-tomoderate and severe levels of OSA severity. Based on a single retrospective study by Holley in 2011, however, there was no significant difference in the percentage of mild OSA patients achieving their target AHI/RDI/REI $(<5,<10,>50 \%$ reduction) after treatment between OAs and CPAP. ${ }^{13}$ For patients with moderate to severe OSA, however, the odds of achieving the target AHI was significantly greater with CPAP than with OAs. ${ }^{13}$ In an RCT conducted by Randerath in 2002, the odds of achieving the target AHI of $<10$ in mild to moderate adult patients was significantly greater with CPAP than OA therapy. ${ }^{14}$ CPAP remains the first-line or primary therapy for the treatment of adult patients with severe OSA. OA therapy should be reserved for use in severe OSA patients who did not benefit from CPAP therapy or were intolerant to CPAP. ${ }^{15,16}$

Our assessment of factors that may be used to predict treatment success in adults with OSA was also based on very limited evidence. We found that treatment success was usually defined as a reduction in the AHI/RDI/REI to a specific level (e.g., post-treatment $\mathrm{AHI} / \mathrm{RDI} / \mathrm{REI}<5,>50 \%$ reduction in $\mathrm{AHI} / \mathrm{RDI} / \mathrm{REI}$ ). However, there were no reported factors that consistently predicted treatment success. Specifically, there was conflicting evidence for the use of age, gender, neck circumference, body mass index (BMI), and cephalometric measurements to predict treatment success.

It should be noted that conclusions drawn from side-by-side comparisons of the meta-analyses should be interpreted with caution in instances where a meta-analysis based on a limited number of RCTs for one appliance type was compared against a meta-analysis of several RCTs for another appliance type.

There was insufficient evidence to compare the efficacy of OAs to other therapies besides CPAP. Patient preference for OAs versus CPAP should be considered by the treating sleep physician before therapy is prescribed. The strength of each recommendation was not only made based on the quality of evidence, but also incorporated patient preference along with other factors such as cost, value, and other patientrelated factors.

\subsection{Primary Snoring}

\subsubsection{Snoring Indices}

Oral appliances are effective for the treatment of primary snoring in adult patients without obstructive sleep apnea (Quality of evidence: High) The efficacy of OAs for the treatment of primary snoring in adult patients with OSA was previously addressed in the AASM Practice Parameters for the Treatment of Snoring and Obstructive Sleep Apnea with Oral Appliances: An Update for $2005 .{ }^{6}$ The existing evidence at that time supported a STANDARD strength of recommendation for use of OAs in the treatment of primary snoring without features of OSA or upper airway resistance syndrome. The prior evidence found these devices reduced subjective snoring. Since that time, additional trials have further supported this recommendation and have explored additional benefits of oral appliance therapy among these patients.

Two RCTs that assessed the effect of OAs in patients with primary snoring were identified. ${ }^{17,18}$ An RCT conducted by
Johnston et al. determined that snoring occurred on fewer nights per week; 1.90 (95\% CI: $1.32,2.48) .{ }^{17}$ Cooke et al. observed fewer snores per hour; 278 (95\% CI: 375.30, 180.70). ${ }^{18}$ While the overall quality of this evidence is high, these trials utilized different snoring scales.

A meta-analysis was performed comparing snoring loudness before and after treatment with an OA. The results are shown in Figure 7. Two trials found snoring loudness was reduced while using an OA; 3.31 (95\% CI: 1.84, 4.77). ${ }^{17,18}$

The summary of findings table for snoring indices is presented in Figure 8.

\subsubsection{Quality of Life}

There was insufficient evidence to determine the efficacy of OAs for the improvement in quality of life (QOL) in patients with primary snoring.

\subsubsection{OAs vs. CPAP}

There was insufficient evidence to compare the efficacy of OAs to CPAP for the reduction in primary snoring. In a prospective, randomized crossover trial, Robertson et al. found that changes in the Snoring Outcomes Survey were similar with the OA and nasal CPAP. The authors also observed that the OA was superior to CPAP in improving sleep quality among bed partners. More patients in this trial also preferred the OA over CPAP for long-term treatment of snoring. ${ }^{19}$

\subsection{Recommendation: We recommend that sleep physicians prescribe oral appliances, rather than no therapy, for adult patients who request treatment of primary snoring (without obstructive sleep apnea). (STANDARD)}

Values and Trade-Offs: Oral appliances reduce the frequency and intensity of snoring, improve sleep quality for both patients who snore and their bed partners, and improve quality of life (QOL) measures. Though the available evidence on these outcomes is limited, we gave this a STANDARD strength of recommendation, as the possible benefits from treatment of primary snoring clearly outweigh the risk. Insufficient evidence exists to conclude that treatment of primary snoring improves other health-related outcomes, or to compare objective sleep quality during use of oral appliances versus other treatments. Therefore, OAs should be recommended for patients who snore who fail conservative measures (such as weight loss, positional therapy, avoiding alcohol) and request further treatment. Diagnosis of primary snoring should be rendered by a sleep physician and not a dentist, as snoring is frequently accompanied by OSA, and misdiagnosis can have serious implications for the patient.

\subsection{OSA}

\subsubsection{Physiologic Sleep Parameters}

The evidence on the efficacy of all OAs for the improvement in physiologic sleep outcome measures is summarized in Figure 40.

The evidence on the efficacy of custom and non-custom OAs for the improvement in physiologic sleep outcome measures is summarized in Figures $\mathbf{4 1}$ and 42, respectively. 
The evidence on the efficacy of custom, titratable and custom, non-titratable OAs for the improvement in physiologic sleep outcome measures is summarized in Figures 43 and 44, respectively.

The evidence on the efficacy of OAs vs. CPAP for the improvement in physiologic sleep outcome measures is summarized in Figure 45.

\subsubsection{APNEA-HYPOPNEA INDEX/RESPIRATORY DISTURBANCE INDEX/RESPIRATORY EVENT INDEX (AHI/RDI/REI)}

\subsection{All Appliance Types}

Oral appliances reduce the AHI in adult patients with OSA. (Quality of evidence: Moderate) Since the previous practice parameter published in 2006, several RCTs evaluating the effect of OAs on AHI have been published including studies comparing OAs to CPAP.

Thirty-four RCTs with 1,301 patients assessed the effect of OAs on AHI and found an overall improvement in AHI. ${ }^{4,9-11,14,17,20-47}$ A meta-analysis was performed on all included trials that compared AHI pre- and post-treatment with OAs. The results are shown in Figure 9. In weighted analysis, the mean reduction in AHI was 13.60 events/h (95\% CI: -15.25, -11.95 ) with an OA compared to the control group without OA.

Twenty-five of the 34 RCTs included in the meta-analysis reported greater than 50\% reduction in AHI with the use of OAs in adult OSA patients. ${ }^{11,20,21,23-25,27-36,38-44,46,47}$

\subsection{Custom vs. Non-Custom OAs}

Custom OAs reduce AHI and RDI in adult patients with OSA. (Quality of evidence: Moderate) Thirty-three RCTs including 1,259 patients that assessed AHI with the use of custom OAs were identified., ${ }^{4-11,14,17,20-28,30-47}$ Overall, custom OAs were found to substantially reduce the AHI. Meta-analysis (Figure 10) showed the mean reduction in AHI/RDI/REI for custom OAs to be 13.89 events/h (95\% CI: 15.57, 12.20). Twenty-eight of the 33 RCTs included in the meta-analysis reported a greater than $50 \%$ reduction in AHI with the use of custom OAs in adult OSA patients. ${ }^{9-11,20,21,23-25,27,28,30-47}$ Five $\mathrm{RCT}$ s reported a mean decrease in AHI of up to 25 events/h with the use of custom OAs. ${ }^{30,34-36,44}$

Non-custom OAs reduce AHI/RDI/REI in adult patients with OSA. (Quality of evidence: Low) Two RCTs including 42 adult patients with OSA that assessed AHI with the use of noncustom OAs were identified. ${ }^{29,45}$ Small improvements in AHI were reported. Meta-analysis (Figure 11) showed the mean reduction in AHI for non-custom OAs to be 6.28 events/h (95\% CI: $-13.13,0.56)$. It should be noted that the meta-analysis reports wide confidence intervals surrounding the mean reduction in AHI for each of the 2 RCTs that studied the efficacy of non-custom OAs.

A comparison of the results of the meta-analyses cited above suggests that custom OAs achieve a greater reduction in AHI in adult patients with OSA than non-custom OAs.

\subsection{Custom, Titratable vs. Custom, Non-Titratable OAs}

Custom, titratable OAs reduce AHI/RDI/REI in adult patients with OSA. (Quality of evidence: Moderate) A meta-analysis (Figure 12) of 27 RCTs including 1,054 patients showed the mean reduction in $\mathrm{AHI} / \mathrm{RDI} / \mathrm{REI}$ for custom, titratable OAs to be 13.80 events/h (95\% CI: 15.74, 11.87)..$^{4,9-11,14,20-22,24-27,30-42,44,47}$ Twenty-two of the 27 RCTs included in the meta-analysis reported greater than $50 \%$ reduction in AHI with the use of custom, titratable OAs in adult OSA patients. $^{9-11,20,21,24,25,27,30-36,38-42,44,47}$ Five RCTs reported a mean decrease in AHI of up to 25 events/h with the use of custom titratable OAs. ${ }^{30,34-36,44}$ In an RCT conducted by Tan et al., the first 10 subjects were treated with a custom, non-titratable OA; but 2 subjects complained of inadequate nocturnal oral respiration and were unable to tolerate the device. ${ }^{43}$ Therefore, the patients in the study were switched to a custom, titratable device for the remainder of the study. ${ }^{43}$ For this reason, the study was excluded from the meta-analyses of custom, titratable and custom, non-titratable OAs.

Custom, non-titratable OAs reduce AHI/RDI/REI in adult patients with OSA. (Quality of evidence: Moderate) A meta-analysis (Figure 13) of 6 RCTs including 164 adult patients with OSA showed the mean reduction in AHI for custom, non-titratable OAs to be 12.51 events/h (95\% CI: 15.23 , 9.80). ${ }^{17,23,24,28,45,46}$ Four of the 6 RCTs included in the metaanalysis reported greater than 50\% reduction in AHI with the use of custom, non-titratable OAs. ${ }^{23,24,28,46}$

A comparison of the results of the meta-analyses cited above suggests that custom, titratable and custom, non-titratable OAs achieve an equivalent reduction in AHI in adult patients with OSA.

\subsection{OAs vs. CPAP}

$C P A P$ reduces $A H I / R D I / R E I$ more than $O A$ s in adult patients with OSA. (Quality of evidence: Moderate) A meta-analysis performed on 15 RCTs ( 9 of them published since the 2006 practice parameters paper) evaluated 491 patients assigned to an OA and 481 assigned to CPAP to assess the effect of these devices on AHI. ${ }^{4,14,20-22,28-30,33-36,40,43,44}$ The results are shown in Figure 14. In weighted analysis, OAs produced a significant mean reduction in AHI, however the mean reduction in AHI was 6.24 events/h (95\% CI: 8.14, 4.34) greater with CPAP than with OA.

A study by Gagnadoux et al. evaluating the effectiveness of OA vs. CPAP over a 2-month treatment period noted a complete response $(>50 \%$ reduction in AHI to $<5$ events $/ \mathrm{h}$ ) in $73.2 \%$ of patients with CPAP and $42.8 \%$ with OA. ${ }^{30}$ The odds of achieving an AHI $\leq 5$ events/h was 49 times greater, and the odds of achieving an AHI $\leq 10$ events/h was 89 times greater with the $\mathrm{OA}$ treated group compared to the control group, based on one RCT. The odds of achieving an AHI $\leq 5$ events/h after treatment was 3.6 times greater. ${ }^{30}$ Ferguson et al. reported that achieving an $\mathrm{AHI} \leq 10$ events/h was 1.9 times greater with CPAP than with OA. ${ }^{4}$ The treatment duration with $\mathrm{OA}$ and CPAP in the above studies varied between 6 weeks and 4 months.

\subsubsection{OXYGEN SATURATION}

\subsection{All Appliance Types}

Oral appliances modestly improve minimum oxygen saturation in adult patients with OSA. (Quality of evidence: Moderate) A meta-analysis was performed on all included trials that compared pre- and post-treatment oxygen saturation when 
treated with OAs vs. control group without OA. The results are shown in Figure 15. In a weighted analysis of 22 RCTs that assessed 946 adult OSA patients treated with OAs, the mean improvement in oxygen saturation was 3.09\% (95\% CI: 2.43, $3.76)^{4,9-11,14,22,26,27,29,31-41,45,47}$ The greatest improvements in minimum oxygen saturation with the use of OAs were reported by Hoekema et al. in 2007 and 2008; 13.0\% (95\% CI: 7.02, 18.98) and $12.1 \%$ (95\% CI: 6.89, 17.31), respectively. ${ }^{34,35}$ Custom, titratable appliances were used in these studies. ${ }^{34,35}$ Nine of the 22 RCTs included in the meta-analysis did not show a statistically significant improvement in oxygen saturation with the use of OAs. ${ }^{4,14,26,27,29,37,41,45,47}$

\subsection{Custom vs. Non-Custom OAs}

Custom OAs modestly improve minimum oxygen saturation in adult patients with OSA. (Quality of Evidence: Moderate) A meta-analysis of 21 RCTs including 908 adult patients with OSA showed the mean increase in minimum oxygen saturation for custom OAs to be $3.22 \%$ (95\% CI: $2.54,3.90){ }^{4,9-11,14,22,26,27,31,32,34-41,45,47}$ The results are shown in Figure 16. Eight of the $21 \mathrm{RCTs}$ included in the meta-analysis did not show a statistically significant improvement in oxygen saturation with the use of custom OAs. ${ }^{4,14,26,27,37,41,45,47}$

Non-custom OAs do not significantly improve minimum oxygen saturation in adult patients with OSA. (Quality of evidence: Moderate) Two RCTs including 42 adult patients with OSA investigated changes in minimum oxygen saturation with non-custom OAs. ${ }^{29,45}$ Meta-analysis (Figure 17) of these 2 studies revealed a statistically insignificant mean decrease in minimum oxygen saturation of $0.29 \%(95 \% \mathrm{CI}:-3.22,2.64)$.

\subsection{Custom, Titratable vs. Custom, Non-titratable OAs}

Custom, titratable OAs modestly improve minimum oxygen saturation in adult patients with OSA. (Quality of Evidence: Moderate) Meta-analyses were performed on 20 RCTs including 851 adult patients with OSA that assessed the impact of custom, titratable OAs on minimum oxygen saturation during their sleep. . $^{4-11,14,22,26,27,31,32,34-41,47}$ The results are shown in

Figure 18. The weighted analysis showed a mean increase of $3.15 \%(95 \%$ CI: $2.46,3.84)$ in minimum oxygen saturation using custom, titratable OAs.

Custom, non-titratable OAs modestly improve minimum oxygen saturation in adult patients with OSA. (Quality of evidence: Low) A meta-analysis (Figure 19) of 3 RCTs including 57 patients showed a mean increase in minimum oxygen saturation of $4.70 \%(95 \%$ CI: $-3.83,13.22)$ when using custom, non-titratable OAs to treat adult patients with OSA. ${ }^{41,45,47} \mathrm{Zhou}$ et al. reported a statistically significant improvement in minimum oxygen saturation, ${ }^{47}$ while Vanderveken et al. and Rose et al. found no significant improvement. ${ }^{41,45}$

A comparison of the results of the meta-analyses cited above suggests that custom, titratable and custom, non-titratable OAs achieve an equivalent improvement in minimum oxygen saturation in adult patients with OSA.

\subsection{OAs vs. CPAP}

CPAP improves minimum oxygen saturation slightly better than OAs in adult patients with OSA. (Quality of evidence: Moderate) Nine RCTs (5 of them published since the 2006 practice parameters paper) evaluated a total of 346 adult patients with OSA randomized to OA and 354 to CPAP to evaluate the effect on oxygen desaturation. ${ }^{4,14,22,29,33-36,40}$ Meta-analysis (Figure 20) revealed the improvement in oxygen saturation was better with CPAP than with an OA (mean difference 3.11\% [95\% CI: 1.74, 4.48] higher with CPAP than with an OA). Of the 9 RCTs included in the meta-analysis, Ferguson et al. reported the greatest improvement in minimum oxygen saturation with the use of CPAP over OAs: $11.9 \%$ (95\% CI: 6.71, 17.09). ${ }^{4}$ Conversely, RCTs conducted by Hoekema et al. reported no significant differences in minimum oxygen saturation with OAs compared to CPAP. ${ }^{34-36}$

\subsubsection{AROUSAL INDEX}

\subsection{All Appliance Types}

Oral appliances reduce the arousal index in adult patients with OSA. (Quality of evidence: Moderate) Fourteen RCTs (6 of them published since the 2006 practice parameters paper) assessed 704 adult patients with OSA randomized to OAs vs. a control group and found an overall reduction in arousal index with OAs. ${ }^{11,14,20-24,27,31,32,38-40,43}$ A meta-analysis (Figure 21) comparing the pre- and post-treatment arousal index with OAs compared to the control group showed a mean reduction of 10.78 arousals/h $(95 \%$ CI: 8.02, 13.54). All RCTs reported a statistically significant reduction in arousal index using OAs. The findings by Barnes et al. and Randerath et al., while statistically significant, were considered clinically insignificant using custom OAs. ${ }^{14,22}$ All other RCTs reported clinically significant reductions in arousal index using custom OAs. ${ }^{20,21,27,31,32,44-46,49}$ Aarab et al., Blanco et al., and Ghazal et al. reported $>50 \%$ reduction in arousal index using OAs..$^{21,23,31}$ Deanne et al. performed an RCT comparing an OA to a tongue retaining device and found that the OAs reduced the arousal index from $33.23 \pm 16.41$ arousals $/ \mathrm{h}$ to $21.09 \pm 9.27$ arousals $/ \mathrm{h}, \mathrm{p}=0.004$, while the tongue retaining device decreased it to $21.09 \pm 10.56$ arousals $/ \mathrm{h}, \mathrm{p}=0.001$. $^{27}$

\subsection{Custom vs. Non-Custom OAs}

Custom appliances have an impact on lowering arousal index. (Quality of Evidence: Moderate) Since all of the custom appliances evaluated for improvement in arousal index were custom, titratable appliances, the meta-analysis results for all OAs above also apply to custom appliances. (Figure 21)

There was insufficient evidence to assess the efficacy of non-custom OAs for improvement in arousal index in adult patients with OSA.

\subsection{Custom, Titratable vs. Custom, Non-titratable OAs}

Custom, titratable appliances have an impact on lowering arousal index. (Quality of Evidence: Moderate) Twelve RCTs assessed 648 adult patients with OSA randomized to OAs vs. a control group and found an overall reduction in arousal index with OAs. ${ }^{11,14,20-22,24,27,31,32,38-40}$ A meta-analysis (Figure 22) comparing the pre- and post-treatment arousal index with OAs compared to the control group showed a mean reduction of 10.44 arousals/h (95\% CI: $7.45,13.44)$. An RCT conducted by Randerath et al. was the only study that reported a statistically insignificant reduction in arousal index using OAs. ${ }^{14}$ In an RCT conducted by Tan et al., the first 10 subjects were treated with 
a custom, non-titratable OA; but 2 subjects complained of inadequate nocturnal oral respiration and were unable to tolerate the device. ${ }^{43}$ Therefore, the patients in the study were switched to a custom, titratable device for the remainder of the study. ${ }^{43}$ For this reason, the study was excluded from the meta-analyses of custom, titratable and custom, non-titratable OAs.

Custom, non-titratable appliances have an impact on lowering arousal index. (Quality of Evidence: Low) A meta-analysis (Figure 23) of $2 \mathrm{RCTs}^{23,24}$ assessed 32 adult patients with OSA found a mean reduction in arousal index of 14.59 arousals/h (95\% CI: 12.48, 16.71).

A comparison of the results of the meta-analyses cited above suggests that custom, titratable and custom, non-titratable OAs achieve an equivalent reduction in arousal index in adult patients with OSA.

\subsection{OAs vs. CPAP}

$C P A P$ reduces the arousal index more than $O A$ s in adult patients with OSA. (Quality of evidence: Moderate) A metaanalysis (Figure 24) of 6 RCTs (3 of them published since the 2006 practice parameters paper) assessed 274 adult patients with OSA randomized to OAs vs. 272 randomized to CPAP. ${ }^{14,20-22,40,43}$ A meta-analysis demonstrated that CPAP was moderately better than an OA in reducing the overall arousal index (mean difference in arousal index reduction was 3.57 arousals/h $(95 \% \mathrm{CI}: 1.64,5.51)$ better with CPAP than OA). Barnes et al. reported the most significant differences in the mean reduction in arousal index between the use of OAs and CPAP; 5.50 arousals/h $\left(95 \%\right.$ CI: 5.82, 5.18). ${ }^{22}$ Aarab et al., Phillips et al., Randerath et al., and Tan et al. reported no significant difference between OAs and CPAP. ${ }^{14,20,21,40,43}$

\subsubsection{OXYGEN DESATURATION INDEX (ODI)}

\subsection{All Appliance Types}

Oral appliances lower the ODI in adult patients with OSA. (Quality of evidence: Moderate) A meta-analysis (Figure 25) of 6 RCTs ( 3 of them published since the 2006 practice parameters paper) that included 399 adult patients with OSA found a mean reduction in ODI of 12.77 events/h (95\% CI: 8.69, 16.85). ${ }^{17,22,31,40,46,47}$ Four out of the 6 RCTs included in the metaanalysis reported $>50 \%$ reduction in ODI using OAs. ${ }^{31,40,46,47}$ In an RCT of 2 different OAs, Ghazal et al. noted an improvement in ODI from 16.0 events/h (4-22) to 8.0 events/h (1-12), $\mathrm{p}<0.05$ in one appliance and 14.0 events/h $(2-16)$ to 4.0 events/h $(0.8-19), \mathrm{p}<0.05$ in the other. ${ }^{31}$

\subsection{Custom vs. Non-Custom OAs}

Custom appliances have an impact on lowering ODI. (Quality of Evidence: Moderate) Since all of the appliances evaluated for improvement in ODI were custom appliances, the meta-analysis results for all OAs above also apply to custom appliances (Figure 25).

There was insufficient evidence to assess the efficacy of noncustom OAs for improvement in ODI in adult patients with OSA.

\subsection{Custom, Titratable vs. Custom, Non-Titratable OAs}

Custom, titratable OAs lower the ODI in adult patients with OSA. (Quality of Evidence: Moderate) Meta-analysis
(Figure 26) of 4 RCTs including 322 adult patients with OSA showed the mean reduction in ODI for custom, titratable OAs to be 9.95 events/h (95\% CI: 16.25, 3.66)..$^{22,31,40,47}$

Custom, non-titratable OAs lower the ODI in adult patients with OSA. (Quality of evidence: Moderate) Three RCTs including 77 patients investigated changes in ODI with custom, nontitratable OAs. ${ }^{17,46,47}$ Meta-analysis (Figure 27) showed the mean reduction in ODI for custom, non-titratable OAs to be 15.65 events/h $(95 \%$ CI: $26.86,4.44)$. Zhou et al. reported the most significant decrease in ODI with the use of a custom, nontitratable OA; 25.00 events/h (95\% CI: 28.81, 21.19). ${ }^{47}$

A comparison of the results of the meta-analyses cited above suggests that custom non-titratable OAs achieve an equivalent reduction in ODI with custom titratable OAs in adult patients with OSA.

\subsection{OAs vs. CPAP}

$C P A P$ reduces the ODI slightly more than OAs in adult patients with OSA. (Quality of evidence: Low) Three RCTs (2 of them published since the 2006 practice parameters paper) evaluated the effectiveness of OAs vs. CPAP for the treatment of adult patients with OSA. ${ }^{22,30,40}$ Meta-analysis (Figure 28) of 234 patients randomized to an OA vs. CPAP found CPAP was slightly better at reducing the ODI compared to OAs with a mean difference in ODI of 4.76 events/h (95\% CI: 2.37 to 7.15$)$ All RCTs included in the meta-analysis reported a statistically significant difference in reduction of ODI favoring CPAP over an OA. ${ }^{22,30,40}$

\subsubsection{SLEEP ARCHITECTURE}

\subsection{All Appliance Types}

Oral appliances have no significant effect on sleep architecture in adult patients with OSA. (Quality of evidence: Low) A meta-analysis (Figure 29) of 17 RCTs including 636 adult patients with OSA found no clinically significant differences in $\mathrm{REM} \%$ pre and post OA treatment (1.67, 95\% CI: 0.51 , 2.84). ${ }^{4,9-11,14,20-24,27,29,31,32,35,38,43}$

There was insufficient evidence to assess the effects of OA therapy on other measures of sleep architecture (e.g., \% sleep stage time) in adult patients with OSA.

\subsection{Custom vs. Non-Custom OAs}

Custom OAs do not have a significant effect on \% of REM sleep. (Quality of evidence: Low) A meta-analysis (Figure 30) of 16 RCTs including 620 adult patients with OSA found a clinically insignificant weighted mean increase in REM of $1.58 \%$ (95\% CI: $0.64,2.53)$ using custom OAs. ${ }^{4,9-11,14,20-24,27,31,32,35,38,43}$

Non-custom OAs do not have a significant effect on $\%$ of REM sleep. (Quality of evidence: Moderate) An RCT conducted by Ferguson et al. including 19 adult patients with OSA found an insignificant weighted mean increase in REM of $5.70 \%(95 \% \mathrm{CI}:-0.56,11.96)$ using a non-custom OA. ${ }^{29}$

\subsection{Custom, Titratable vs. Custom, Non-Titratable OAs}

Custom, titratable OAs do not have a significant effect on $\%$ of REM sleep. (Quality of evidence: Low) A meta-analysis (Figure 31) of 14 RCTs including 561 adult patients with OSA found an insignificant weighted mean increase of $1.24 \%(95 \%$ CI: $-0.09,2.56) .{ }^{4,9-11,14,20-22,24,27,31,32,35,38}$ 
Custom, non-titratable OAs do not have a significant effect on \% of REM sleep. (Quality of evidence: Moderate) A metaanalysis (Figure 32) of 2 RCTs including 32 adult patients with OSA found an insignificant weighted mean increase of $0.97 \%$ (95\% CI: $0.41,1.53) .^{23,24}$

\subsection{OAs vs. CPAP}

OAs and CPAP do not significantly improve \% of REM sleep in adult patients with OSA. (Quality of evidence: Low) A metaanalysis (Figure 33) of 8 RCTs (3 of them published since the 2006 parameters paper) evaluated the effectiveness of OAs vs. CPAP in 244 adult patients with OSA randomized to CPAP and 244 randomized to an OA. The analyses found no significant differences in the \% of REM sleep; 0.72 (95\% CI: -1.09 , 2.52). ${ }^{4,14,20-22,29,30,36,43}$

There was insufficient evidence to assess the effects of OAs vs. CPAP on other measures of sleep architecture (e.g., \% sleep stage time) in adult patients with OSA.

\subsubsection{SLEEP EFFICIENCY}

\subsection{All Appliance Types}

Oral appliances have no significant effect on sleep efficiency in adult patients with OSA. (Quality of evidence: Moderate) A meta-analysis (Figure 34) of 17 RCTs (7 of them published since the 2006 practice parameters paper) looked at 721 adult patients with OSA to evaluate sleep efficiency. There were no significant improvements in sleep efficiency; 0.95 (95\% CI: -0.21, 2.12). ${ }^{4,9-11,22-24,27,29,31,32,35,38,39,43,45,47}$ Deanne et al. performed an RCT comparing an OA vs. a tongue retaining device (TRD) and found no significant differences in sleep efficiency (baseline $80 \% \pm 11 \%$ to $78 \% \pm 17 \%$ with OA, $\mathrm{p}=\mathrm{ns}$ vs. TRD at $79 \% \pm 11 \%, \mathrm{p}=\mathrm{ns}) .{ }^{27}$

\subsection{Custom vs. Non-Custom OAs}

Custom OAs have no significant effect on sleep efficiency in adult patients with OSA. (Quality of Evidence: Low) A metaanalysis (Figure 35) was performed on 16 RCTs including 679 adult patients with OSA that assessed the impact of custom OAs on sleep efficiency., ${ }^{4-11,22-24,27,31,32,35,38,39,43,45,47}$ The weighted analyses showed an insignificant mean improvement in sleep efficiency for custom appliances to be $0.98 \%$ (95\% CI: -0.22 , 2.18). RCTs conducted by Barnes et al., Ghazal et al., Gauthier et al., Gotsopoulos et al., and Zhou et al. reported statistically significant increases in sleep efficiency using custom OAs. $^{9-11,22,31,47}$

Non-custom OAs have no significant effect on sleep efficiency in adult patients with OSA. (Quality of evidence: Moderate) A meta-analysis (Figure 36) was performed on 2 RCTs including 42 adult patients with OSA that assessed the impact of non-custom OAs on sleep efficiency. ${ }^{29,45}$ The results show no significant change in sleep efficiency. The weighted analyses showed the mean decrease in sleep efficiency for non-custom OAs to be $0.30 \%(95 \% \mathrm{CI}:-4.02,4.62)$.

\subsection{Custom, Titratable vs. Custom, Non-Titratable OAs}

Custom, titratable OAs have an insignificant impact on sleep efficiency in adult patients with OSA. (Quality of Evidence: Low) A meta-analysis (Figure 37) was performed on 13 RCTs including 584 patients with OSA that assessed the efficacy of custom, titratable OAs for sleep efficiency. ${ }^{4,9-11,22,24,27,31,32,36,38,39,47}$ The weighted analysis showed the mean increase in sleep efficiency to be $0.87 \%$ (95\% CI: $-0.43,2.17)$.

Custom, non-titratable OAs have an insignificant impact on sleep efficiency in adult patients with OSA. (Quality of Evidence: Moderate) A meta-analysis (Figure 38) was performed on 4 RCTs including 71 patients with OSA that assessed the efficacy of custom, non-titratable OAs for sleep efficiency. ${ }^{23,24,45,47}$ The weighted analysis showed the mean increase in sleep efficiency to be $2.71 \%$ (95\% CI: $-2.32,7.73)$.

\subsection{OAs vs. CPAP}

OAs and CPAP do not significantly improve sleep efficiency in adult patients with OSA (Quality of evidence: Moderate) A meta-analysis (Figure 39) of 5 RCTs (1 of them published since the 2006 practice parameters paper), that evaluated 190 patients randomized to OAs and 191 to CPAP, found no significant difference between the 2 therapies in improving sleep efficiency; $0.37 \%$ (95\% CI: $-0.47,1.21)$. $^{4,22,29,36,43}$

\subsubsection{Daytime sleepiness}

\subsubsection{AlL APPLIANCE TYPES}

Oral appliances reduce daytime sleepiness in adult patients with OSA. (Quality of evidence: Moderate) This is an expansion of the recommendations in the 2006 AASM Practice Parameters for the Treatment of Snoring and Obstructive Sleep Apnea with Oral Appliances. Since publication of the 2006 practice parameters, several high quality clinical trials have established the benefits of oral appliance therapy in improving daytime sleepiness in patients with OSA.

Compared with no treatment or non-therapeutic (sham) therapy, treatment with OAs significantly improved daytime sleepiness. In meta-analysis (Figure 46) of 25 studies that measured subjective somnolence as an outcome of OA therapy, the mean reduction in the ESS was 3.81 (95\% CI: 4.39, $3.23){ }^{9-11,17,22-26,28,30,31,33-40,43-45,47,48}$ In a study comparing a custom OA set at $75 \%$ of the maximum mandibular advancement to a similar OA that did not advance the mandible, Blanco et al. found that daytime somnolence was improved with therapy. ${ }^{23}$ ESS scores improved more in the advanced group, decreasing from $14.7 \pm 5.1$ before treatment to $5.1 \pm 1.9$ after 3 months of treatment $(\mathrm{p}<0.05) .{ }^{23}$ There was not a significant reduction in ESS among the non-advanced group (16.3 \pm 2.5 to only $13.6 \pm 6.7, \mathrm{p}=\mathrm{NS}) .{ }^{23}$ Similarly, Gauthier et al. conducted an RCT of patients using OAs for the treatment of OSA and, after a mean follow-up period of 40.9 months, reported a decrease in ESS from $13.9 \pm 1.3$ to $9.3 \pm 1.2$ for one custom, titratable OA and from $13.9 \pm 1.3$ to $9.9 \pm 1.3$ for the other. ${ }^{9}$ In contrast, an RCT conducted by Johnson et al. did not observe that OAs led to significant improvements in daytime sleepiness when compared to placebo. ${ }^{17}$ The investigators utilized a fixed, nontitratable OA, which may explain the discrepancy between their observed treatment effect and other trials exploring the impact of OAs. ${ }^{17}$ In that RCT, the ESS changed from 13.9 \pm 6.4 at baseline to $11.6 \pm 6.7$ with an $\mathrm{OA}$ and $12.7 \pm 6.3$ with placebo $(\mathrm{p}=0.414) .{ }^{17}$ However, $45 \%$ of those using an OA achieved a normal ESS $(<10)$ following treatment. ${ }^{17}$ 
The evidence on the efficacy of OAs for the improvement of subjective daytime sleepiness is summarized in Figure $\mathbf{5 1 .}$

\subsubsection{CUSTOM VS. NON-CUSTOM OAS}

Custom oral appliances reduce daytime sleepiness in adult patients with OSA. (Quality of evidence: Moderate) Twenty-five RCTs including 948 patients were identified that evaluated the change in ESS with the use of custom OAs. ${ }^{9-11,17,22-26,28,30,31,33-40,43-45,47,48}$ Reductions in ESS were modest. Meta-analysis (Figure 47) showed the mean reduction in ESS score for custom OAs to be 1.95 (95\% CI: 2.03, 1.88). Phillips et al., in one of the largest studies with 108 subjects, found a significant $(\mathrm{p}<0.01)$ reduction in ESS from a baseline of $9.1 \pm 0.4$ to $7.2 \pm 0.4 .^{40}$ Others such as Hoekema et al. reported larger improvements in ESS score (12.9 \pm 5.6 to $4.8 \pm 5.4){ }^{35}$

Non-custom oral appliances do not significantly reduce daytime sleepiness in adult patients with OSA. (Quality of evidence: Moderate) A single RCT including 23 patients assessed the effects of non-custom OA therapy on sleepiness in adult patients with OSA. The study reported an insignificant mean reduction in ESS of 1.0 (95\% CI: -3.62, 1.62).

The evidence on the efficacy of custom and non-custom OAs for the improvement of subjective daytime sleepiness is presented in Figures 52 and 53, respectively.

\subsubsection{Custom, TItRATABle VS. CUstom, NON-TItRATABLE OAS}

Custom, titratable oral appliances reduce daytime sleepiness in adult patients with OSA. (Quality of evidence: Moderate) Nineteen RCTs including 768 patients were identified that evaluated the change in ESS with the use of custom, titratable OAs. ${ }^{9-11,22,24-26,30,31,33-40,44,47}$ Reductions in ESS were modest. Meta-analysis (Figure 48) showed the mean reduction in ESS score for custom, titratable OAs to be 3.95 (95\% CI: 4.61, 3.28).

Custom, non-titratable oral appliances reduce daytime sleepiness in adult patients with OSA. (Quality of evidence: High) Eight RCTs including 156 patients were identified that evaluated the change in ESS with the use of custom, non-titratable OAs. ${ }^{17,23-25,28,45,47,48}$ Meta-analysis (Figure 49) showed the mean reduction in ESS score for custom, non-titratable OAs to be 3.65 (95\% CI: 5.18, 2.13).

The evidence on the efficacy of custom, titratable and custom, non-titratable OAs for the improvement of subjective daytime sleepiness is summarized in Figures $\mathbf{5 4}$ and 55, respectively.

\subsubsection{OAS VS. CPAP}

OAs are equivalent to CPAP in reducing subjective daytime sleepiness in adult patients with OSA. (Quality of evidence: Low) Meta-analyses were performed on 10 RCTs that compared measures of daytime sleepiness between OAs and CPAP (Figure 50). ${ }^{22,28,30,33-36,40,43,44}$ The weighted analysis of 10 trials comparing changes in the ESS between OAs and CPAP found an insignificant increase of 0.08 (95\% CI: $-0.21,0.38)$ in posttreatment measures of subjective sleepiness between these 2 therapies.

In an RCT of patients with mild to moderate OSA, Barnes et al. compared the impact of OAs and CPAP on daytime sleepiness. ${ }^{22}$ Both treatments led to clinically and statistically significant improvements in daytime sleepiness, with greater effects noted with CPAP therapy.22 Compared with placebo, both treatments significantly improved subjective sleepiness as measured by the ESS ( $p<0.001$ for both OAs and CPAP). ${ }^{22}$ There was no difference in the measured treatment effect between the 2 interventions..$^{22}$ The investigators did not observe improvements in objective sleepiness with either treatment. ${ }^{22}$ However, the mean sleep latency on baseline maintenance of wakefulness testing (MWT) was normal among the cohort (30.7 \pm 0.9 minutes), and only $18.4 \%$ had objective somnolence prior to therapy. ${ }^{22}$ Alertness, as measured by a visual analog scale, was improved with CPAP $(\mathrm{p}<0.001)$ but unchanged with OAs. ${ }^{22}$ In an RCT, Hoekema et al. found that OAs performed similarly to CPAP in improving daytime sleepiness. ${ }^{36}$ Specifically, ESS changed from $12.9 \pm 5.6$ at baseline to $6.9 \pm 5.5$ following treatment with an OA, compared with a change from $14.2 \pm 5.6$ to $5.9 \pm 4.8$ with CPAP. ${ }^{36}$

The evidence on the efficacy of OAs vs. CPAP for the improvement of subjective daytime sleepiness is presented in Figure 56.

\subsubsection{Quality of Life}

\subsubsection{ALL APPLIANCE TYPES}

Oral appliances improve quality of life measures in adult patients with OSA. (Quality of evidence: Moderate) This is an expansion of the statements and associated recommendations provided in the 2006 AASM Practice Parameters for the Treatment of Snoring and Obstructive Sleep Apnea with Oral Appliances. Since the publication of the 2006 practice parameters, several high quality clinical trials have established the benefits of OA therapy in improving QOL measures in patients with OSA.

Compared with no treatment or non-therapeutic (sham) therapy, treatment with OAs significantly improved QOL measures. A meta-analysis of 8 RCTs exploring the impact of OAs on QOL was performed. ${ }^{22,23,26,28,31,35,37,40}$ The results are shown in Figure 57. Oral appliances were associated with significant improvements in QOL measures. In a weighted analysis, the mean improvement in the SF-36 scores was 6.41 (95\% CI: $5.08,7.75)$. In a study comparing a custom OA set at $75 \%$ of the maximum mandibular advancement to a similar OA that did not advance the mandible, Blanco et al. found that QOL was improved with therapy. ${ }^{23}$ After 3 months of treatment, the overall FOSQ scores also improved by $27.1 \%$ from baseline in the mandibular advancement group $(\mathrm{p}<0.001$, effect size $0.90){ }^{23}$ In comparison, the non-advanced group experienced a $-1.7 \%$ decline in FOSQ. ${ }^{23}$ Similarly, Gauthier et al. conducted an RCT of patients using OAs for the treatment of OSA. ${ }^{10}$ After a mean follow-up period of 40.9 months, mean overall FOSQ scores improved from $13.9 \pm 0.8$ to $17.2 \pm 0.6(\mathrm{p} \leq 0.01) .{ }^{10}$

The evidence on the efficacy of OAs for the improvement in QOL is summarized in Figure 61.

\subsubsection{CUSTOM VS. NON-CUSTOM OAS}

Custom appliances improve quality of life in patients with obstructive sleep apnea in adult patients with OSA. (Quality of Evidence: Moderate) The meta-analysis for all appliance types applies to custom OAs as all of the appliances were custom made (Figure 57). 
There was insufficient evidence to assess the efficacy of non-custom OAs for improvement in QOL.

\subsubsection{Custom, Titratable OAs vs. Custom, NON-TItratABle OAS}

Custom, titratable appliances improve quality of life. (Quality of Evidence: Moderate) Six RCTs including 2,223 patients were identified that evaluated the change in SF-36 with the use of custom, titratable OAs. ${ }^{22,26,31,35,37,40}$ Meta-analysis (Figure 58) showed the mean reduction in SF-36 score for custom, titratable OAs to be 6.84 (95\% CI: 5.42, 8.26).

Custom, non-titratable appliances do not improve quality of life in adult patients with OSA. (Quality of Evidence: Low) Two RCTs including 102 patients were identified that evaluated the change in SF-36 with the use of custom, non-titratable OAs. ${ }^{23,28}$ Meta-analysis (Figure 59) showed no significant improvement in QOL for custom, non-titratable OAs; -0.95 (95\% CI: -4.55 , 2.64).

The evidence on the efficacy of custom, titratable and custom, non-titratable OAs for the improvement in QOL is summarized in Figures 62 and 63.

\subsubsection{OAs vs. CPAP}

$O A$ s are nearly equivalent to CPAP for improving $Q O L$ in adult patients with OSA. (Quality of evidence: Low) Metaanalyses were performed on 4 RCTs that compared measures of QOL between OAs and CPAP (Figure 60) and found that both therapies performed similarly; a clinically insignificant weighted mean improvement in SF-36 scores of 2.18 (95\% CI: $1.10,3.25)$ with CPAP compared to OAs. ${ }^{22,28,36,40}$ In an RCT of patients with mild to moderate OSA, Barnes et al. compared the impact of OAs and CPAP on several functional outcomes. Both treatments led to clinically and statistically significant improvements in QOL, with greater effects noted with CPAP therapy. Neither treatment was superior to placebo for changes in neuropsychologic function or improvements in mood. ${ }^{22}$ In an RCT, Hoekema et al. found that OAs performed similarly to CPAP in improving QOL. ${ }^{36}$ Specifically, FOSQ scores improved from $13.7 \pm 3.1$ to $16.6 \pm 2.8$ with OAs and from $13.9 \pm 3.7$ to $16.7 \pm 3.1$ with CPAP therapy. ${ }^{36}$ Phillips et al. observed that baseline FOSQ scores improved from $16.3 \pm 0.2$ to $17.3 \pm 0.2$ with CPAP and $17.3 \pm 0.2$ with an OA..$^{40}$ In addition, SF-36 scores related to Bodily Pain, Vitality, Social Function, Mental Health, and Mental Component had similar improvements with both therapies. ${ }^{40}$

The evidence on the efficacy of OA vs. CPAP for the improvement in QOL is presented in Figure 64.

\subsubsection{Hypertension}

\subsubsection{AlL APPLIANCE TYPES}

Oral appliances have a modest impact on reducing blood pressure in adult patients with OSA. (Quality of evidence: Moderate) This is a new clinical question that was not addressed in the 2006 AASM Practice Parameters for the Treatment of Snoring and Obstructive Sleep Apnea with Oral Appliances: An Update for 2005. ${ }^{6}$ Since that time, several RCTs exploring the effect of OA therapy on cardiovascular outcomes, specifically blood pressure (BP) measures have been conducted.
A meta-analysis was performed on all included trials that compared pre- and post-treatment BP recordings between OAs and non-therapeutic (sham) or no treatment. The results are shown in Figures 65 and 66. In a weighted analysis, the mean reduction in systolic BP was $2.09 \mathrm{mmHg}(95 \% \mathrm{CI}: 0.96,3.22)$. Oral appliances lead to a greater reduction in diastolic BP recordings, with a mean decrease of $3.15 \mathrm{~mm} \mathrm{Hg}$ (95\% CI: 2.03, 4.26).

Seven RCTs including 343 patients that assessed BP measures as an outcome were identified. ${ }^{9,10,22,32,40,44,48}$ Overall, OAs were found to lower the systolic, diastolic, and mean BP. However, these reductions were modest at best. An RCT by Gotsopoulos et al. compared the effect on BP of 4 weeks of an OA vs. a non-therapeutic OA. ${ }^{32}$ Compared to controls (non-therapeutic $\mathrm{OA}$ ), OAs led to a $1.8 \pm 0.5 \mathrm{~mm} \mathrm{Hg}$ greater reduction in the mean 24-hour diastolic BP $(\mathrm{p}=0.001){ }^{32}$ However, there was no difference in the mean 24-hour systolic BP between the two OAs. Both systolic and diastolic BP measures during wake were improved with OAs compared to non-therapeutic controls. ${ }^{32}$ Specifically, the mean awake systolic BP decreased by $4.4 \mathrm{~mm} \mathrm{Hg}$ in those treated with OAs, compared to only 1.4 $\mathrm{mm} \mathrm{Hg}$ in those receiving non-therapeutic OAs $(\mathrm{p}=0.003) .{ }^{32}$ Similarly, OA therapy produced a greater reduction in the mean diastolic BP while awake compared to controls $(-3.3 \mathrm{~mm}$ Hg vs. $-0.1 \mathrm{~mm} \mathrm{Hg}, \mathrm{p}<0.0001){ }^{32}$ Gauthier et al. observed significant reductions in $\mathrm{BP}$ with OA therapy, specifically, a mean reduction in diastolic $\mathrm{BP}$ of $10.1 \mathrm{~mm} \mathrm{Hg}$ and a mean reduction in systolic BP of $4.3 \mathrm{~mm} \mathrm{Hg.}{ }^{10}$ Other trials found less robust improvements in $\mathrm{BP}$ recordings. ${ }^{22,40}$

The evidence on the efficacy of OAs for the improvement in hypertension is summarized in Figure 71.

\subsubsection{CUSTOM VS. NON-CUSTOM OAS}

Custom OAs modestly reduce blood pressure in adult patients with OSA. (Quality of evidence: Moderate) The metaanalyses for all appliance types apply to custom OAs as all of the appliances were custom made (see Figures 65 and 66).

There was insufficient evidence to assess the efficacy of non-custom OAs for the reduction in BP in adult patients with OSA.

\subsubsection{Custom, TITRATABLE VS. CUSTOM, NON-TITRATABLE OAS}

Custom, titratable OAs modestly reduce blood pressure in adult patients with OSA. (Quality of evidence: Moderate) Six RCTs including 307 patients were identified that assessed the impact of custom, titratable OAs on systolic BP., ${ }^{9,10,22,32,40,44}$ A meta-analysis (Figure 67) of these studies showed the mean reduction in systolic BP for custom, titratable OAs to be -2.37 $\mathrm{mm} \mathrm{Hg}(95 \% \mathrm{CI}:-3.55,-1.20)$. In a group $(\mathrm{n}=12)$ with higher baseline systolic BP, Trzepizur et al. reported decrease in mean systolic BP from $149.3 \pm 3.7$ to $140.5 \pm 7.4 \mathrm{~mm} \mathrm{Hg} .{ }^{44} \mathrm{In}$ a larger group $(n=67)$ with a lower baseline systolic BP, Gotsopoulos et al. reported a modest reduction from a baseline of $127.3 \pm 1.3$ to $125.2 \pm 1.3 \mathrm{~mm} \mathrm{Hg}{ }^{32}$

Six RCTs including 307 patients were identified that assessed the impact of custom, titratable OAs on diastolic BP. ${ }^{9,10,22,32,40,44}$ A meta-analysis (Figure 68) of these studies showed the mean reduction in diastolic BP for custom, titratable OAs to be $-2.77 \mathrm{~mm} \mathrm{Hg}(95 \% \mathrm{CI}:-3.88,-1.67)$. After 2.5 
to 4.5 years of treatment, Gauthier et al. reported an improvement in diastolic BP from a baseline of $92.0 \pm 3.0$ to $81.9 \pm 2.3$ mm Hg. ${ }^{10}$ Gotsoupolos et al. reported a more modest change over a shorter treatment period from $77.7 \pm 0.9$ to $76.4 \pm 0.9$ mm Hg. ${ }^{32}$

Custom, non-titratable OAs modestly reduce BP in adult patients with OSA. (Quality of evidence: High) One RCT including 36 patients investigated changes in systolic and diastolic BP with custom, non-titratable OAs. ${ }^{48}$ There were no significant changes found. The mean reduction in systolic BP for a custom, non-titratable OA was $-2.30 \mathrm{~mm} \mathrm{Hg}$ (95\% CI: -7.20 , 2.60). The mean reduction in diastolic BP for a custom, nontitratable OA was $-2.20 \mathrm{~mm} \mathrm{Hg}(95 \% \mathrm{CI}:-6.22,1.82)$.

The evidence on the efficacy of custom, titratable and custom, non-titratable OAs for the improvement in hypertension is summarized in Figures $\mathbf{7 2}$ and 73, respectively.

\subsubsection{OAs vs. CPAP}

$O A$ s are nearly equivalent to $C P A P$ in reducing blood pressure in adult patients with OSA. (Quality of evidence: Low) In a meta-analysis (Figures 69 and 70) of 3 RCTs comparing OA to CPAP, OAs were nearly equivalent to CPAP in lowering the systolic BP; 0.54 (95\% CI: 0.32, 0.76) and diastolic BP; 0.24 (95\% CI: $-0.50,0.020) .{ }^{22,40,44}$ Trzepizur et al. reported no significant difference in post-treatment BP changes between OAs and CPAP. ${ }^{44}$ Similarly, Phillips et al. found that neither treatment produced significant improvements in BP measures. ${ }^{40}$

The evidence on the efficacy of OA vs. CPAP for the improvement in hypertension is summarized in Figure 74.

\subsubsection{Adherence}

The adherence with oral appliances is better overall than with CPAP in adult patients with OSA. (Quality of evidence: Low) A meta-analysis was performed on 11 RCT studies (Figure 75) that evaluated the adherence rate with OA compared to CPAP, with 9 studies published since the last practice parameters paper in 2006. $22,28,30,33-36,40,44,49,50$ Overall, the absolute difference between the mean subjective adherence rate for OA users was 0.70 (95\% CI: $0.11,1.30)$ more hours per night than the objective adherence rate among CPAP users. Though CPAP adherence was assessed objectively from the download data, OA adherence was assessed subjectively based on patients' self-reports or by reviewing self-entered information in their diaries. The adherence rate for the devices was based on 4 hours a night use, $70 \%$ of the time. There were no RCT studies that assessed OA adherence rate objectively.

Among patients randomly assigned to CPAP or OAs, Barnes et al. found CPAP was used $4.2 \pm 0.3$ nights/week for an average of $3.6 \pm 0.3 \mathrm{~h} /$ night compared to $5.3 \pm 0.3$ nights/week for $5.5 \pm 0.3 \mathrm{~h} /$ night with OAs. ${ }^{22}$ Three of the 11 trials included in the meta-analysis clearly showed that adherence rates with OAs were superior to CPAP ( $>1$ more hour of use). ${ }^{22,40,44}$ Seven of the remaining 8 studies also observed an increase use of OAs compared with CPAP. ${ }^{28,30,33,34,36,49,50}$ However, these differences were less robust (less than or equal to 1 hour improvement in adherence rate compared to CPAP). It should be noted that all included trials compared subjective reports of OA use to objective measures of CPAP use. Although measures to obtain objective oral appliance adherence data do exist, they are not widely used. Therefore, few objective data exist to include in this clinical practice guideline.

The evidence comparing adherence with the use of OAs vs. CPAP is summarized in Figure 76.

\subsubsection{Assessment of Side Effects}

Side effects, serious enough to cause patients to discontinue use of their oral appliance, are less common than side effects causing adult patients with OSA to discontinue the use of CPAP. (Quality of evidence: Moderate) The purpose of followup is to monitor patient adherence, evaluate OA deterioration or maladjustment, evaluate the health of the oral and craniofacial structures and integrity of the occlusion, and assess the patient for signs and symptoms of worsening OSA. Intolerance and improper use of the OA are potential problems for patients using OAs, which require patient effort to use properly. OAs may aggravate temporomandibular disorder (TMD) and may cause dental misalignment and discomfort that are unique to each device. In addition, OAs can be rendered ineffective by patient alteration of the device. Specific side effects differ widely in types and severity, but most are of a dental nature: sore teeth, gum problems, sore jaw muscles, excessive salivation, difficulty chewing in the morning, dry mouth, and change in occlusion. ${ }^{13,28,35,57,58}$ Doff et al. reported that changes in craniofacial morphology should be anticipated in OSA patients using an OA for 2 years when compared with CPAP therapy. These changes were predominantly dental in nature. ${ }^{51}$ Long-term use of an OA resulted in small but significant dental changes compared with CPAP. In the OA group, overbite and overjet decreased $1.2 \pm 1.1 \mathrm{~mm}$ and $1.5 \pm 1.5 \mathrm{~mm}$, respectively. ${ }^{51}$ It should be noted, however, that in a prospective study conducted by Tsuda et al. to assess the craniofacial changes in adult subjects with OSA after CPAP use found that use of nasal CPAP for $>2$ years resulted in a significant retrusion of the anterior maxilla, a decrease in maxillary-mandibular discrepancy, a setback of the supramentale and chin positions, a retroclination of maxillary incisors, and a decrease of convexity. ${ }^{52}$ However, significant correlations between the craniofacial changes, demographic variables, or the duration of CPAP use could not be identified. None of the patients self-reported any permanent change of occlusion or facial profile. ${ }^{52}$

A meta-analysis (Figure 77) was performed on 9 studies that evaluated the discontinuation of therapy due to side effects resulting from the use of OAs. ${ }^{4,21-23,29,31,35,40,43}$ The results showed that the odds of experiencing a side effect leading to discontinuation of therapy with OAs are 6.65:1 (95\% CI: 2.51, 17.62).

A meta-analysis (Figure 78) was performed on 8 RCT studies of OAs versus CPAP and discontinuation of therapy from side effects. ${ }^{4,20-22,29,35,40,43}$ The overall odds of discontinuing therapy due to the use of an OA vs. CPAP are 0.54:1 (95\% CI: $0.26,1.12)$ indicating that the risk of side effects resulting in the discontinuation of OA therapy is less than those resulting in the discontinuation of CPAP. Ferguson et al. reported that patients "had fewer side effects and greater patient satisfaction than with CPAP." ${ }^{\prime 3,29}$ Aarab et al. reported 2 patients discontinuing OA therapy (vs. 6 patients with CPAP) because they reported experiencing more side effects than benefits. ${ }^{21}$ The overall quality of evidence for these 8 RCT studies was 
moderate, with 299 patients in the OA group and 298 patients in the CPAP group. The treatment duration for all the 8 RCT studies varied from 1-12 months. A total of 14 patients withdrew from OA therapy and 25 withdrew from CPAP use.

In a study conducted by Ghazal et al., it was mentioned that "patients who complained of wearing discomfort had the fit of their OA and retention checked...PSG was carried out once the patient had tolerated the OA for at least 5 nights per week." ${ }^{31} \mathrm{~A}$ study conducted by Rose et al. reported that subjective assessments of the OAs must be made after they are worn. ${ }^{41}$ Patients in the study described loss of retention during the night, TMJ pain, gingival irritations, and tenderness in the masseter region. ${ }^{41}$ More dental sessions were required for these patients.

Cunali et al. reported that temporomandibular disorder (TMD) has been the most common contraindication for OAs as a treatment for OSA. ${ }^{26}$

The evidence on the frequency of discontinuation of side effects from the use of OAs in adult patients with OSA is summarized in Figure 79.

The evidence comparing the frequency of occurrence of side effects with the use of OAs vs. CPAP in adult patients with OSA is summarized in Figure 80.

\section{2a Recommendation: When oral appliance therapy is prescribed by a sleep physician for an adult patient with obstructive sleep apnea, we suggest that a qualified dentist use a custom, titratable appliance over non-custom oral devices. (GUIDELINE)}

Values and Trade-Offs: The overall grade for the body of evidence exploring the impact of custom vs. non-custom OAs to treat OSA varies between low and moderate depending on the physiologic sleep outcome measures. A systematic review of the evidence has shown that custom, titratable OAs reduce the AHI, arousal index, and oxygen desaturation index, and increase oxygen saturation to a greater extent than do non-custom OAs. The evidence supports the use of custom, titratable OAs over other types of appliances. Although the reduction in AHI and ODI are similar for both custom, titratable and custom, non-titratable OAs, the confidence interval for the effect of the custom, titratable OAs is considerably smaller than for the custom, non-titratable appliances. Both types of custom appliances are more effective than non-custom OAs.

Neither custom nor non-custom OAs have been shown to significantly affect sleep architecture and sleep efficiency. The overall improvement in physiologic sleep parameters with the use of custom OAs in adult patients with OSA should result in an improvement in daily function and quality of life.

The available data also suggest that OAs effectively improve daytime sleepiness. The mean change in the Epworth Sleepiness Scale (ESS) with custom, titratable OAs is moderate. The reduction in subjective daytime sleepiness achieved with custom titratable OAs is not inferior to that reported with CPAP therapy. In contrast, very limited data suggest that custom, non-titratable OAs do not produce a significant change in ESS. Insufficient data are available to assess objective measures of sleepiness or wakefulness following OA therapy.

The evidence indicates that OAs are also effective in improving QOL. Specifically, custom titratable OAs provide moderate improvement in QOL outcomes. The data on QOL is very limited for custom, non-titratable OAs, therefore, their use cannot be recommended.

\section{2b Recommendation: We recommend that sleep physicians consider prescription of oral appliances, rather than no treatment, for adult patients with obstructive sleep apnea who are intolerant of CPAP therapy or prefer alternate therapy. (STANDARD)}

Values and Trade-Offs: CPAP is superior to OAs in the measured outcomes and, therefore, should be the first-line option for treating OSA. A review of the evidence suggests that adherence rates using OAs are greater than those observed with CPAP. However, no randomized controlled trials have assessed objective OA adherence rate as compared with CPAP. The subjective reporting of adherence rate is prone to bias and needs to be interpreted with caution, as patients may overestimate their OA use. However, a patient whose OSA does not improve with the use of CPAP or is intolerant to CPAP may benefit from the use of an OA. Overall, the discontinuation of therapy due to side effects occurs less when using OAs versus CPAP to treat adult patients with OSA. Therefore, OAs can be offered to patients with OSA who strongly prefer alternate therapies due to side effects or inability to use CPAP.

OAs were not compared to other alternate therapies as there were not sufficient head-to-head studies to analyze.

The overall grade for the body of evidence on the impact of OAs to treat obstructive sleep apnea (OSA) varies between low and moderate depending on the physiologic sleep outcome measures. A systematic review of the evidence has shown that OAs reduce AHI, arousal index, oxygen desaturation index, and increase oxygen saturation. However, OAs have shown no significant effect on sleep architecture and sleep efficiency. The overall improvement in physiologic sleep parameters with the use of OAs in adult patients with OSA should result in an improvement in daily function and quality of life. Although OAs have been shown to improve physiologic sleep parameters, CPAP appears, in our meta-analyses, to be superior to OAs in reducing the AHI, arousal index, and oxygen desaturation index and improving oxygen saturation, and therefore should still generally be the first-line option for treating OSA. The improvement in QOL produced by custom, titratable OAs is not inferior to that reported with CPAP therapy. The quality of evidence for the use of these OAs to improve QOL is moderate, whereas the quality of evidence comparing OAs to CPAP is low. The custom, titratable OAs improve QOL, but as with CPAP, reduced QOL may persist despite otherwise adequate therapy.

The available data regarding the impact of OAs on blood pressure are more limited (overall grade for the body of evidence is low) than the data addressing blood pressure change with CPAP. For example, the role of OAs in patients with resistant hypertension has not yet been evaluated. However, the available data suggest that OAs may be as effective as CPAP in at least select patient populations to lower blood pressure and, therefore, should not preclude the use of either therapy or diminish the other established benefits that accrue from treatment of OSA. Of note, no RCTs have assessed the impact of OA therapy on other cardiovascular endpoints.

In summary, OAs may be effective in improving sleep parameters and outcomes of OSA, and there is little likelihood of 
harm. Although they are not as effective as PAP therapy, the benefits of using OAs outweigh risks of not using OAs. Thus, a STANDARD strength of recommendation to use OAs was provided.

\section{2c Recommendation: We suggest that qualified dentists provide oversight-rather than no follow- up-of oral appliance therapy in adult patients with obstructive sleep apnea, to survey for dental-related side effects or occlusal changes and reduce their incidence. (GUIDELINE)}

Values and Trade-Offs: Beneficial treatment effects may be reduced by treatment-related side effects, and most OA therapy side effects are dental. A wide range of devices made from a variety of materials and having different characteristics, are utilized in clinical practice. Literature on dentists performing interventions to prevent failure of OA therapy is limited, although the topic is mentioned in the results and discussion sections of some publications. Therefore, the overall evidence in support of the above recommendation was considered low. Nevertheless, minimization of side effects may improve adherence and thereby patient outcomes. Several studies demonstrated dental interventions to mitigate side effects. Additionally, knowledge of dental materials and a variety of dental devices including the knowledge of the patients' dental status will likely ensure fewer side effects. A qualified dentist will be able to screen for many problems and choose and/or build the OA with features to minimize the side effects of the therapy. A qualified dentist will have the skills to choose the proper OA and make necessary modifications to accommodate patients who, among other things, may have allergies to metals or acrylics, are strong teeth grinders, or have anatomical deviations. The patient's history and exam, appliance preference, and review of any side effects should be taken into account to avoid device breakage, allergic reactions, or discomfort that leads to frustration or discontinuation of the therapy.

\subsubsection{Long-term Management}

Follow-up evaluations and sleep testing improves long-term management of adult patients with OSA. (Quality of evidence: Low) Although insufficient data was attained to produce a meta-analysis, several studies demonstrated that adjustments made to the OA, based on data obtained from PSGs and home sleep apnea tests (a 7-channel unattended test recording chest and abdominal movement, oxygen saturation, oro-nasal airflow, heart rate, body position, and parapharyngeal noise was utilized by Rose et al.), resulted in greater success. ${ }^{41}$ Gagnadoux et al. compared CPAP and OAs after one-night PSG titration of both treatments. Titration of the OA was designed to optimize its efficacy. The results showed a $70 \%$ success with OA therapy vs. an $82 \%$ success with CPAP. ${ }^{30}$ In a study conducted by Hoekema et al., participants used an OA (or CPAP) for 8 weeks, and the effect was assessed with a PSG. ${ }^{36}$ For those with an $\mathrm{AHI} \geq 5$, the $\mathrm{OA}$ was adjusted and another PSG was performed. This sequence was repeated until the AHI was $<5$ or the adjustments caused discomfort. Of the total OA population $76.5 \%$ were effectively treated $(69.2 \%$ of the severe patients were considered effectively treated and $84.0 \%$ of the non-severe patients were considered effectively treated). ${ }^{36}$ Aarab et al. demonstrated that, through PSG, an effective reduction in AHI was seen at 25\% (1 patient), 50\% (7 patients) and at 75\% (12 patients). ${ }^{21}$

\section{2d Recommendation: We suggest that sleep physicians conduct follow-up sleep testing to improve or confirm treatment efficacy, rather than conduct follow-up without sleep testing, for patients fitted with oral appliances. (GUIDELINE)}

Values and Trade-Offs: The overall grade of evidence for support of follow-up evaluations and testing by sleep physicians is low due to a lack of evidence. However, the discussion sections in most research studies report significant improvement in OA effectiveness when changes were made to the appliances based on data obtained either during or after the sleep studies. While insufficient evidence exists to produce a metaanalysis, the available data suggest that subjective feedback is not sufficient to determine the optimal setting of the OA in the management of OSA. Without objective data the patient may, unnecessarily, remain suboptimally treated. Follow-up sleep testing by sleep physicians should also be considered for OAtreated patients who develop recurrent symptoms, show substantial weight changes, or receive diagnoses of comorbidities relevant to OSA.

\section{2e Recommendation: We suggest that sleep physicians and qualified dentists instruct adult patients treated with oral appliances for obstructive sleep apnea to return for periodic office visits-as opposed to no follow-up-with a qualified dentist and a sleep physician. (GUIDELINE)}

Values and Trade-Offs: A review of the evidence suggests that patients may benefit from periodic follow-up visits with a physician and with a qualified dentist. Several studies have demonstrated that adjustments made to the OA by a dentist, based on data obtained from PSGs and home sleep apnea tests conducted by a physician, may result in greater long-term improvement in OSA. The absence of periodic follow-up visits may result in suboptimal improvement in OSA or side effects that increase risk for discontinuation of therapy.

\subsection{FUTURE DIRECTIONS}

Since the publication of the previous practice parameters on the use of OAs for the management of OSA, a considerable amount of literature has been published on the efficacy of OA treatment using different types of appliances. Nevertheless, there are a number of unresolved issues that require additional consideration. Suggestions for future research are summarized below.

- There should be a consistent and standardized nomenclature when referring to OAs. We suggest that future studies should use the term "oral appliance" rather than use terms such as splints.

- Future studies should consider clinically relevant protocols when assessing custom, non-titratable OAs and when comparing different types of OAs. Methods that use more than one non-titratable OA at difference protrusive positions, or cut apart and reposition 
appliances do not replicate the methods clinicians expect to use with non-titratable OAs. Clinicians expect to fabricate a non-titratable $\mathrm{OA}$ at one protrusive position and leave it there for the course of treatment. Titration protocols that use a titratable OA during sleep to predetermine an effective protrusive position prior to the fabrication of a non-titratable OA may be valuable.

- As the current data indicate benefits with custom titratable OAs to treat OSA compared to other types of OAs, future studies evaluating outcome measures related to OSA treatment should consider using only custom titratable OAs to compare with other therapies such as CPAP.

- A consistent and objective measure of snoring is needed when evaluating treatment benefit.

- Standard protocols are needed to document adverse effects related to OAs.

- Subjective reporting of adherence by patients is the current method of assessing OA adherence. As this is prone for reporting bias and with a lack of randomized control trials assessing objective OA use, future efforts and studies are needed to obtain objective OA adherence data, similar to CPAP. There are several recent non-RCTs published that report on the use of objective adherence monitors in OAs. Further RCTs are needed to evaluate the efficacy of these monitors and also to compare it with the CPAP objective adherence rate.

- Larger and longer RCTs examining the benefits of OA treatment to cardiac, metabolic, and neurocognitive health will also be valuable to clinicians contemplating OA treatment for their patients.

- Studies are needed to assess the long-term outcomes associated with OA therapy in adult patients with OSA.

- Current data demonstrates that mild side effects are associated with OA therapy when compared to CPAP therapy. Few research studies conduct head to head comparisons of devices and many devices have little research investigating side effects at this time. Further research demonstrating an association between specific devices and associated side effects would be useful.

- While evidence is low in assessing the relationship of dental involvement, side effects, and adherence to OA therapy, the discussion section of many RCTs describe incidences of patients requiring additional follow up visits with dentists to make the OAs more comfortable. It is reasonable to conclude that a mitigation of side effects will increase patient adherence with therapy. There were no RCT studies assessing objective OA adherence rate because reliable technology was not available until recently. The subjectively reported adherence in RCTs is prone to bias. Future studies, utilizing newly developed technologies that produce objective data are needed.

- Studies are needed to assess the effects of mandibular exercises and other methods to mitigate side effects associated with OAs.

- Knowing the predictive factors for OA success to treat OSA will be helpful for a clinician. However, studies to date have had significant study methodology limitations, resulting in predictive factors that are not consistent in all studies. Also, some of these factors cannot be readily accessed or be used by the clinician. Future studies evaluating for predictive factors for success of OSA treatment with OAs are needed, and ideally these factors should be readily accessed and applied by the clinician.

- Also, future studies evaluating cost benefit analysis and effectiveness are needed compared to CPAP.

While significant progress has been made in defining an effective OA for the treatment of patients with OSA, this guideline underscores the need to enhance the quantity, quality, and scope of future studies to optimize patient care strategies.

\section{REFERENCES}

1. Nieto FJ, Young TB, Lind BK et al. Association of sleep-disordered breathing, sleep apnea, and hypertension in a large community-based study. Sleep Heart Health Study. JAMA 2000;283:1829-36.

2. Beninati W, Harris CD, Herold DL, Shepard JW, Jr. The effect of snoring and obstructive sleep apnea on the sleep quality of bed partners. Mayo Clin Proc 1999;74:955-8.

3. Hu FB, Willett WC, Manson JE et al. Snoring and risk of cardiovascular disease in women. J Am Coll Cardiol 2000;35:308-13.

4. Ferguson KA, Ono T, Lowe AA, al-Majed S, Love LL, Fleetham JA. A shortterm controlled trial of an adjustable oral appliance for the treatment of mild to moderate obstructive sleep apnoea. Thorax 1997;52:362-8.

5. Ferguson KA, Cartwright $R$, Rogers $R$, Schmidt-Nowara W. Oral appliances for snoring and obstructive sleep apnea: a review. Sleep 2006;29:244-62.

6. Kushida CA, Morgenthaler TI, Littner MR et al. Practice parameters for the treatment of snoring and obstructive sleep apnea with oral appliances: an update for 2005. Sleep 2006;29:240-3.

7. Parthasarathy S, Subramanian S, Quan SF. A multicenter prospective comparative effectiveness study of the effect of physician certification and center accreditation on patient-centered outcomes in obstructive sleep apnea. J Clin Sleep Med 2014;10:243-9.

8. Scherr SC DL, Almeida FR, Bennett KM, et al. Definition of an effective oral appliance for the treatment of obstructive sleep apnea and snoring: a report of the American Academy of Dental Sleep Medicine. J Dent Sleep Med 2014;1:39-50.

9. Gauthier L, Laberge L, Beaudry M, Laforte M, Rompre PH, Lavigne GJ. Efficacy of two mandibular advancement appliances in the management of snoring and mild-moderate sleep apnea: a cross-over randomized study. Sleep Med 2009;10:329-36.

10. Gauthier L, Laberge L, Beaudry M, Laforte M, Rompre PH, Lavigne GJ. Mandibular advancement appliances remain effective in lowering respiratory disturbance index for 2.5-4.5 years. Sleep Med 2011;12:844-9.

11. Gotsopoulos H, Chen C, Qian J, Cistulli PA. Oral appliance therapy improves symptoms in obstructive sleep apnea: a randomized, controlled trial. Am J Respir Crit Care Med 2002;166:743-8.

12. Aurora RN, Morgenthaler TI. On the goodness of recommendations: the changing face of practice parameters. Sleep 2010;33:1273-6.

13. Holley AB, Lettieri CJ, Shah AA. Efficacy of an adjustable oral appliance and comparison with continuous positive airway pressure for the treatment of obstructive sleep apnea syndrome. Chest 2011;140:1511-6.

14. Randerath WJ, Heise M, Hinz R, Ruehle KH. An individually adjustable oral appliance vs continuous positive airway pressure in mild-to-moderate obstructive sleep apnea syndrome. Chest 2002;122:569-75.

15. Qaseem A, Holty JE, Owens DK, et al. Management of obstructive sleep apnea in adults: a clinical practice guideline from the American College of Physicians. Ann Intern Med. 2013;159:471-83.

16. Epstein LJ, Kristo D, Strollo PJ Jr, et al. Clinical guideline for the evaluation, management and long-term care of obstructive sleep apnea in adults. J Clin Sleep Med 2009;5:263-76.

17. Johnston CD, Gleadhill IC, Cinnamond MJ, Gabbey J, Burden DJ. Mandibular advancement appliances and obstructive sleep apnoea: a randomized clinical trial. Eur J Orthod 2002;24:251-62.

18. Cooke ME, Battagel JM. A thermoplastic mandibular advancement device for the management of non-apnoeic snoring: a randomized controlled trial. Eur J Orthod 2006:28:327-38. 
19. Robertson S, Murray M, Young D, Pilley R, Dempster J. A randomized crossover trial of conservative snoring treatments: mandibular repositioning splint and nasal CPAP. Otolaryngol Head Neck Surg 2008;138:283-88.

20. Aarab G, Lobbezoo F, Hamburger HL, Naeije M. Oral appliance therapy versus nasal continuous positive airway pressure in obstructive sleep apnea: a randomized, placebo-controlled trial. Respiration 2011;81:411-9.

21. Aarab G, Lobbezoo F, Heymans MW, Hamburger HL, Naeije M. Longterm follow-up of a randomized controlled trial of oral appliance therapy in obstructive sleep apnea. Respiration 2011;82:162-8.

22. Barnes M, McEvoy RD, Banks S, et al. Efficacy of positive airway pressure and oral appliance in mild to moderate obstructive sleep apnea. Am J Respir Crit Care Med 2004;170:656-64.

23. Blanco J, Zamarron C, Abeleira Pazos MT, Lamela C, Suarez Quintanilla D. Prospective evaluation of an oral appliance in the treatment of obstructive sleep apnea syndrome. Sleep Breath 2005;9:20-5.

24. Bloch KE, Iseli A, Zhang JN et al. A randomized, controlled crossover trial of two oral appliances for sleep apnea treatment. Am J Respir Crit Care Med 2000;162:246-51.

25. Campbell AJ, Reynolds G, Trengrove H, Neill AM. Mandibular advancement splint titration in obstructive sleep apnoea. Sleep Breath 2009;13:157-62.

26. Cunali PA, Almeida FR, Santos CD, et al. Mandibular exercises improve mandibular advancement device therapy for obstructive sleep apnea. Sleep Breath 2011;15:717-27.

27. Deane SA, Cistulli PA, Ng AT, Zeng B, Petocz P, Darendeliler MA. Comparison of mandibular advancement splint and tongue stabilizing device in obstructive sleep apnea: a randomized controlled trial. Sleep 2009;32:648-53.

28. Engleman HM, McDonald JP, Graham D et al. Randomized crossover trial of two treatments for sleep apnea/hypopnea syndrome: continuous positive airway pressure and mandibular repositioning splint. Am J Respir Crit Care Med 2002;166:855-9.

29. Ferguson KA, Ono T, Lowe AA, Keenan SP, Fleetham JA. A randomized crossover study of an oral appliance vs nasal-continuous positive airway pressure in the treatment of mild-moderate obstructive sleep apnea. Chest 1996;109:1269-75.

30. Gagnadoux F, Fleury B, Vielle B, et al. Titrated mandibular advancement versus positive airway pressure for sleep apnoea. Eur Respir J 2009;34:91420.

31. Ghazal A, Sorichter S, Jonas I, Rose EC. A randomized prospective longterm study of two oral appliances for sleep apnoea treatment. J Sleep Res 2009;18:321-8.

32. Gotsopoulos H, Kelly JJ, Cistulli PA. Oral appliance therapy reduces blood pressure in obstructive sleep apnea: a randomized, controlled trial. Sleep 2004:27:934-41.

33. Hoekema A, Stegenga B, Bakker M, et al. Simulated driving in obstructive sleep apnoea-hypopnoea; effects of oral appliances and continuous positive airway pressure. Sleep Breath 2007;11:129-38.

34. Hoekema A, Stel AL, Stegenga B, et al. Sexual function and obstructive sleep apnea-hypopnea: a randomized clinical trial evaluating the effects of oral-appliance and continuous positive airway pressure therapy. J Sex Med 2007:4:1153-62

35. Hoekema A, Stegenga B, Wijkstra PJ, van der Hoeven JH, Meinesz AF, de Bont LG. Obstructive sleep apnea therapy. J Dent Res 2008;87:882-7.

36. Hoekema A, Voors AA, Wijkstra PJ, et al. Effects of oral appliances and CPAP on the left ventricle and natriuretic peptides. Int J Cardiol 2008;128:232-9.

37. Lawton HM, Battagel JM, Kotecha B. A comparison of the Twin Block and Herbst mandibular advancement splints in the treatment of patients with obstructive sleep apnoea: a prospective study. Eur J Orthod 2005;27:82-90.

38. Mehta A, Qian J, Petocz P, Darendeliler MA, Cistulli PA. A randomized, controlled study of a mandibular advancement splint for obstructive sleep apnea. Am J Respir Crit Care Med 2001;163:1457-61.

39. Naismith SL, Winter VR, Hickie IB, Cistulli PA. Effect of oral appliance therapy on neurobehavioral functioning in obstructive sleep apnea: a randomized controlled trial. J Clin Sleep Med 2005;1:374-80.
40. Phillips CL, Grunstein RR, Darendeliler MA, et al. Health outcomes of continuous positive airway pressure versus oral appliance treatment for obstructive sleep apnea: a randomized controlled trial. Am J Respir Crit Care Med 2013;187:879-87.

41. Rose E, Staats R, Virchow C, Jonas IE. A comparative study of two mandibular advancement appliances for the treatment of obstructive sleep apnoea. Eur J Orthod 2002;24:191-8.

42. Sutherland K, Deane SA, Chan AS, et al. Comparative effects of two oral appliances on upper airway structure in obstructive sleep apnea. Sleep 2011;34:469-77.

43. Tan YK, L'Estrange PR, Luo YM, et al. Mandibular advancement splints and continuous positive airway pressure in patients with obstructive sleep apnoea: a randomized cross-over trial. Eur J Orthod 2002;24:239-49.

44. Trzepizur W, Gagnadoux F, Abraham P, et al. Microvascular endothelial function in obstructive sleep apnea: impact of continuous positive airway pressure and mandibular advancement. Sleep Med 2009;10:746-52.

45. Vanderveken OM, Devolder A, Marklund M, et al. Comparison of a custommade and a thermoplastic oral appliance for the treatment of mild sleep apnea. Am J Respir Crit Care Med 2008;178:197-202.

46. Wilhelmsson B, Tegelberg A, Walker-Engstrom ML, et al. A prospective randomized study of a dental appliance compared with uvulopalatopharyngoplasty in the treatment of obstructive sleep apnoea. Acta Otolaryngol 1999;119:503-9.

47. Zhou J, Liu YH. A randomised titrated crossover study comparing two oral appliances in the treatment for mild to moderate obstructive sleep apnoea/ hypopnoea syndrome. J Oral Rehabil 2012;39:914-22.

48. Andren A, Hedberg P, Walker-Engstrom ML, Wahlen P, Tegelberg A. Effects of treatment with oral appliance on 24-h blood pressure in patients with obstructive sleep apnea and hypertension: a randomized clinical trial. Sleep Breath 2013;17:705-12.

49. Doff MH, Veldhuis SK, Hoekema A, et al. Long-term oral appliance therapy in obstructive sleep apnea syndrome: a controlled study on temporomandibular side effects. Clin Oral Investig 2012;16:689-97.

50. Doff MH, Finnema KJ, Hoekema A, Wijkstra PJ, de Bont LG, Stegenga B. Long-term oral appliance therapy in obstructive sleep apnea syndrome: a controlled study on dental side effects. Clin Oral Investig 2013;17:475-82.

51. Lam B, Sam K, Mok WY, et al. Randomised study of three non-surgical treatments in mild to moderate obstructive sleep apnoea. Thorax 2007;62:354-9.

52. Doff MH, Hoekema A, Pruim GJ, Huddleston Slater JJ, Stegenga B. Longterm oral-appliance therapy in obstructive sleep apnea: a cephalometric study of craniofacial changes. J Dent 2010;38:1010-8.

53. Tsuda H, Almeida FR, Tsuda T, Moritsuchi Y, Lowe AA. Craniofacial changes after 2 years of nasal continuous positive airway pressure use in patients with obstructive sleep apnea. Chest 2010;138:870-4.

\section{SUBMISSION \& CORRESPONDENCE INFORMATION}

\section{Submitted for publication May, 2015 \\ Accepted for publication May, 2015}

Address correspondence to: Sherene M. Thomas, American Academy of Sleep Medicine, 2510 N. Frontage Road, Darien, IL 60561-1511; Tel: (630) 737-9700; Fax: (630) 737-9790; Email: sthomas@aasmnet.org

\section{DISCLOSURE STATEMENT}

This was not an industry supported study. Dr. Dort receives royalties from a tongue retaining device (MPowRx) and has financial interest in Zephyr. Dr. Lettieri is on the speakers' bureau of Teva Pharmaceuticals. Dr. Chervin is a board member of the American Academy of Sleep Medicine, consults for Zansors, and receives royalties from UpToDate and Cambridge University Press. The other authors have indicated no financial conflicts of interest. 


\section{APPENDIX}

\section{Meta-Analyses and GRADE Summary of Findings Reports}

Figure 1-Custom, Non-Titratable (C-NT) OAs for Mild to Moderate Adult OSA (AHI/RDI/REI).

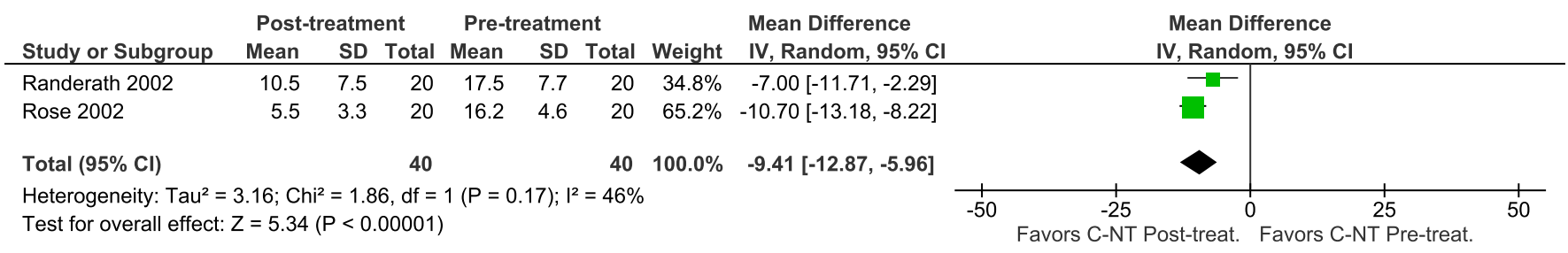

Figure 2-Custom, Non-Titratable OAs for Moderate to Severe Adult OSA (AHI/RDI/REI).

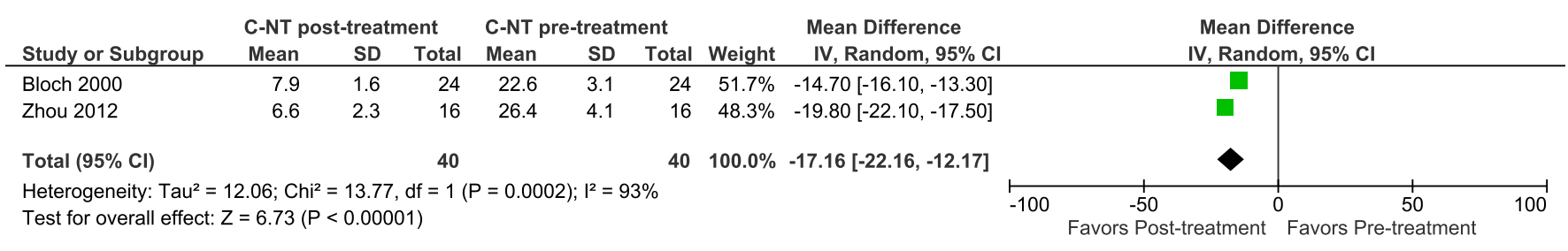

Figure 3-Custom, Titratable (C-T) OAs for Mild to Moderate Adult OSA (AHI/RDI/REI).

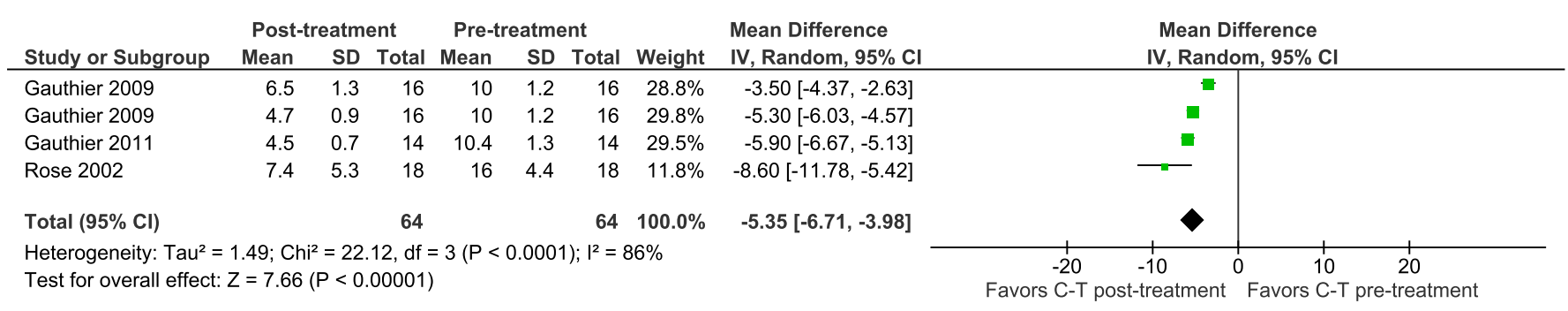

Figure 4-Custom, Titratable OAs for Moderate to Severe Adult OSA (AHI/RDI/REI).

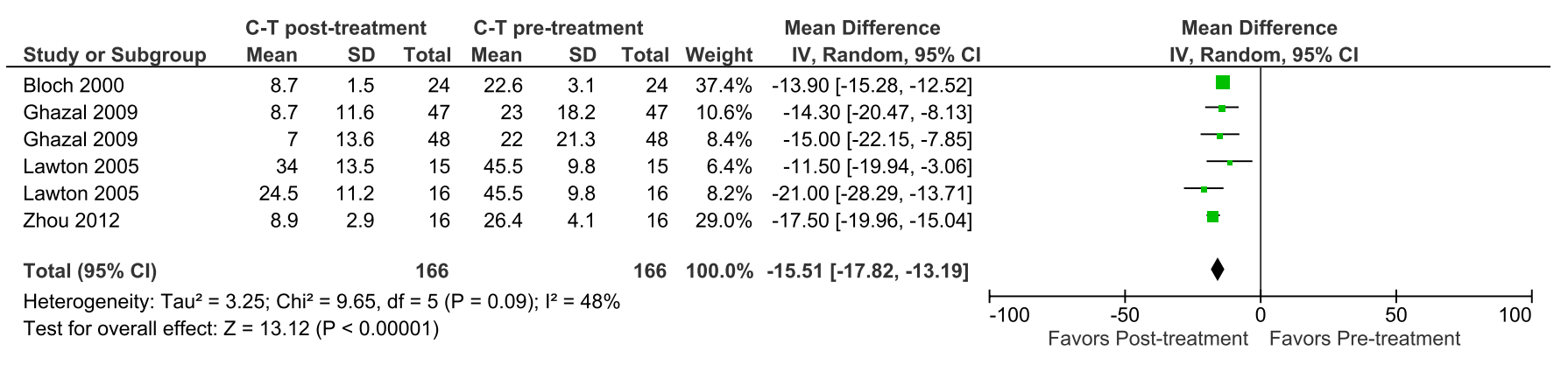

Figure 5-CPAP for Mild to Moderate Adult OSA (AHI/RDI/REI).

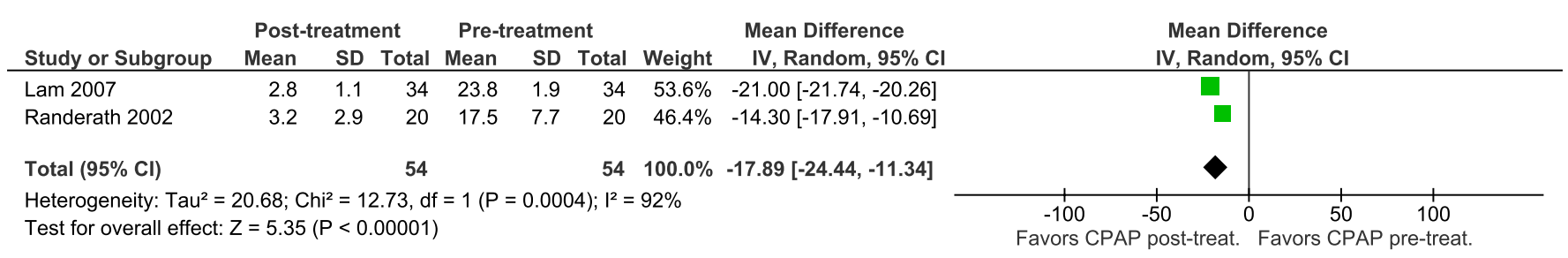


Figure 6—CPAP for Severe Adult OSA (AHI/RDI/REI).

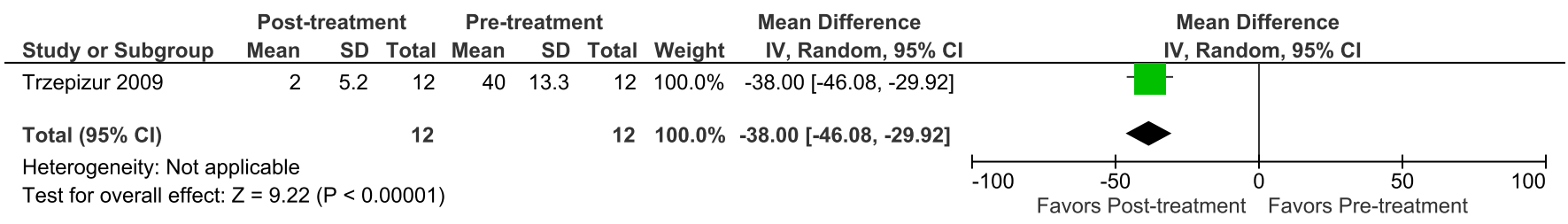

Figure 7-OAs for Primary Snoring (Snoring Loudness).

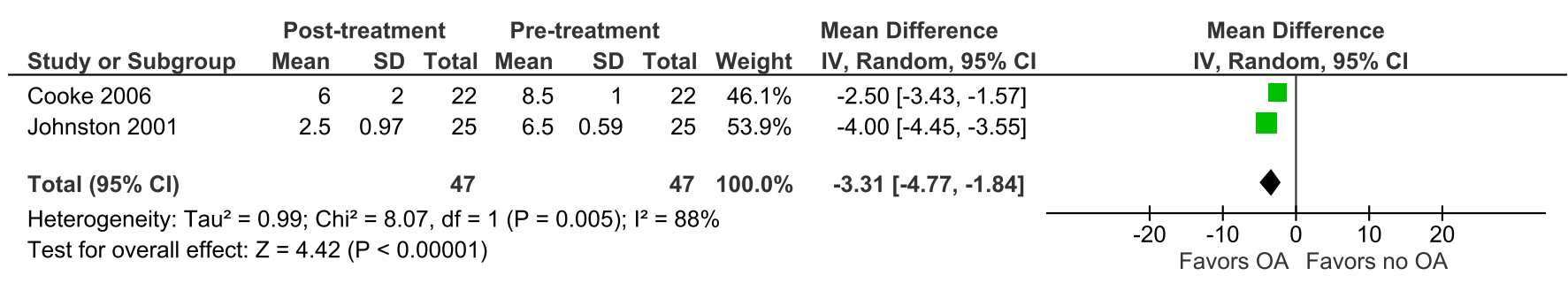

Figure 8-Summary of Findings (Primary Snoring, Snoring Indices).

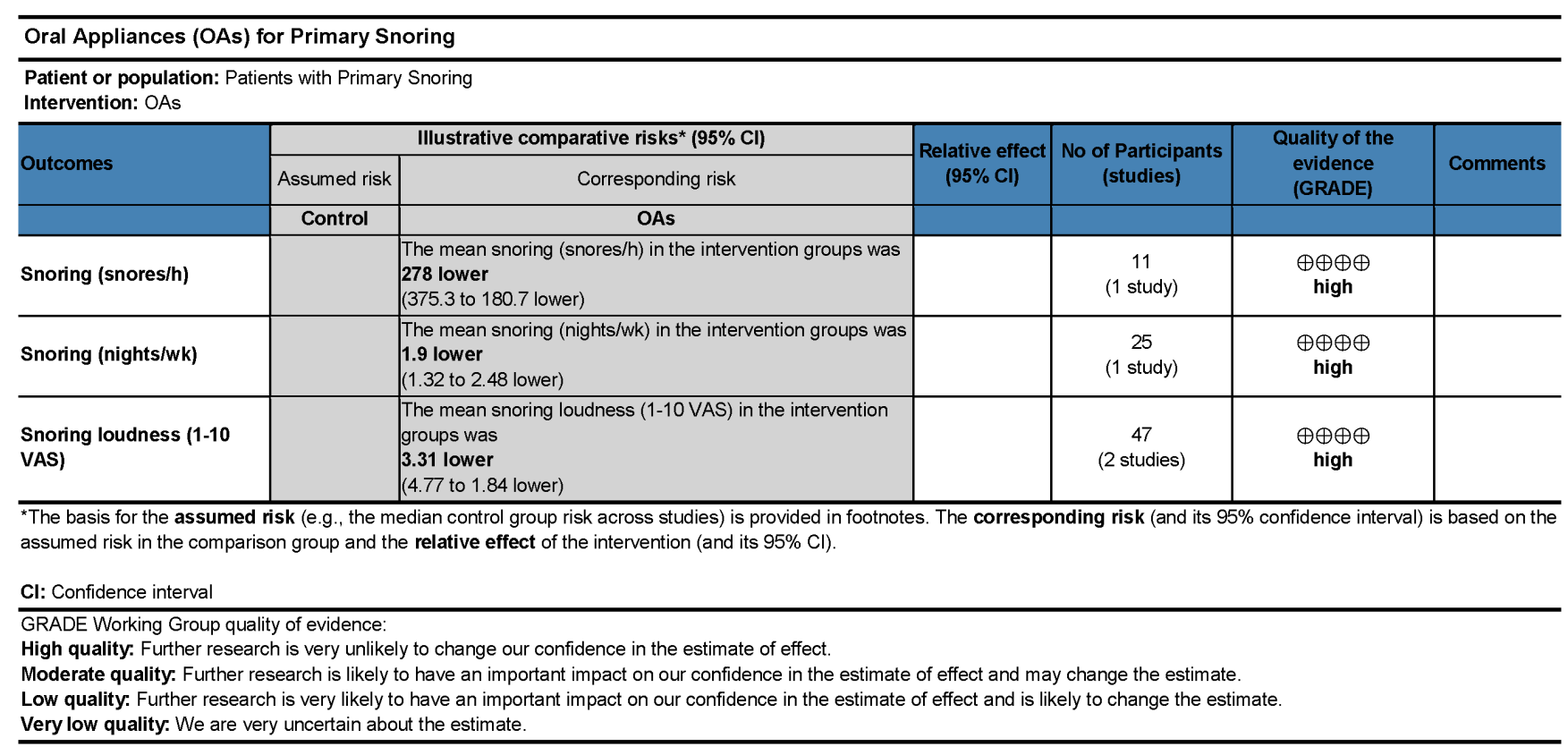


Figure 9-OAs for OSA (AHI/RDI/REI).

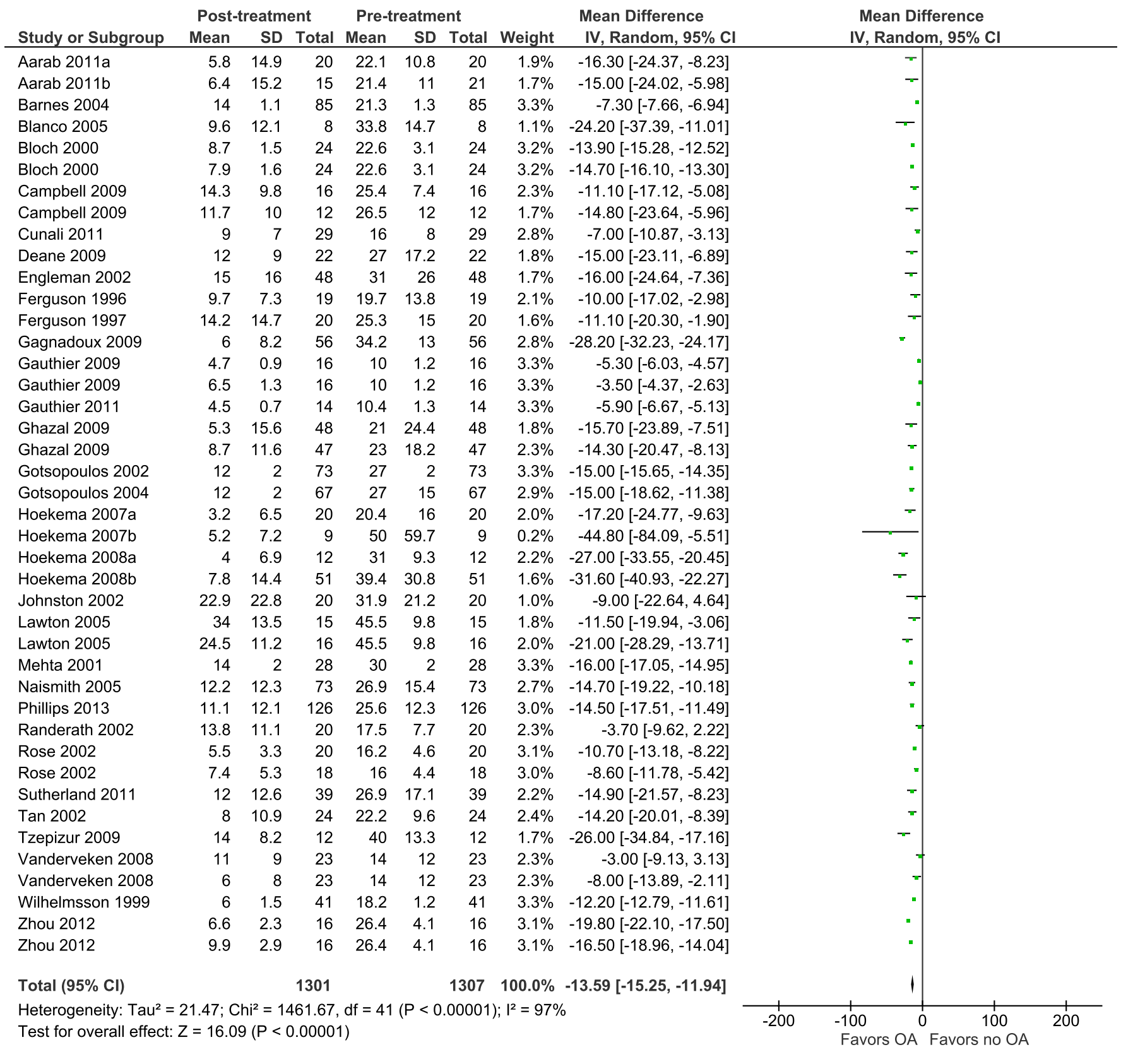


Figure 10—Custom OAs for OSA (AHI/RDI/REI).

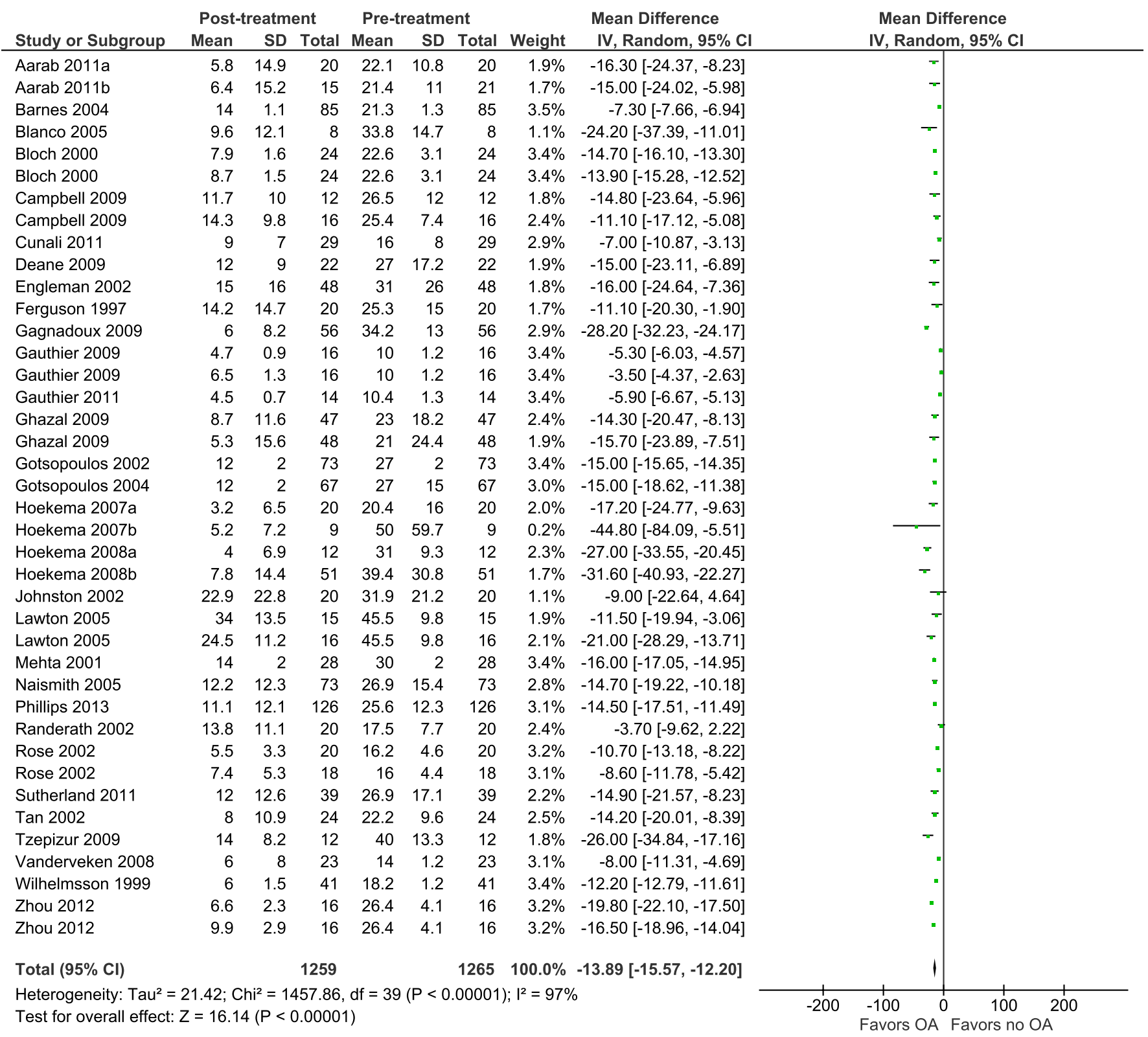

Figure 11-Non-Custom OAs for OSA (AHI/RDI/REI).

\begin{tabular}{|c|c|c|c|c|c|c|c|c|c|}
\hline \multirow[b]{2}{*}{ Study or Subgroup } & \multicolumn{3}{|c|}{ Post-treatment } & \multicolumn{3}{|c|}{ Pre-treatment } & \multirow[b]{2}{*}{ Weight } & \multirow{2}{*}{$\begin{array}{l}\text { Mean Difference } \\
\text { IV, Random, } 95 \% \mathrm{CI}\end{array}$} & \multirow{2}{*}{$\begin{array}{c}\text { Mean Difference } \\
\text { IV, Random, } 95 \% \mathrm{Cl}\end{array}$} \\
\hline & Mean & SD & Total & Mean & SD & Total & & & \\
\hline Ferguson 1996 & 9.7 & 7.3 & 19 & 19.7 & 13.8 & 19 & $46.9 \%$ & $-10.00[-17.02,-2.98]$ & \\
\hline Vanderveken 2008 & 11 & 9 & 23 & 14 & 12 & 23 & $53.1 \%$ & $-3.00[-9.13,3.13]$ & \\
\hline Total $(95 \% \mathrm{Cl})$ & & & 42 & & & 42 & $100.0 \%$ & $-6.28[-13.13,0.56]$ & \\
\hline \multicolumn{9}{|c|}{ Heterogeneity: $\operatorname{Tau}^{2}=13.19 ; \mathrm{Chi}^{2}=2.17, \mathrm{df}=1(P=0.14) ; \mathrm{I}^{2}=54 \%$} & $\begin{array}{ccccc}1 & 1 & 1 & 1 \\
-20 & -10 & 0 & 10 & 20 \\
\text { Favors OA } & \text { Favors no }\end{array}$ \\
\hline
\end{tabular}


Figure 12—Custom, Titratable OAs for OSA (AHI/RDI/REI).

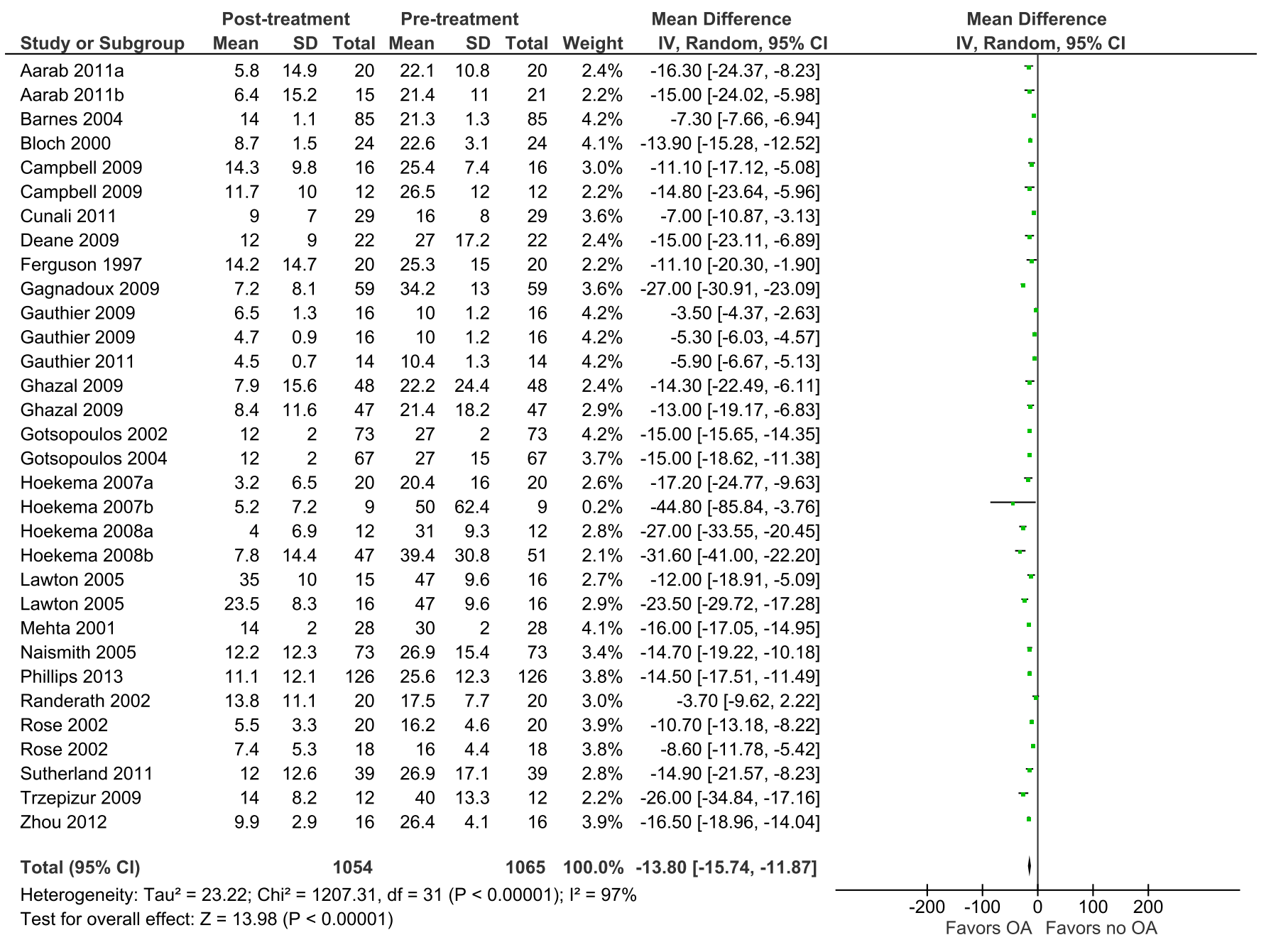

Figure 13-Custom, Non-Titratable OAs for OSA (AHI/RDI/REI).

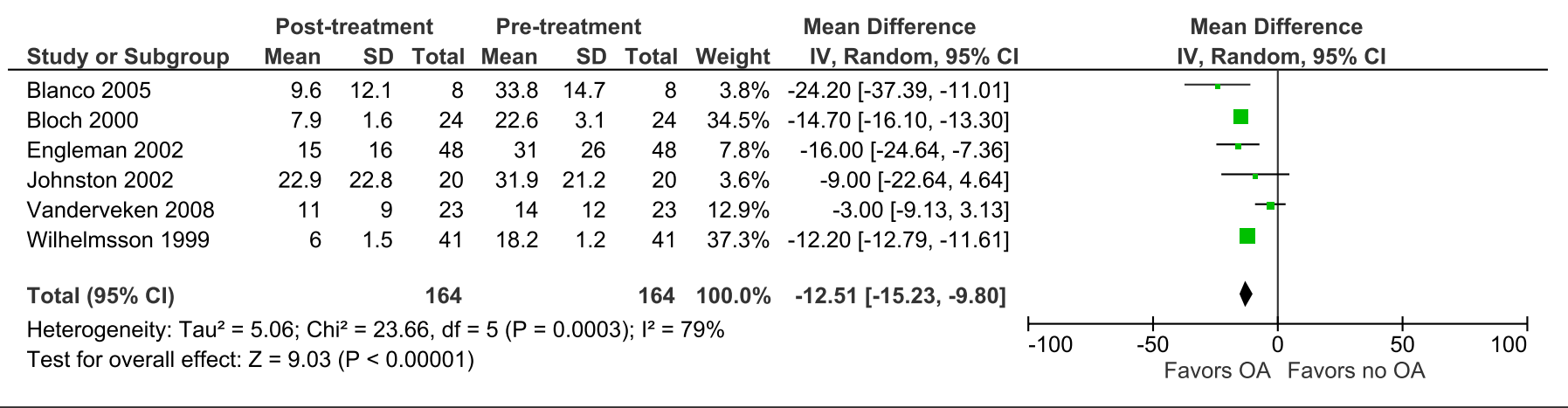


Figure 14-OAs vs. CPAP for OSA (AHI/RDI/REI).

\begin{tabular}{|c|c|c|c|c|c|c|c|c|c|c|c|}
\hline Study or Subgroup & \multicolumn{3}{|c|}{ OA } & \multicolumn{3}{|c|}{ CPAP } & \multicolumn{2}{|r|}{ Mean Difference } & \multicolumn{2}{|c|}{$\begin{array}{c}\text { Mean Difference } \\
\text { IV, Random, } 95 \% \mathrm{CI}\end{array}$} & \\
\hline Aarab 2011b & 6.4 & 15.2 & 15 & 0 & 12.4 & 13 & $2.6 \%$ & $6.40[-3.83,16.63]$ & & & \\
\hline Engleman 2002 & 15 & 16 & 48 & 8 & 6 & 48 & $6.4 \%$ & $7.00[2.17,11.83]$ & & - & \\
\hline Ferguson 1996 & 14.2 & 14.7 & 20 & 4 & 2.2 & 20 & $4.8 \%$ & $10.20[3.69,16.71]$ & & - & \\
\hline Ferguson 1997 & 9.7 & 7.3 & 19 & 3.6 & 1.7 & 20 & $8.2 \%$ & $6.10[2.73,9.47]$ & & - & \\
\hline Hoekema 2007b & 5.2 & 7.2 & 9 & 0 & 3.6 & 10 & $6.0 \%$ & $5.20[-0.01,10.41]$ & & -- & \\
\hline Hoekema 2008a & 4 & 6.9 & 12 & 2.6 & 4.7 & 13 & $6.6 \%$ & $1.40[-3.27,6.07]$ & & - & \\
\hline Hoekema 2008b & 7.8 & 14.4 & 47 & 2.4 & 4.2 & 47 & $7.1 \%$ & $5.40[1.11,9.69]$ & & - & \\
\hline Phillips 2013 & 11.1 & 12.1 & 108 & 4.5 & 6.6 & 108 & $9.1 \%$ & $6.60[4.00,9.20]$ & & - & \\
\hline Randerath 2002 & 13.8 & 11.1 & 20 & 3.2 & 2.9 & 20 & $6.2 \%$ & $10.60[5.57,15.63]$ & & $\longrightarrow$ & \\
\hline Tan 2002 & 8 & 10.9 & 21 & 3.1 & 2.8 & 21 & $6.5 \%$ & $4.90[0.09,9.71]$ & & - & \\
\hline
\end{tabular}

Figure 15-OAs for OSA (Minimum Oxygen Saturation).

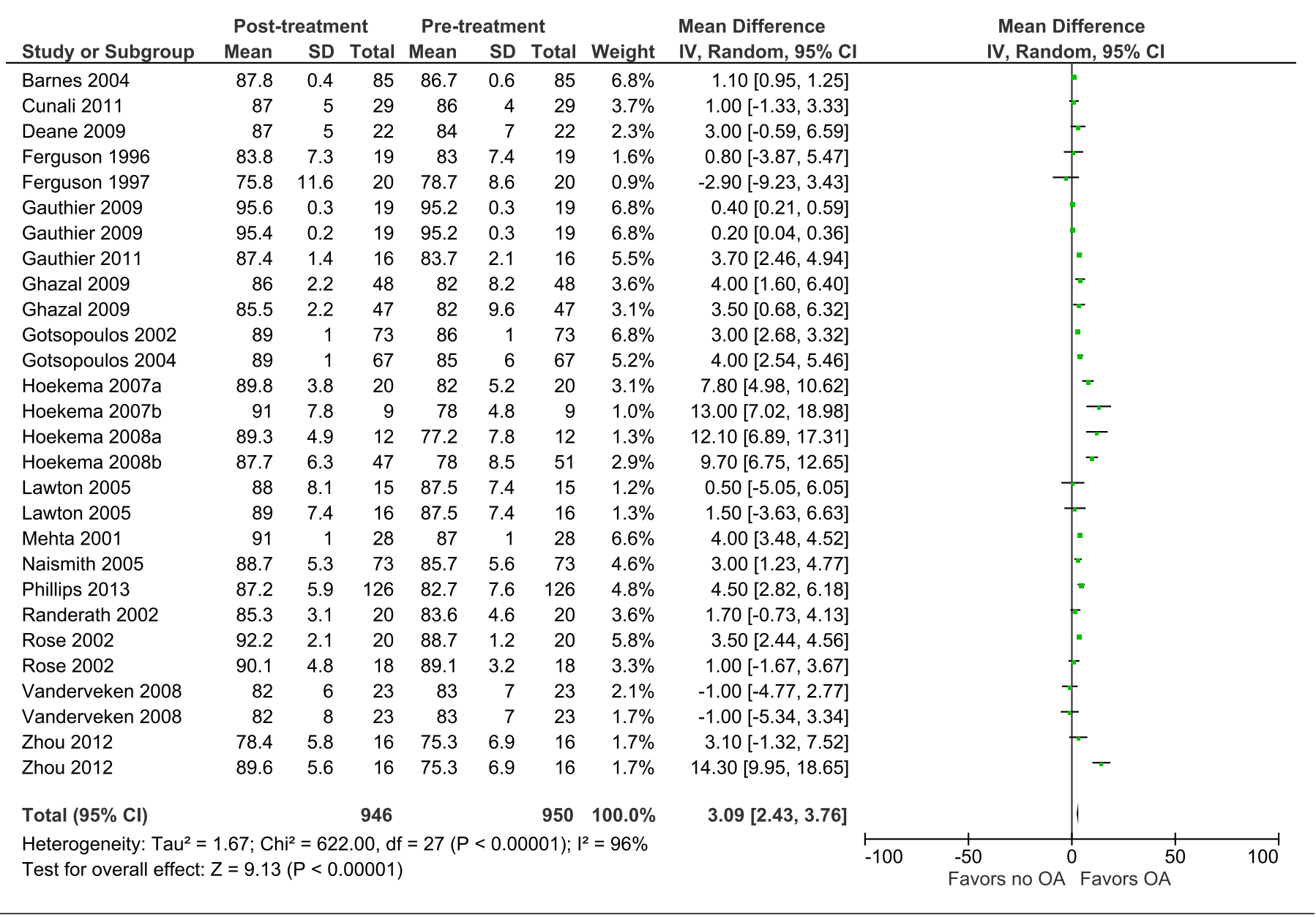


Figure 16-Custom OAs for OSA (Minimum Oxygen Saturation).

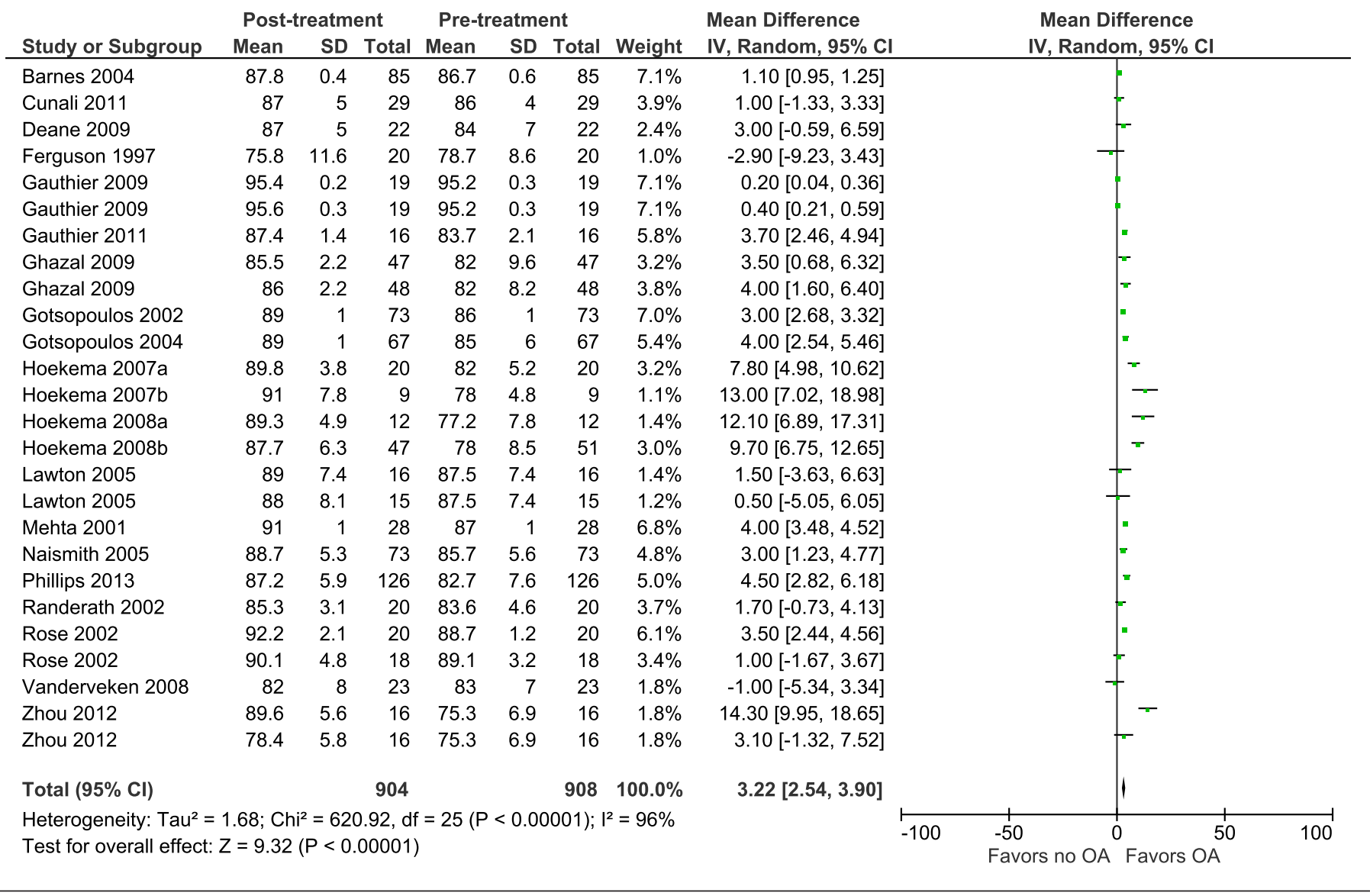

Figure 17-Non-Custom OAs for OSA (Minimum Oxygen Saturation).

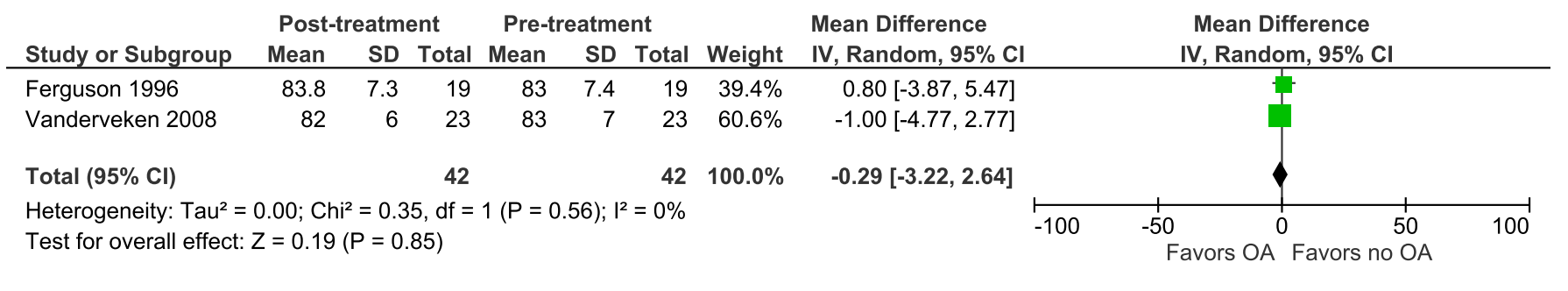


Figure 18-Custom, Titratable OAs for OSA (Minimum Oxygen Saturation).

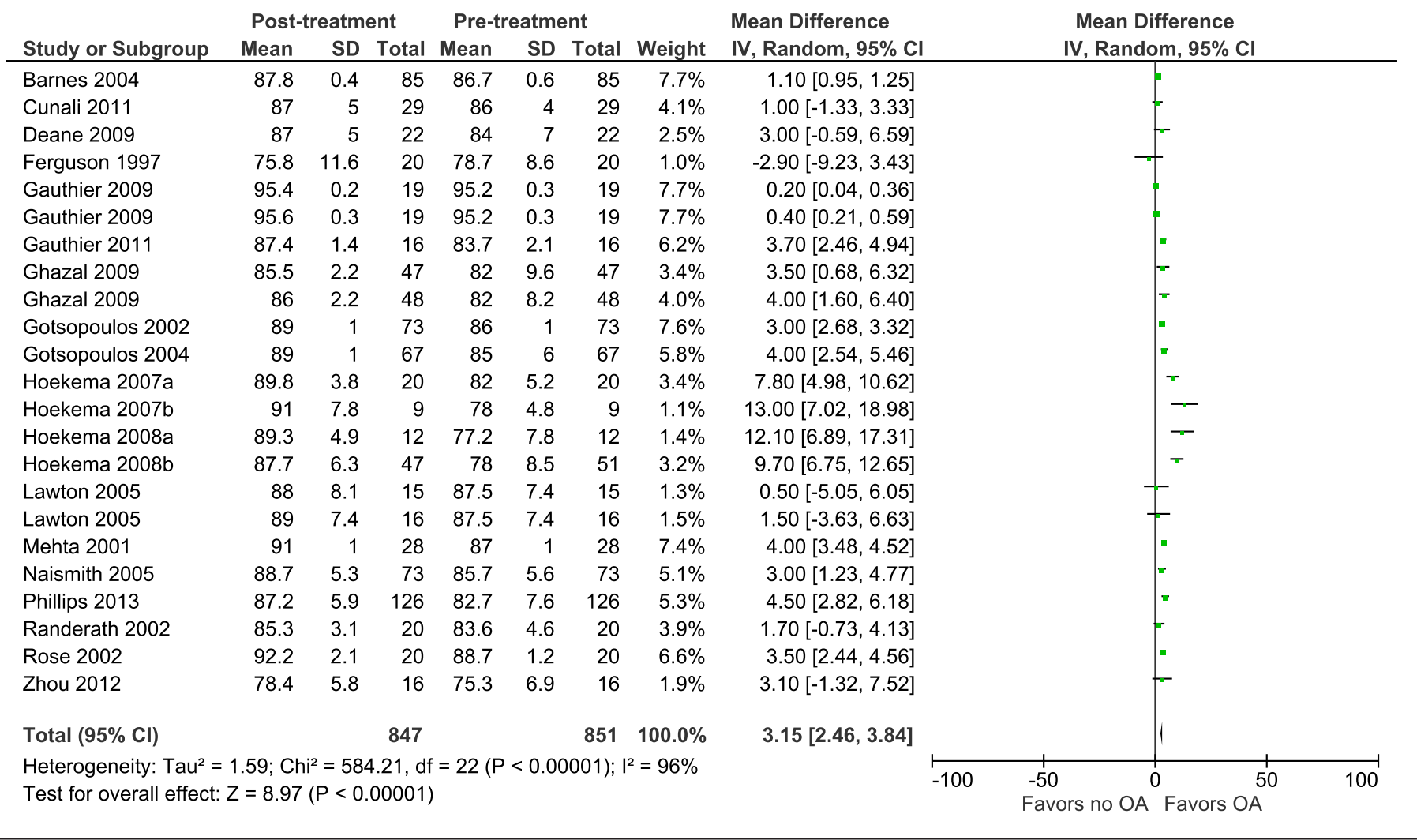

Figure 19-Custom, Non-Titratable OAs for OSA (Minimum Oxygen Saturation).

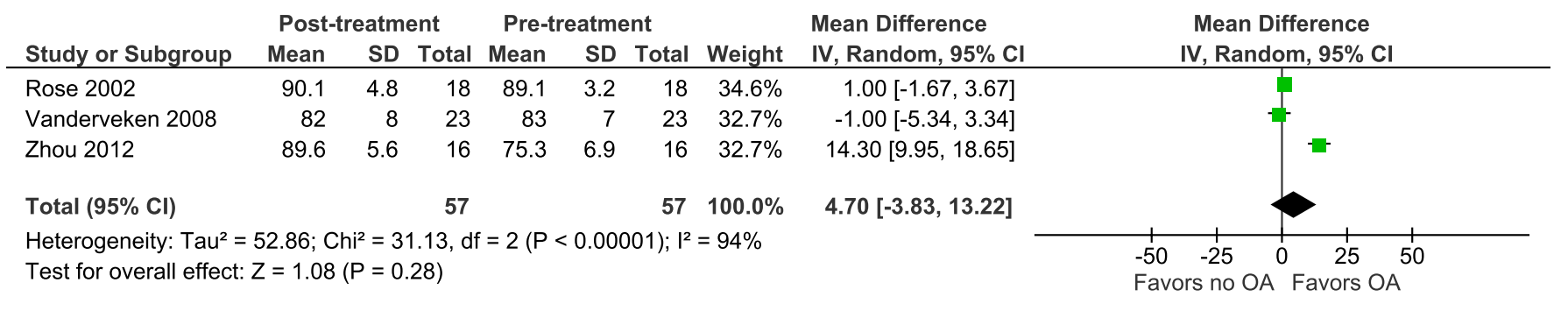

Figure 20-OAs vs. CPAP for OSA (Minimum Oxygen Saturation).

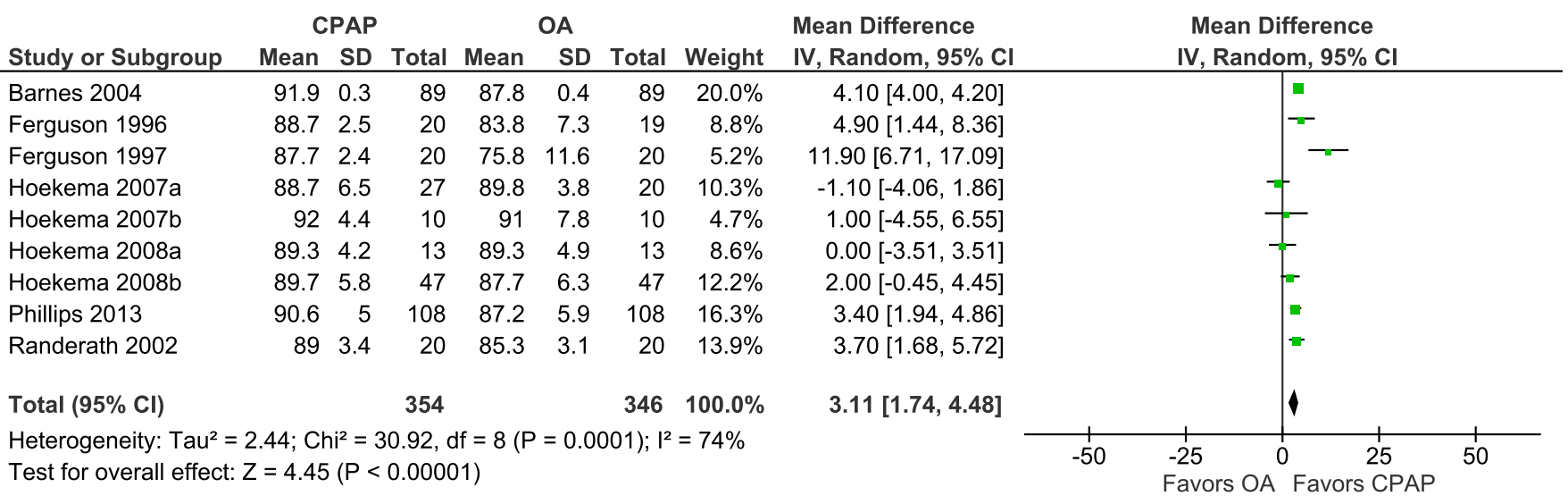


Figure 21-OAs for OSA (Arousal Index).

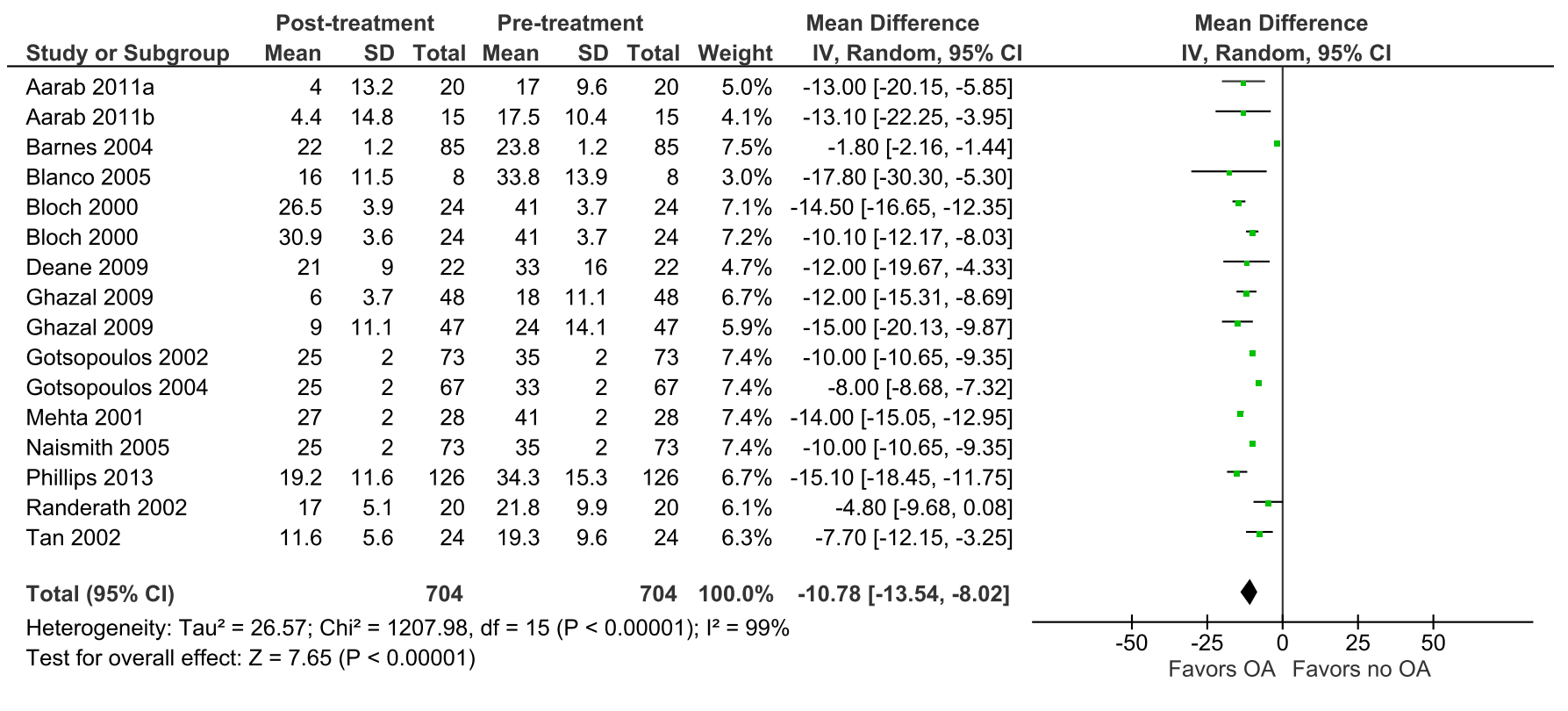

Figure 22—Custom, Titratable OAs for OSA (Arousal Index).

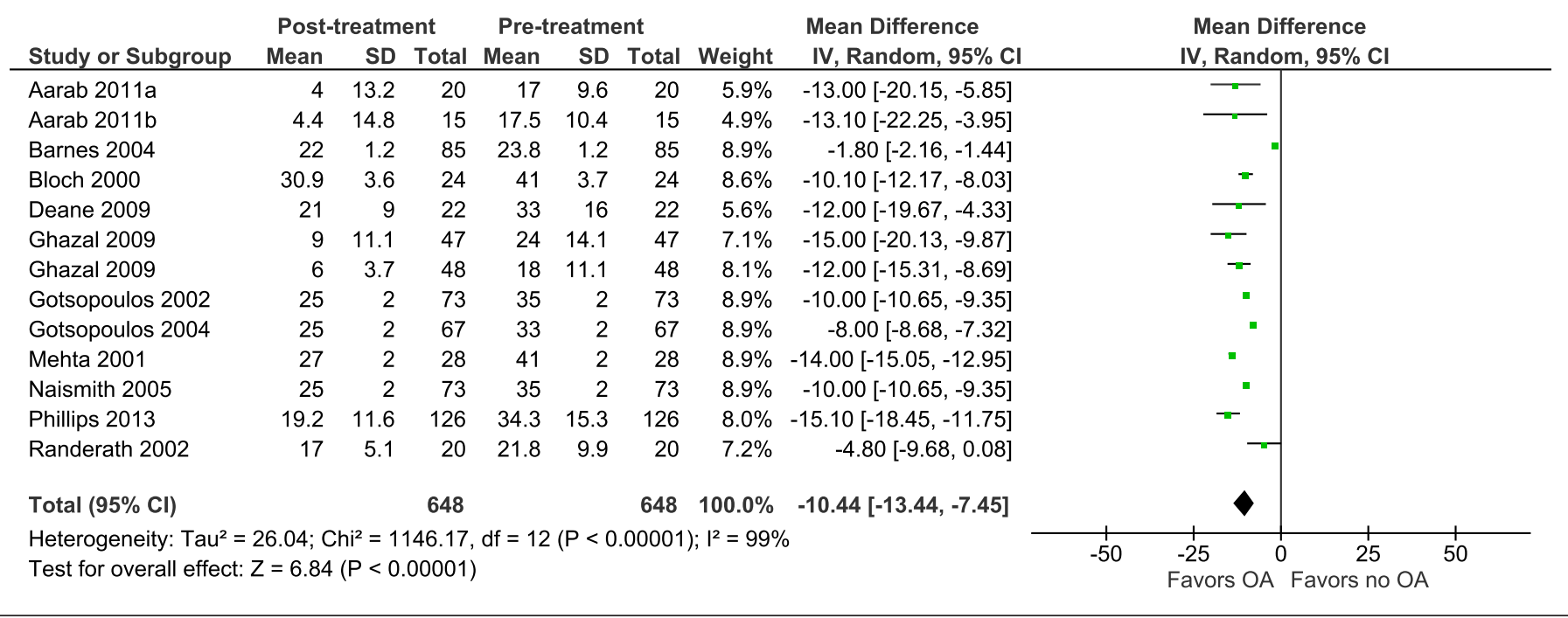

Figure 23-Custom, Non-Titratable OAs for OSA (Arousal Index).

\begin{tabular}{|c|c|c|c|c|c|c|c|c|c|c|c|c|}
\hline \multirow[b]{2}{*}{ Study or Subgroup } & \multicolumn{3}{|c|}{ Post-treatment } & \multicolumn{3}{|c|}{ Pre-treatment } & \multirow{2}{*}{$\begin{array}{r}\text { Weight } \\
2.9 \%\end{array}$} & \multirow{2}{*}{$\begin{array}{l}\text { Mean Difference } \\
\text { IV, Random, } 95 \% \mathrm{Cl}\end{array}$} & \multirow{2}{*}{\multicolumn{4}{|c|}{$\begin{array}{c}\text { Mean Difference } \\
\text { IV, Random, } 95 \% \mathrm{Cl}\end{array}$}} \\
\hline & Mean & SD & Total & Mean & SD & Total & & & & & & \\
\hline Bloch 2000 & 26.5 & 3.9 & 24 & 41 & 3.7 & 24 & $97.1 \%$ & $-14.50[-16.65,-12.35]$ & & & & \\
\hline Total $(95 \% \mathrm{Cl})$ & & & 32 & & & 32 & $100.0 \%$ & $-14.59[-16.71,-12.48]$ & & 1 & & \\
\hline \multicolumn{9}{|c|}{ Heterogeneity: $\mathrm{Tau}^{2}=0.00 ; \mathrm{Chi}^{2}=0.26, \mathrm{df}=1(\mathrm{P}=0.61) ; \mathrm{I}^{2}=0 \%$} & -100 & -50 & ${ }^{0}$ A Favors no OA & 100 \\
\hline
\end{tabular}


Figure 24-OAs vs. CPAP for OSA (Arousal Index).

\begin{tabular}{|c|c|c|c|c|c|c|c|c|c|}
\hline \multirow[b]{2}{*}{ Study or Subgroup } & \multicolumn{3}{|c|}{ OA } & \multicolumn{3}{|c|}{ CPAP } & \multirow[b]{2}{*}{ Weight } & \multirow{2}{*}{$\begin{array}{l}\text { Mean Difference } \\
\text { IV, Random, } 95 \% \mathrm{CI}\end{array}$} & \multirow{2}{*}{$\begin{array}{c}\text { Mean Difference } \\
\text { IV, Random, } 95 \% \mathrm{Cl}\end{array}$} \\
\hline & Mean & SD & Total & Mean & SD & Total & & & \\
\hline Aarab 2011b & 4.4 & 14.8 & 15 & 1 & 15.5 & 13 & $2.7 \%$ & $3.40[-7.87,14.67]$ & \\
\hline Phillips 2013 & 19.2 & 11.6 & 110 & 16.6 & 10.6 & 108 & $20.1 \%$ & $2.60[-0.35,5.55]$ & - \\
\hline Randerath 2002 & 17 & 5.1 & 20 & 14.1 & 5.1 & 20 & $18.8 \%$ & $2.90[-0.26,6.06]$ & - \\
\hline Tan 2002 & 11.6 & 5.6 & 24 & 9.8 & 6.6 & 24 & $17.1 \%$ & $1.80[-1.66,5.26]$ & - \\
\hline $\begin{array}{l}\text { Heterogeneity: } \mathrm{Tau}^{2}= \\
\text { Test for overall effect }\end{array}$ & $\begin{array}{l}2.60 ; \mathrm{Ch} \\
z=3.61\end{array}$ & $\begin{array}{l}\mathrm{i}^{2}=11 \\
(\mathrm{P}=\mathrm{C}\end{array}$ & $\begin{array}{l}.25, \mathrm{df} \\
.0003)\end{array}$ & $=5(P$ & $=0.05)$ & $; 1^{2}=5$ & & & $\begin{array}{ccccc}1 & 1 & 1 & 1 & 1 \\
-20 & -10 & 0 & 10 & 20 \\
\text { Favors OA } & \text { Favors } & \mathrm{CPA}\end{array}$ \\
\hline
\end{tabular}

Figure 25-OAs for OSA (Oxygen Desaturation Index; ODI).

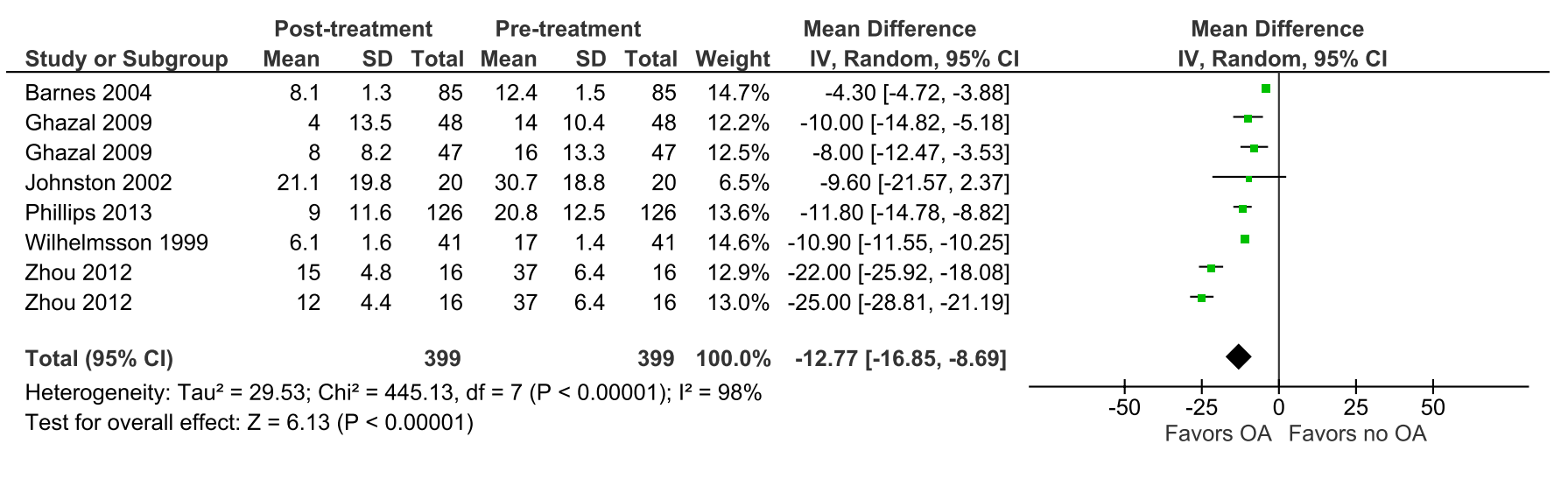

Figure 26-Custom, Titratable OAs for OSA (ODI).

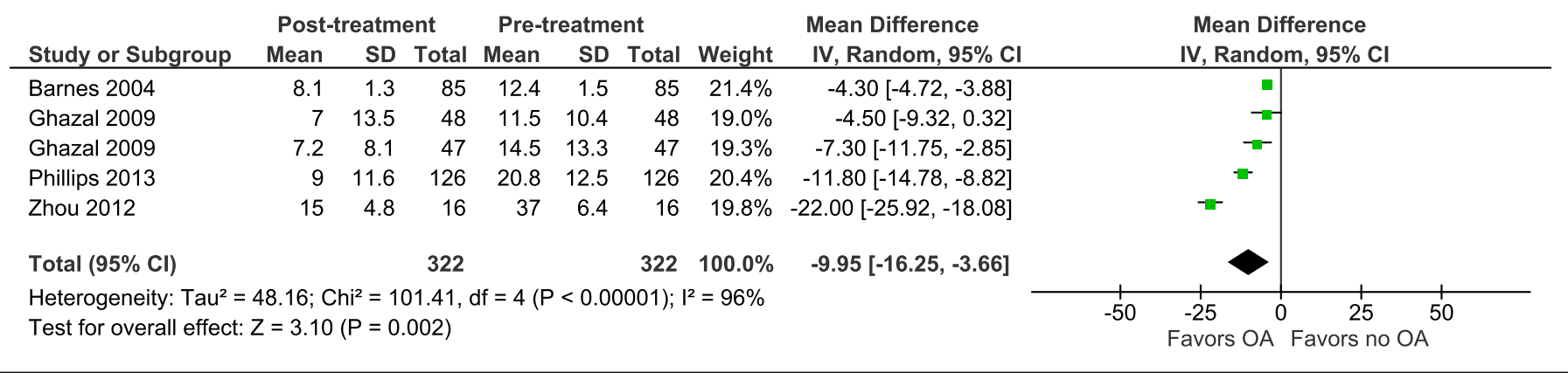

Figure 27-Custom, Non-Titratable OA for OSA (ODI).

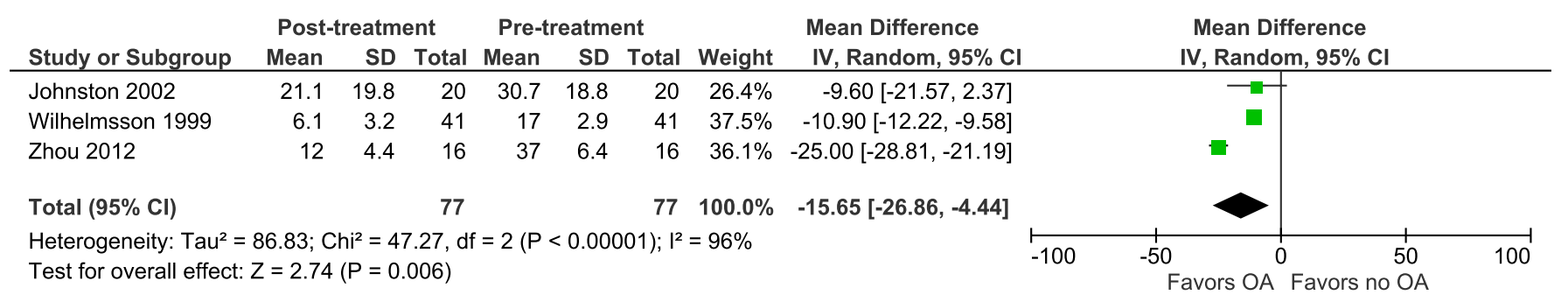


Figure 28-OAs vs. CPAP for OSA (ODI).

\begin{tabular}{|c|c|c|c|c|c|c|c|c|c|}
\hline \multirow[b]{2}{*}{ Study or Subgroup } & \multicolumn{3}{|c|}{ OA } & \multicolumn{3}{|c|}{ CPAP } & \multirow[b]{2}{*}{ Weight } & \multirow{2}{*}{$\begin{array}{l}\text { Mean Difference } \\
\text { IV, Random, } 95 \% \text { CI }\end{array}$} & \multirow{2}{*}{$\begin{array}{c}\text { Mean Difference } \\
\text { IV, Random, } 95 \% \mathrm{Cl}\end{array}$} \\
\hline & Mean & SD & Total & Mean & SD & Total & & & \\
\hline Gagnadoux 2009 & 6.3 & 5 & 28 & 2.3 & 3.2 & 28 & $30.9 \%$ & $4.00[1.80,6.20]$ & - \\
\hline Total $(95 \% \mathrm{Cl})$ & & & 234 & & & 234 & $100.0 \%$ & $4.76[2.37,7.15]$ & \\
\hline \multicolumn{10}{|c|}{ 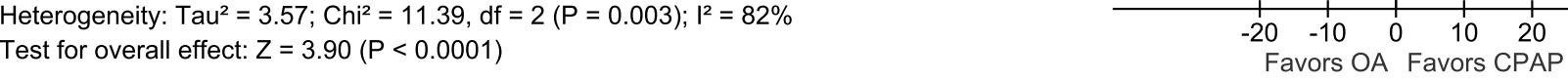 } \\
\hline
\end{tabular}

Figure 29_OAs for OSA (\% Rapid Eye Movement; \%REM).

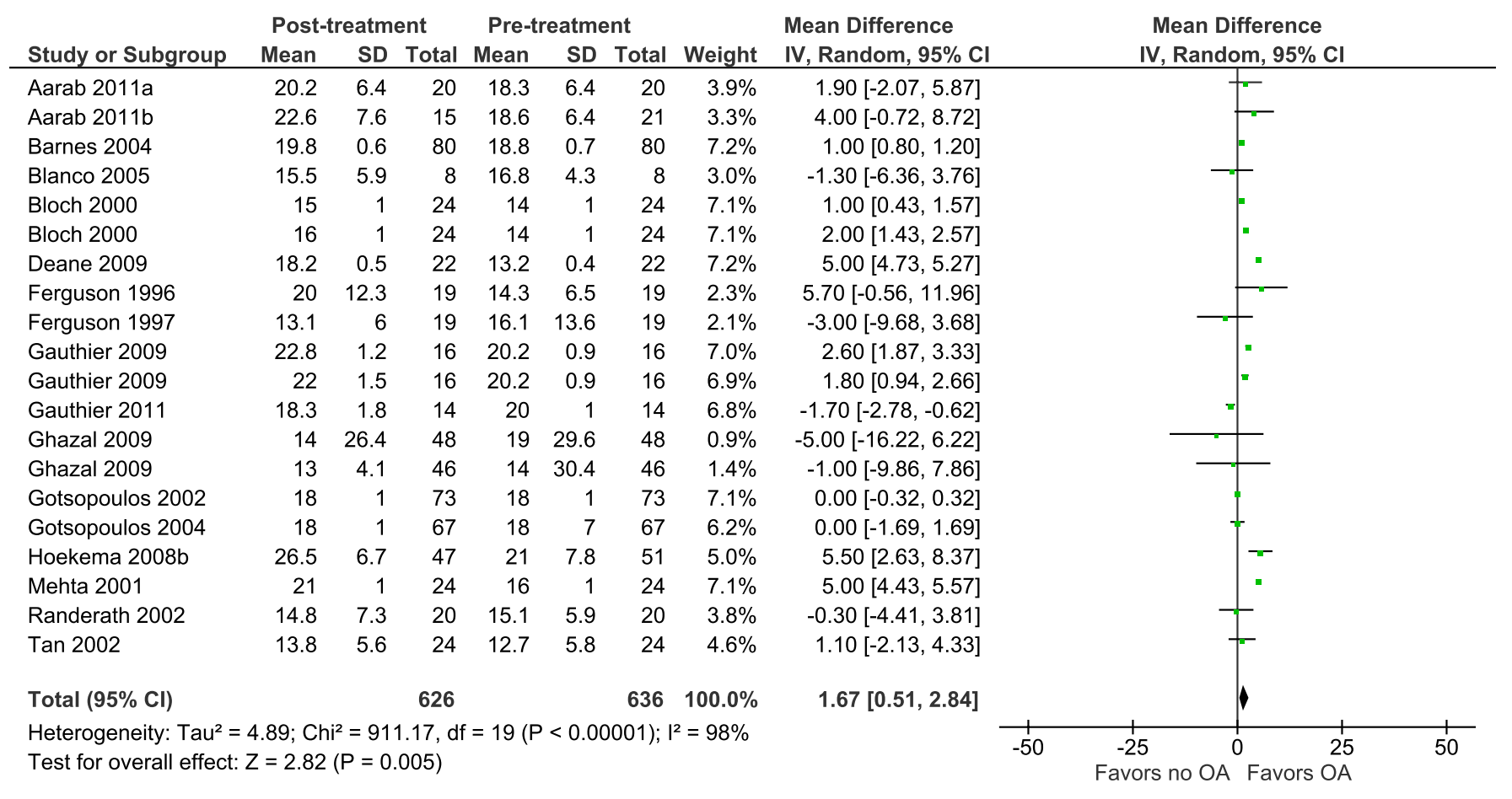


Figure 30-Custom OAs (\%REM).

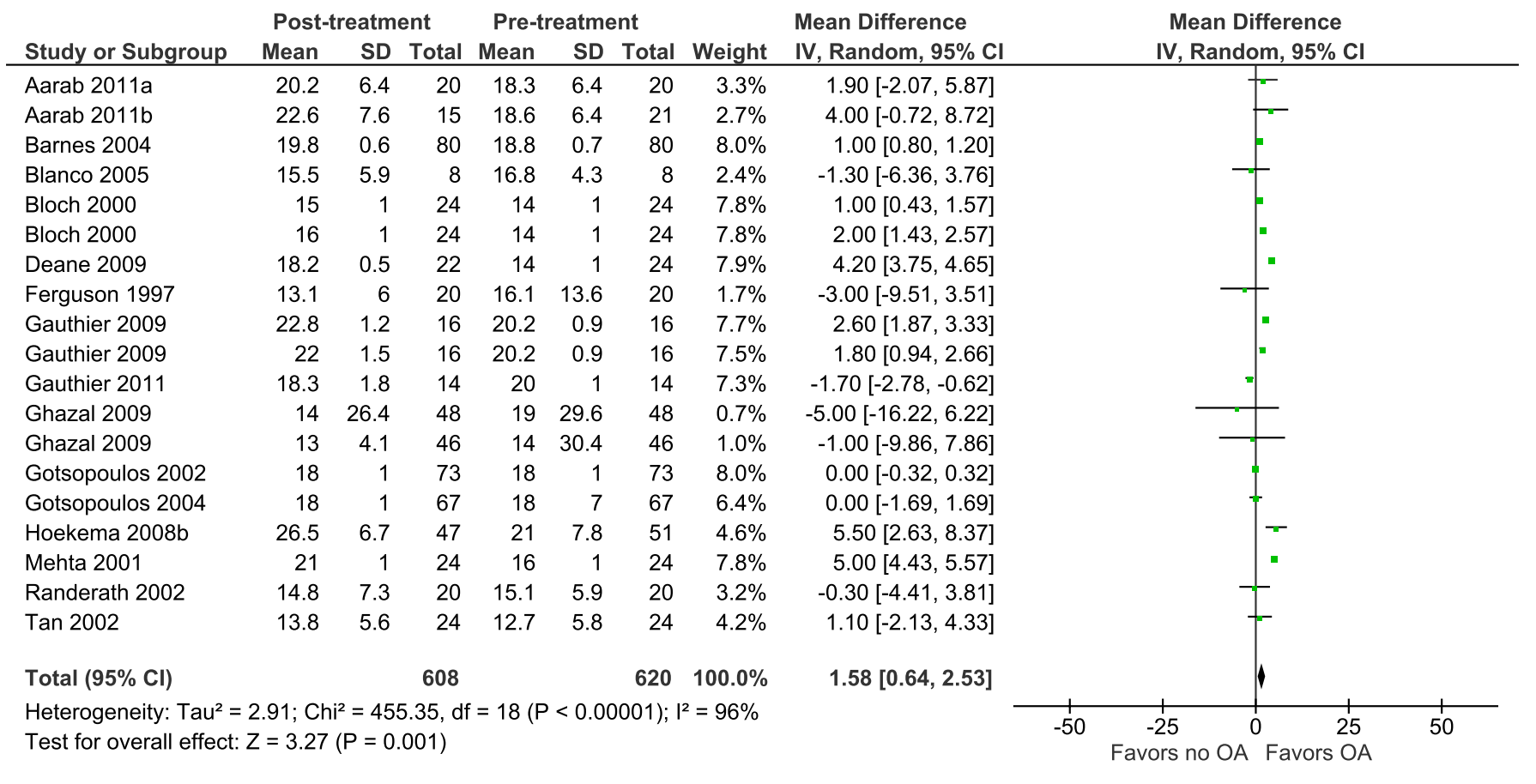

Figure 31-Custom, Titratable OAs for OSA (\%REM).

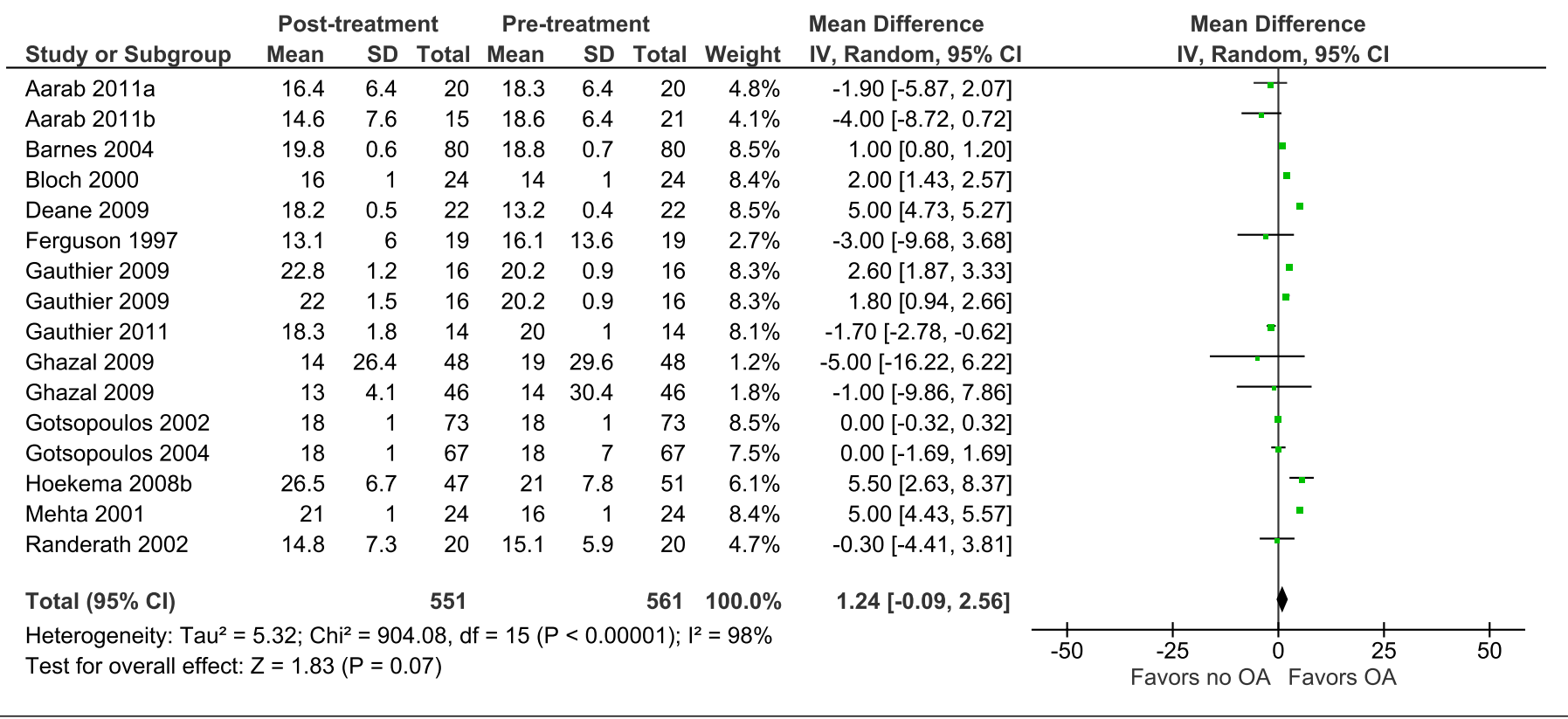

Figure 32-Custom, Non-Titratable OA for OSA (\%REM).

\begin{tabular}{|c|c|c|c|c|c|c|c|c|c|}
\hline Study or Subgroup & \multicolumn{3}{|c|}{ Post-treatment } & \multicolumn{3}{|c|}{ Pre-treatment } & Weight & $\begin{array}{l}\text { Mean Difference } \\
\text { IV, Random, } 95 \% \mathrm{CI}\end{array}$ & $\begin{array}{c}\text { Mean Difference } \\
\text { IV, Random, } 95 \% \mathrm{Cl}\end{array}$ \\
\hline Bloch 2000 & 15 & 1 & 24 & 14 & 1 & 24 & $98.8 \%$ & $1.00[0.43,1.57]$ & \\
\hline Total $(95 \% \mathrm{Cl})$ & & & 32 & & & 32 & $100.0 \%$ & $0.97[0.41,1.53]$ & 1 \\
\hline \multicolumn{9}{|c|}{$\begin{array}{l}\text { Heterogeneity: } \text { Tau }^{2}=0.00 ; \mathrm{Chi}^{2}=0.78, \mathrm{df}=1(P=0.38) ; \mathrm{I}^{2}=0 \% \\
\text { Test for overall effect: } Z=3.39(P=0.0007)\end{array}$} & $\begin{array}{ccccc}-20 & -10 & 0 & 10 & 20 \\
\text { Favors no } & \text { OA } & \text { Favors } \mathrm{OA}\end{array}$ \\
\hline
\end{tabular}


Figure 33-OAs vs. CPAP for OSA (\%REM).

\begin{tabular}{|c|c|c|c|c|c|c|c|c|c|c|c|c|}
\hline \multirow[b]{2}{*}{ Study or Subgroup } & \multicolumn{3}{|c|}{ CPAP } & \multicolumn{3}{|c|}{ OA } & \multicolumn{3}{|c|}{ Mean Difference } & \multirow{2}{*}{\multicolumn{2}{|c|}{$\begin{array}{c}\text { Mean Difference } \\
\text { IV, Random, } 95 \% \mathrm{CI}\end{array}$}} & \\
\hline & Mean & SD & Total & Mean & SD & Total & Weight & IV, Random, $95 \% \mathrm{Cl}$ & & & & \\
\hline Aarab 2011b & 19.3 & 10.6 & 13 & 14.6 & 7.6 & 15 & $5.3 \%$ & $4.70[-2.23,11.63]$ & & & $f=$ & \\
\hline Ferguson 1996 & 16.1 & 6.1 & 20 & 14.3 & 6.5 & 19 & $11.1 \%$ & $1.80[-2.16,5.76]$ & & & + & \\
\hline Ferguson 1997 & 12.1 & 5.4 & 20 & 13.1 & 6 & 19 & $12.3 \%$ & $-1.00[-4.59,2.59]$ & & & 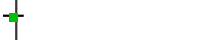 & \\
\hline Hoekema 2008b & 24.1 & 5.7 & 47 & 26.5 & 6.7 & 47 & $16.4 \%$ & $-2.40[-4.91,0.11]$ & & & 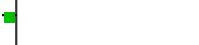 & \\
\hline Total $(95 \% \mathrm{Cl})$ & & & 244 & & & 244 & $100.0 \%$ & $0.72[-1.09,2.52]$ & & & 1 & \\
\hline \multicolumn{9}{|c|}{$\begin{array}{l}\text { Heterogeneity: } \text { Tau }^{2}=3.54 ; \mathrm{Chi}^{2}=20.45, \mathrm{df}=7(P=0.005) ; \mathrm{I}^{2}=66 \% \\
\text { Test for overall effect: } Z=0.78(P=0.44)\end{array}$} & -100 & $\begin{array}{r}-50 \\
F\end{array}$ & $\begin{array}{cc}0 & 50 \\
A & \text { Favors } \\
\text { CPAP }\end{array}$ & 100 \\
\hline
\end{tabular}

Figure 34-OAs for OSA (Sleep Efficiency).

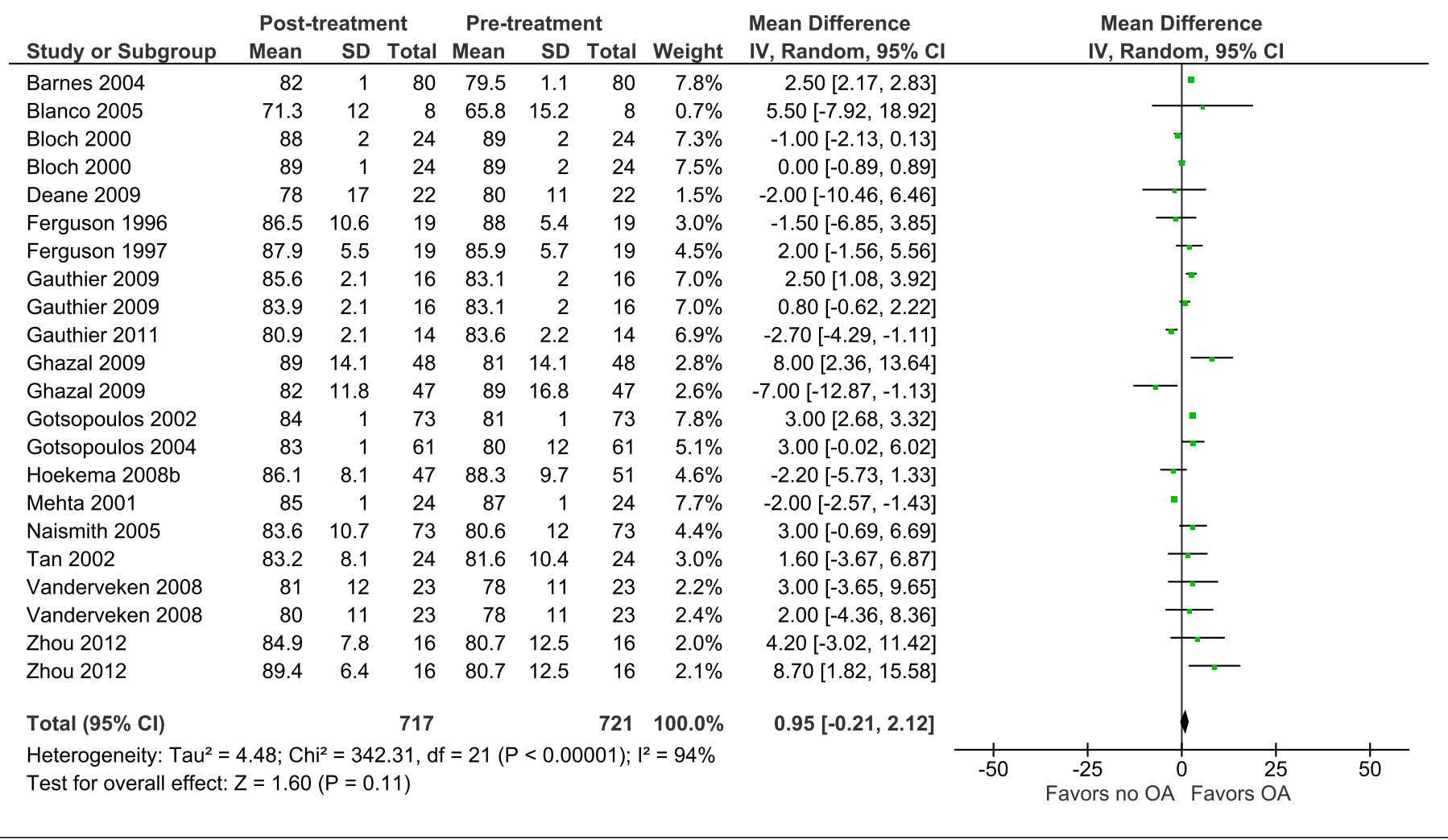


Figure 35-Custom OAs for OSA (Sleep Efficiency).

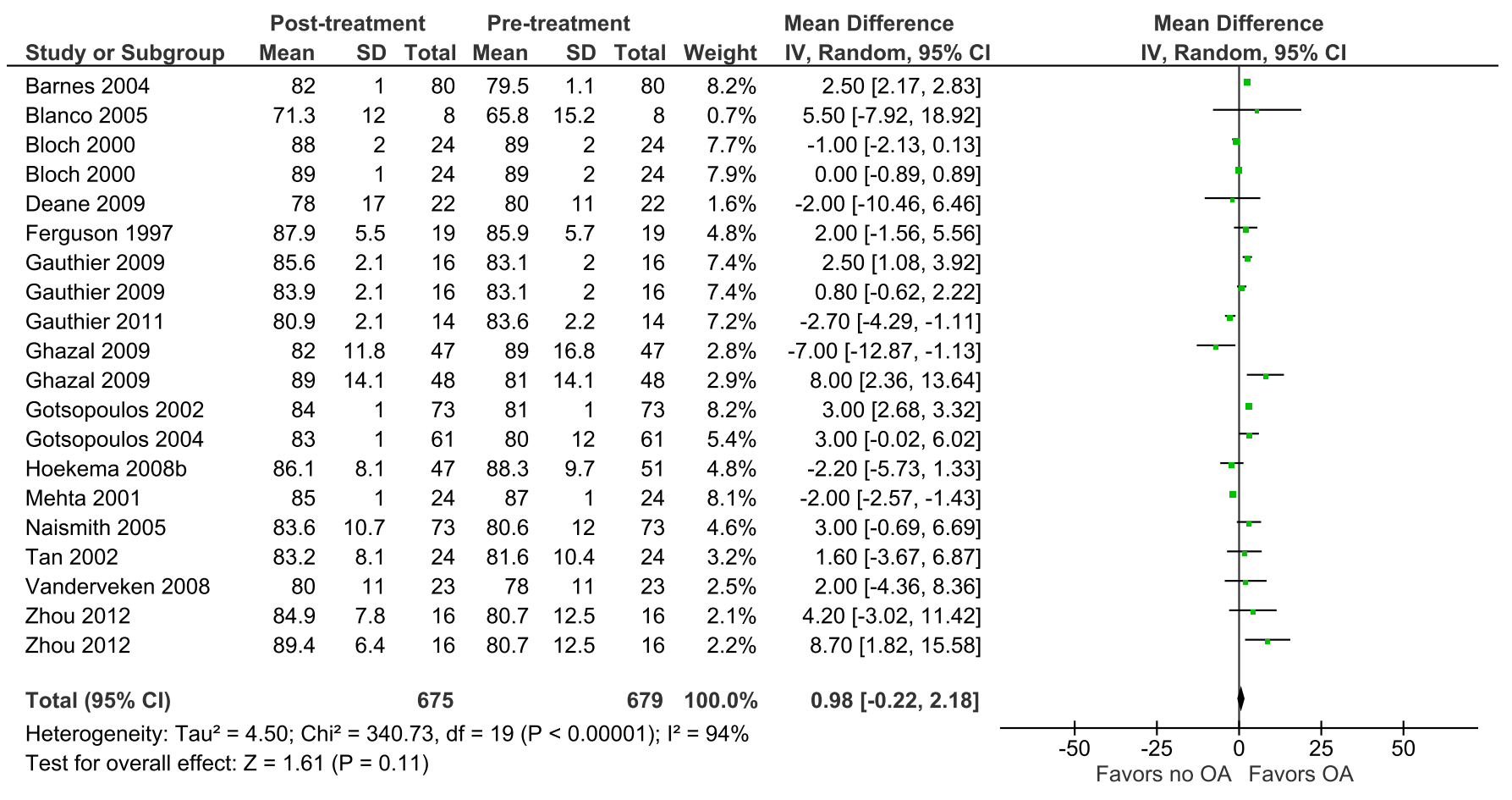

Figure 36-Non-Custom OAs for OSA (Sleep Efficiency).

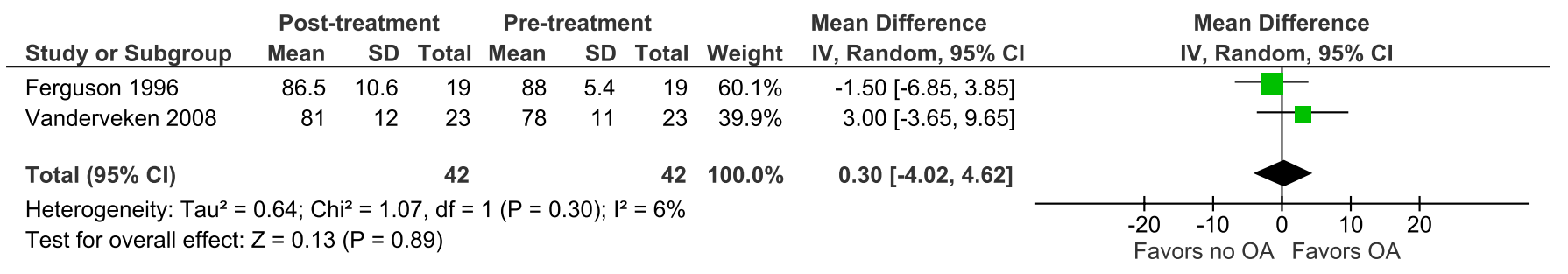

Figure 37-Custom, Titratable OA for OSA (Sleep Efficiency).

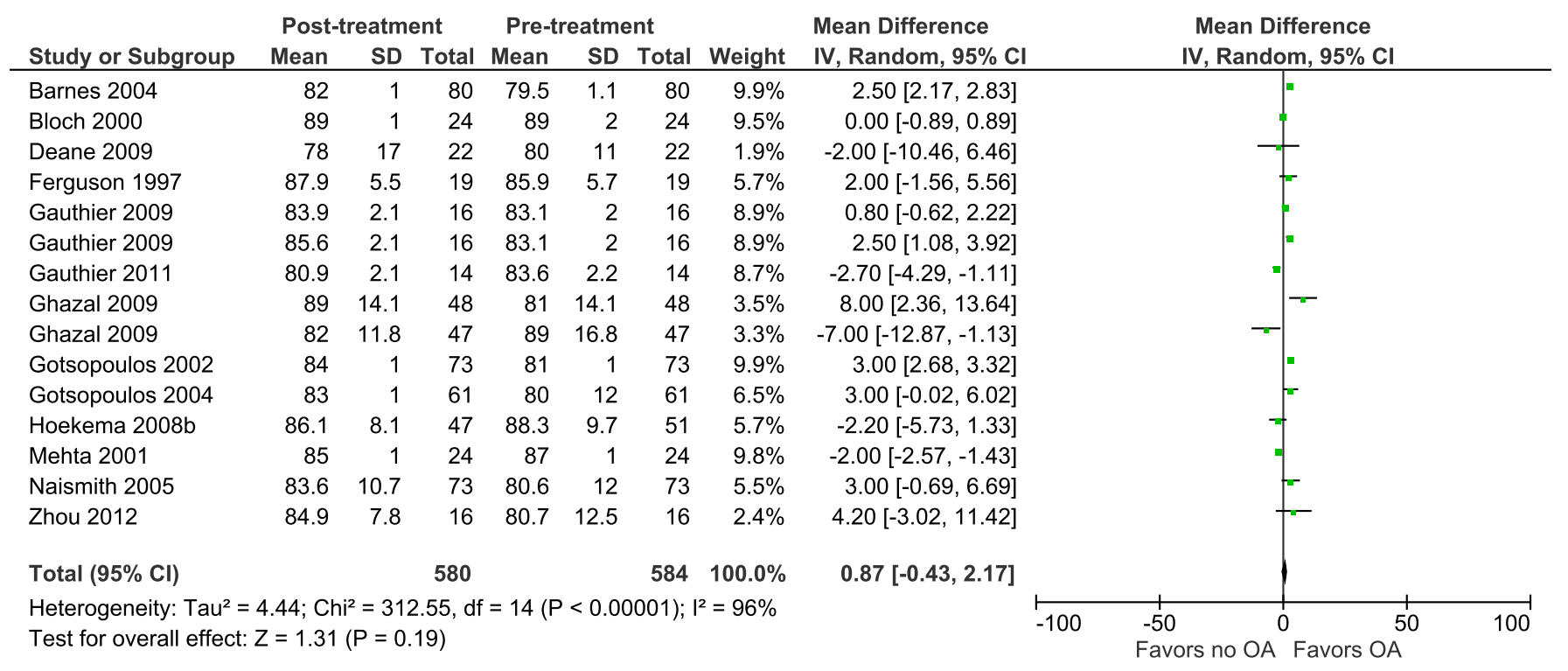


Figure 38-Custom, Non-Titratable OA for OSA (Sleep Efficiency).

\begin{tabular}{|c|c|c|c|c|c|c|c|c|c|}
\hline Study or Subgroup & \multicolumn{3}{|c|}{ Post-treatment } & \multicolumn{3}{|c|}{ Pre-treatment } & Weight & $\begin{array}{l}\text { Mean Difference } \\
\text { IV, Random, } 95 \% \mathrm{Cl}\end{array}$ & $\begin{array}{c}\text { Mean Difference } \\
\text { IV, Random, } 95 \% \mathrm{Cl}\end{array}$ \\
\hline Bloch 2000 & 88 & 2 & 24 & 89 & 2 & 24 & $41.0 \%$ & $-1.00[-2.13,0.13]$ & \\
\hline Zhou 2012 & 89.4 & 6.4 & 16 & 80.7 & 12.5 & 16 & $23.4 \%$ & $8.70[1.82,15.58]$ & 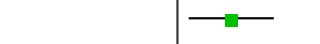 \\
\hline \multirow{2}{*}{\multicolumn{9}{|c|}{$\begin{array}{l}\text { Heterogeneity: } \text { Tau }^{2}=15.70 ; \mathrm{Chi}^{2}=8.93, \mathrm{df}=3(\mathrm{P}=0.03) ; \mathrm{I}^{2}=66 \% \\
\text { Test for overall effect: } Z=1.06(P=0.29)\end{array}$}} & \\
\hline & & & & & & & & & $\begin{array}{ccccc}-20 & -10 & 0 & 10 & 20 \\
\text { Favors no } & \text { OA } & \text { Favors } & \text { FA }\end{array}$ \\
\hline
\end{tabular}

Figure 39-OAs vs. CPAP (Sleep Efficiency).

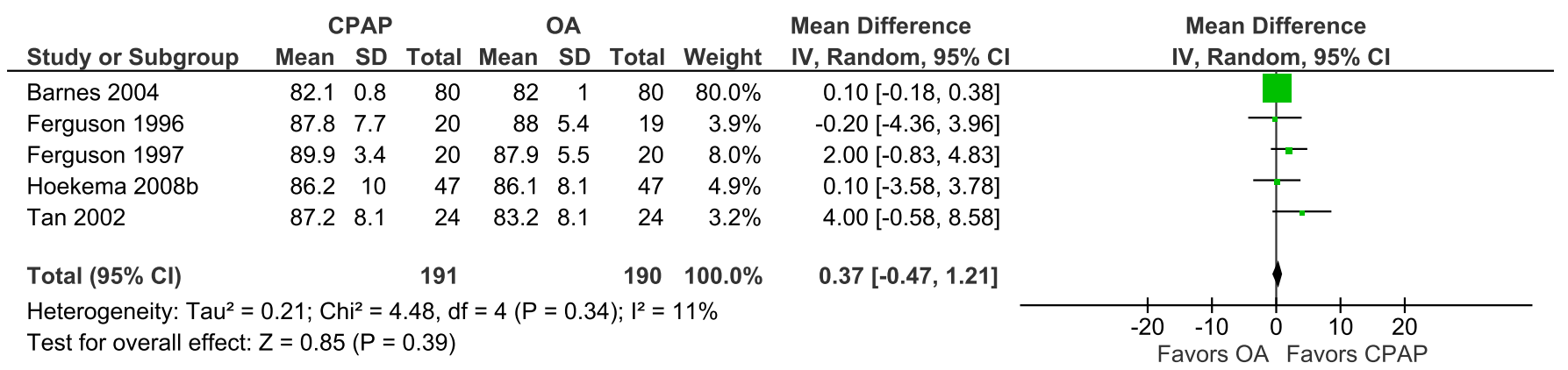

Figure 40-Summary of Findings: OA Pre- vs. Post-Treatment of OSA (All Physiologic Sleep Outcome Measures).

\begin{tabular}{|c|c|c|c|c|c|c|}
\hline \multicolumn{7}{|l|}{ OAs for OSA } \\
\hline \multicolumn{7}{|c|}{$\begin{array}{l}\text { Patient or population: Patients with OSA } \\
\text { Intervention: OAs }\end{array}$} \\
\hline \multirow{2}{*}{ Outcomes } & \multicolumn{2}{|r|}{ Illustrative comparative risks* $(95 \% \mathrm{Cl})$} & $\begin{array}{l}\text { Relative effect } \\
(95 \% \mathrm{Cl})\end{array}$ & $\begin{array}{l}\text { No of Participants } \\
\text { (studies) }\end{array}$ & $\begin{array}{l}\text { Quality of the evidence } \\
\text { (GRADE) }\end{array}$ & Comments \\
\hline & Control & OAs & & & & \\
\hline AHI/RDI/REI & & $\begin{array}{l}\text { The mean AHI/RDI in the intervention groups was } \\
13.59 \text { lower } \\
\text { (15.25 to } 11.94 \text { lower) }\end{array}$ & & $\begin{array}{c}1301 \\
\text { (34 studies) }\end{array}$ & $\stackrel{\oplus \oplus \oplus \ominus}{\text { moderate }}$ & \\
\hline Arousal Index & & $\begin{array}{l}\text { The mean arousal index in the intervention groups was } \\
10.78 \text { lower } \\
\text { (13.54 to } 8.02 \text { lower) }\end{array}$ & & $\begin{array}{c}704 \\
\text { (14 studies) }\end{array}$ & $\stackrel{\oplus \oplus \oplus \ominus}{\text { moderate }^{1}}$ & \\
\hline ODI & & $\begin{array}{l}\text { The mean ODI in the intervention groups was } \\
12.77 \text { lower } \\
\text { (16.85 to } 8.69 \text { lower) }\end{array}$ & & $\begin{array}{c}399 \\
\text { (6 studies) }\end{array}$ & $\stackrel{\oplus \oplus \oplus \ominus}{\text { moderate }^{1}}$ & \\
\hline Sleep Efficiency & & $\begin{array}{l}\text { The mean sleep efficiency in the intervention groups was } \\
0.95 \text { higher } \\
\text { ( } 0.21 \text { lower to } 2.12 \text { higher) }\end{array}$ & & $\begin{array}{l}717 \\
(17 \text { studies })\end{array}$ & $\begin{array}{c}\oplus \oplus \oplus \ominus \\
\text { moderate }\end{array}$ & \\
\hline \multicolumn{7}{|c|}{$\begin{array}{l}\text { "The basis for the assumed risk (e.g., the median control group risk across studies) is provided in footnotes. The corresponding risk (and its } 95 \% \text { confidence interval) is based on th } \\
\text { assumed risk in the comparison group and the relative effect of the intervention (and its } 95 \% \mathrm{Cl} \text { ). }\end{array}$} \\
\hline \multicolumn{7}{|c|}{$\mathrm{Cl}$ : Confidence interval } \\
\hline \multicolumn{7}{|c|}{$\begin{array}{l}\text { GRADE Working Group quality of evidence: } \\
\text { High quality: Further research is very unlikely to change our confidence in the estimate of effect. } \\
\text { Moderate quality: Further research is likely to have an important impact on our confidence in the estimate of effect and may change the estimate. } \\
\text { Low quality: Further research is very likely to have an important impact on our confidence in the estimate of effect and is likely to change the estimate. } \\
\text { Very low quality: We are very uncertain about the estimate. }\end{array}$} \\
\hline
\end{tabular}


Figure 41-Summary of Findings: Custom OAs Pre- vs. Post-Treatment of OSA (All Physiologic Sleep Outcome Measures).

\begin{tabular}{|c|c|c|c|c|c|c|}
\hline \multicolumn{7}{|l|}{ Custom OAs for OSA } \\
\hline \multicolumn{7}{|c|}{$\begin{array}{l}\text { Patient or population: Patients with OSA } \\
\text { Intervention: Custom OAs }\end{array}$} \\
\hline \multirow{3}{*}{ Outcomes } & \multicolumn{2}{|c|}{\begin{tabular}{|c|} 
Illustrative comparative risks ${ }^{\star}(95 \% \mathrm{Cl})$ \\
\end{tabular}} & \multirow{2}{*}{\begin{tabular}{|c|} 
Relative effect \\
$(95 \% \mathrm{Cl})$
\end{tabular}} & \multirow{2}{*}{$\begin{array}{l}\text { No of Participants } \\
\text { (studies) }\end{array}$} & \multirow{2}{*}{$\begin{array}{c}\text { Quality of the evidence } \\
\text { (GRADE) }\end{array}$} & \multirow{2}{*}{ Comments } \\
\hline & Assumed risk & Corresponding risk & & & & \\
\hline & Control & Custom OAs & & & & \\
\hline AHI/RDI/REI & & $\begin{array}{l}\text { The mean AHI/RDI in the intervention groups was } \\
13.89 \text { lower } \\
\text { (15.57 to } 12.20 \text { lower) }\end{array}$ & & $\begin{array}{c}1259 \\
\text { (33 studies) }\end{array}$ & $\begin{array}{c}\oplus \oplus \oplus \ominus \\
\text { moderate }^{1}\end{array}$ & \\
\hline Minimum Oxygen Saturation & & $\begin{array}{l}\text { The mean min oxygen sat. in the intervention groups } \\
\text { was } \\
3.22 \text { higher } \\
\text { ( } 2.54 \text { to } 3.90 \text { higher) }\end{array}$ & & $\begin{array}{c}904 \\
\text { (21 studies) }\end{array}$ & $\underset{\text { moderate }^{1}}{\oplus \oplus \oplus{ }^{1}}$ & \\
\hline Arousal Index & & \begin{tabular}{|l|} 
The mean arousal index in the intervention groups \\
was \\
10.78 lower \\
(13.54 to 8.02 lower)
\end{tabular} & & $\begin{array}{c}704 \\
\text { (14 studies) }\end{array}$ & $\begin{array}{c}\oplus \oplus \oplus \ominus \\
\text { moderate }^{1}\end{array}$ & \\
\hline ODI & & $\begin{array}{l}\text { The mean ODI in the intervention groups was } \\
12.77 \text { lower } \\
\text { (16.85 to } 8.69 \text { lower) }\end{array}$ & & $\begin{array}{c}399 \\
\text { (6 studies) }\end{array}$ & $\begin{array}{c}\oplus \oplus \oplus \ominus \\
\text { moderate }^{1}\end{array}$ & \\
\hline \%REM & & $\begin{array}{l}\text { The mean \%REM in the intervention groups was } \\
1.58 \text { higher } \\
\text { ( } 0.64 \text { to } 2.53 \text { higher) }\end{array}$ & & $\begin{array}{c}608 \\
\text { (16 studies) }\end{array}$ & $\begin{array}{c}\oplus \oplus \ominus \ominus \\
\text { low }^{1,2}\end{array}$ & \\
\hline Sleep Efficiency & & $\begin{array}{l}\text { The mean sleep efficiency in the intervention groups } \\
\text { was } \\
0.95 \text { higher } \\
\text { (0.22 lower to } 2.18 \text { higher })\end{array}$ & & $\begin{array}{c}675 \\
\text { (16 studies) }\end{array}$ & $\begin{array}{c}\oplus \oplus \ominus \ominus \\
\text { low }^{1,2}\end{array}$ & \\
\hline \multirow{2}{*}{\multicolumn{7}{|c|}{$\begin{array}{l}{ }^{\circledR} \text { The basis for the assumed risk (e.g., the median control group risk across studies) is provided in footnotes. The corresponding risk (and its } 95 \% \text { confidence interval) is based on the } \\
\text { assumed risk in the comparison group and the relative effect of the intervention (and its } 95 \% \mathrm{Cl} \text { ). }\end{array}$}} \\
\hline & & & & & & \\
\hline \multicolumn{7}{|c|}{$\begin{array}{l}\text { GRADE Working Group quality of evidence: } \\
\text { High quality: Further research is very unlikely to change our confidence in the estimate of effect. } \\
\text { Moderate quality: Further research is likely to have an important impact on our confidence in the estimate of effect and may change the estimate. } \\
\text { Low quality. Further research is very likely to have an important impact on our confidence in the estimate of effect and is likely to change the estimate. } \\
\text { Very low quality. We are very uncertain about the estimate. }\end{array}$} \\
\hline \multicolumn{7}{|c|}{$\begin{array}{l}\text { I squared is high } \\
{ }^{2} \mathrm{Cl} \text { crosses the decision making threshold }\end{array}$} \\
\hline
\end{tabular}

Figure 42-Summary of Findings: Non-Custom OAs Pre- vs. Post-Treatment of OSA (All Physiologic Sleep Outcome Measures).

\begin{tabular}{|c|c|c|c|c|c|c|}
\hline \multicolumn{7}{|l|}{ Non-Custom OAs for OSA } \\
\hline \multicolumn{7}{|c|}{$\begin{array}{l}\text { Patient or population: Patients with OSA } \\
\text { Intervention: Non-Custom OAs }\end{array}$} \\
\hline \multirow{2}{*}{ Outcomes } & \multicolumn{2}{|r|}{ Illustrative comparative risks* $(95 \% \mathrm{Cl})$} & \multirow{2}{*}{$\begin{array}{l}\text { Relative effect } \\
(95 \% \mathrm{Cl})\end{array}$} & \multirow{2}{*}{$\begin{array}{l}\text { No of Participants } \\
\text { (studies) }\end{array}$} & \multirow{2}{*}{$\begin{array}{l}\text { Quality of the evidence } \\
\text { (GRADE) }\end{array}$} & \multirow{2}{*}{ Comments } \\
\hline & Assumed risk & Corresponding risk & & & & \\
\hline & Control & Non-Custom OAs & & & & \\
\hline AHI/RDI/REI & & $\begin{array}{l}\text { The mean AHI/RDI in the intervention groups was } \\
6.28 \text { lower } \\
\text { (13.13 to } 0.56 \text { lower) }\end{array}$ & & $\begin{array}{c}42 \\
\text { (2 studies) }\end{array}$ & $\begin{array}{c}\oplus \oplus \Theta \Theta \\
\text { low }^{1,2}\end{array}$ & \\
\hline Minimum Oxygen Saturation & & $\begin{array}{l}\text { The mean min oxygen sat. in the intervention groups } \\
\text { was } \\
\text { 0.29 lower } \\
\text { (3.22 lower to } 2.64 \text { higher) }\end{array}$ & & $\begin{array}{c}42 \\
\text { (2 studies) }\end{array}$ & $\begin{array}{c}\oplus \oplus \oplus \Theta \\
\text { moderate }^{2}\end{array}$ & \\
\hline Arousal Index & & & & ( 0 studies) & N/A & \\
\hline ODI & & & & ( 0 studies) & N/A & \\
\hline \%REM & & $\begin{array}{l}\text { The mean \%REM in the intervention groups was } \\
\mathbf{5 . 7 0} \text { higher } \\
(0.56 \text { lower to } 11.96 \text { higher) }\end{array}$ & & $\begin{array}{c}19 \\
(1 \text { study })\end{array}$ & $\begin{array}{c}\oplus \oplus \oplus \ominus \\
\text { moderate }^{2}\end{array}$ & \\
\hline Sleep Efficiency & & $\begin{array}{l}\text { The mean sleep efficiency in the intervention groups } \\
\text { was } \\
0.3 \text { higher } \\
\text { (4.02 lower to } 4.62 \text { higher) }\end{array}$ & & $\begin{array}{c}42 \\
\text { (2 studies) }\end{array}$ & $\begin{array}{c}\oplus \oplus \oplus \ominus \\
\text { moderate }\end{array}$ & \\
\hline \multicolumn{7}{|c|}{$\begin{array}{l}\text { The basis for the assumed risk (e.g., the median control group risk across studies) is provided in footnotes. The corresponding risk (and its } 95 \% \text { confidence interval) is based on the } \\
\text { assumed risk in the comparison group and the relative effect of the intervention (and its } 95 \% \mathrm{Cl} \text { ). }\end{array}$} \\
\hline \multicolumn{7}{|l|}{$\mathrm{Cl}$ : Confidence interval } \\
\hline \multicolumn{7}{|c|}{$\begin{array}{l}\text { GRADE Working Group quality of evidence: } \\
\text { High quality. Further research is very unlikely to change our confidence in the estimate of effect. } \\
\text { Moderate quality: Further research is likely to have an important impact on our confidence in the estimate of effect and may change the estimate. } \\
\text { Low quality: Further research is very likely to have an important impact on our confidence in the estimate of effect and is likely to change the estimate. } \\
\text { Very low quality: We are very uncertain about the estimate. }\end{array}$} \\
\hline
\end{tabular}


Figure 43-Summary of Findings: Custom, Titratable OAs Pre- vs. Post-Treatment of OSA (All Physiologic Sleep Outcome Measures).

\begin{tabular}{|c|c|c|c|c|c|c|}
\hline \multicolumn{7}{|c|}{ Custom, titratable OAs for OSA } \\
\hline \multicolumn{7}{|c|}{$\begin{array}{l}\text { Patient or population: Patients with OSA } \\
\text { Intervention: Custom, titratable OAs } \\
\end{array}$} \\
\hline \multirow{3}{*}{ Outcomes } & \multicolumn{2}{|r|}{ Illustrative comparative risks* $(95 \% \mathrm{Cl})$} & \multirow{2}{*}{\begin{tabular}{|c|} 
Relative effect \\
$(95 \% \mathrm{Cl})$
\end{tabular}} & \multirow{2}{*}{$\begin{array}{l}\text { No of Participants } \\
\text { (studies) }\end{array}$} & \multirow{2}{*}{$\begin{array}{l}\text { Quality of the evidence } \\
\text { (GRADE) }\end{array}$} & \multirow{2}{*}{ Comments } \\
\hline & Assumed risk & $\begin{array}{c}\text { Corresponding risk } \\
\end{array}$ & & & & \\
\hline & \begin{tabular}{|c|} 
Control \\
\end{tabular} & Custom, titratable OAs & & & & \\
\hline AHI/RDI/REI & & $\begin{array}{l}\text { The mean AHI/RDI in the intervention groups was } \\
\text { 13.80 lower } \\
\text { (15.74 to } 11.87 \text { lower) }\end{array}$ & & $\begin{array}{c}1054 \\
\text { (27 studies) }\end{array}$ & $\begin{array}{c}\oplus \oplus \oplus \ominus \\
\text { moderate }\end{array}$ & \\
\hline Minimum Oxygen Saturation & & $\begin{array}{l}\text { The mean oxygen saturation in the intervention groups } \\
\text { was } \\
\text { 3.15 higher } \\
\text { (2.46 to } 3.84 \text { higher) }\end{array}$ & & $\begin{array}{c}847 \\
\text { (20 studies) }\end{array}$ & $\begin{array}{c}\oplus \oplus \oplus \ominus \\
\text { moderate }^{1,2}\end{array}$ & \\
\hline Arousal Index & & $\begin{array}{l}\text { The mean arousal index in the intervention groups } \\
\text { was } \\
\text { 10.44 lower } \\
\text { (13.44 to } 7.45 \text { lower) }\end{array}$ & & $\begin{array}{c}648 \\
\text { (12 studies) }\end{array}$ & $\begin{array}{c}\oplus \oplus \oplus \Theta^{\oplus} \\
\text { moderate }^{1}\end{array}$ & \\
\hline ODI & & $\begin{array}{l}\text { The mean ODI in the intervention groups was } \\
9.95 \text { lower } \\
\text { (16.25 to } 3.66 \text { lower) }\end{array}$ & & $\begin{array}{c}322 \\
\text { (4 studies) }\end{array}$ & $\begin{array}{c}\oplus \oplus \oplus \ominus \\
\text { moderate }^{1}\end{array}$ & \\
\hline \%REM & & $\begin{array}{l}\text { The mean \%REM in the intervention groups was } \\
1.24 \text { higher } \\
(0.09 \text { to } 2.56 \text { higher) }\end{array}$ & & $\begin{array}{c}551 \\
\text { (14 studies) }\end{array}$ & $\begin{array}{c}\oplus \oplus \Theta \Theta \\
\text { low }^{1,2}\end{array}$ & \\
\hline Sleep Efficiency & & $\begin{array}{l}\text { The mean sleep efficiency in the intervention groups } \\
\text { was } \\
0.87 \text { higher } \\
\text { (0.43 lower to } 2.17 \text { higher) }\end{array}$ & & $\begin{array}{c}580 \\
\text { (13 studies) }\end{array}$ & $\begin{array}{c}\oplus \oplus \Theta \Theta \\
\text { low }^{1,2}\end{array}$ & \\
\hline \multicolumn{7}{|c|}{$\begin{array}{l}\text { "The basis for the assumed risk (e.g., the median control group risk across studies) is provided in footnotes. The corresponding risk (and its } 95 \% \text { confidence interval) is based on the } \\
\text { assumed risk in the comparison group and the relative effect of the intervention (and its } 95 \% \mathrm{Cl} \text { ). } \\
\mathrm{Cl} \text { : Confidence interval }\end{array}$} \\
\hline \multicolumn{7}{|c|}{$\begin{array}{l}\text { GRADE Working Group quality of evidence: } \\
\text { High quality: Further research is very unlikely to change our confidence in the estimate of effect. } \\
\text { Moderate quality. Further research is likely to have an important impact on our confidence in the estimate of effect and may change the estimate. } \\
\text { Low quality: Further research is very likely to have an important impact on our confidence in the estimate of effect and is likely to change the estimate. } \\
\text { Very low quality: We are very uncertain about the estimate. }\end{array}$} \\
\hline $\begin{array}{l}1 \text { I squared is high } \\
{ }^{2} \mathrm{Cl} \text { of absolute effect crosses } \mathrm{C}\end{array}$ & clinical decision & threshold & & & & \\
\hline
\end{tabular}

Figure 44-Summary of Findings: Custom, Non-Titratable OAs Pre- vs. Post-Treatment of OSA (All Physiologic Sleep Outcome Measures).

\begin{tabular}{|c|c|c|c|c|c|c|}
\hline \multicolumn{7}{|c|}{ Custom, non-titratable OAs for OSA } \\
\hline \multicolumn{7}{|c|}{$\begin{array}{l}\text { Patient or population: Patients with OSA } \\
\text { Intervention: Custom, non-titratable OAs }\end{array}$} \\
\hline \multirow{3}{*}{ Outcomes } & \multicolumn{2}{|r|}{ Illustrative comparative risks* $(95 \% \mathrm{Cl})$} & \multirow{2}{*}{\begin{tabular}{|l} 
Relative effect \\
$(95 \% \mathrm{Cl})$
\end{tabular}} & \multirow{2}{*}{$\begin{array}{l}\text { No of Participants } \\
\text { (studies) }\end{array}$} & \multirow{2}{*}{$\begin{array}{l}\text { Quality of the evidence } \\
\text { (GRADE) }\end{array}$} & \multirow{2}{*}{ Comments } \\
\hline & Assumed risk & \begin{tabular}{|c|} 
Corresponding risk \\
\end{tabular} & & & & \\
\hline & Control & Custom, non-titratable OAs & & & & \\
\hline AHI/RDI/REI & & $\begin{array}{l}\text { The mean AHl in the intervention groups was } \\
\text { 12.51 lower } \\
\text { (15.23 to } 9.8 \text { lower) }\end{array}$ & & $\begin{array}{c}164 \\
\text { (6 studies) }\end{array}$ & $\begin{array}{c}\oplus \oplus \oplus \Theta \\
\text { moderate }^{1}\end{array}$ & \\
\hline Minimum Oxygen Saturation & & $\begin{array}{l}\text { The mean min oxygen sat. in the intervention groups } \\
\text { was } \\
4.70 \text { higher } \\
\text { (3.83 to } 13.22 \text { higher) }\end{array}$ & & $\begin{array}{c}57 \\
\text { (3 studies) }\end{array}$ & $\begin{array}{c}\oplus \oplus \Theta \Theta \\
\text { low }^{1,2}\end{array}$ & \\
\hline Arousal Index & & $\begin{array}{l}\text { The mean arousal index in the intervention groups } \\
\text { was } \\
\text { 14.59 lower } \\
\text { (12.48 to } 16.71 \text { lower) }\end{array}$ & & $\begin{array}{c}272 \\
\text { (2 studies) }\end{array}$ & $\begin{array}{c}\oplus \oplus \ominus \ominus \\
\text { low }^{1,2}\end{array}$ & \\
\hline ODI & & $\begin{array}{l}\text { The mean ODl in the intervention groups was } \\
15.65 \text { lower } \\
\text { (28.86 to } 4.44 \text { lower) }\end{array}$ & & $\begin{array}{c}77 \\
\text { (3 studies) }\end{array}$ & $\underset{\text { moderate }^{1}}{\oplus \oplus \oplus \Theta^{1}}$ & \\
\hline \%REM & & $\begin{array}{l}\text { The mean \%REM in the intervention groups was } \\
0.97 \text { lower } \\
\text { (0.41 to } 1.53 \text { lower) }\end{array}$ & & $\begin{array}{c}32 \\
\text { (2 studies) }\end{array}$ & $\underset{\text { moderate }^{2}}{\oplus \oplus \oplus \ominus}$ & \\
\hline Sleep Efficiency & & $\begin{array}{l}\text { The mean sleep efficiency in the intervention groups } \\
\text { was } \\
2.71 \text { higher } \\
\text { (2.32 lower to } 7.73 \text { higher) }\end{array}$ & & $\begin{array}{c}71 \\
\text { (4 studies) }\end{array}$ & $\begin{array}{c}\oplus \oplus \oplus \ominus \\
\text { moderate }^{2}\end{array}$ & \\
\hline \multicolumn{7}{|c|}{$\begin{array}{l}\text { The basis for the assumed risk (e.g., the median control group risk across studies) is provided in footnotes. The corresponding risk (and its } 95 \% \text { confidence interval) is based on the } \\
\text { assumed risk in the comparison group and the relative effect of the intervention (and its } 95 \% \mathrm{Cl} \text { ). } \\
\text { Cl: Confidence interval }\end{array}$} \\
\hline \multicolumn{7}{|c|}{$\begin{array}{l}\text { GRADE Working Group quality of evidence: } \\
\text { High quality: Further research is very unlikely to change our confidence in the estimate of effect. } \\
\text { Moderate quality: Further research is likely to have an important impact on our confidence in the estimate of effect and may change the estimate. } \\
\text { Low quality: Further research is very likely to have an important impact on our confidence in the estimate of effect and is likely to change the estimate. } \\
\text { Very low quality: We are very uncertain about the estimate. }\end{array}$} \\
\hline
\end{tabular}


Figure 45-Summary of Findings: OAs vs. CPAP for OSA (All Physiologic Sleep Outcome Measures).

\begin{tabular}{|c|c|c|c|c|c|c|}
\hline \multicolumn{7}{|c|}{ OAs compared to CPAP for OSA } \\
\hline \multicolumn{7}{|c|}{$\begin{array}{l}\text { Patient or population: patients with OSA } \\
\text { Intervention: OAs } \\
\text { Comparison: CPAP }\end{array}$} \\
\hline \multirow{2}{*}{ Outcomes } & \multicolumn{2}{|c|}{ Illustrative comparative risks* $(95 \% \mathrm{Cl})$} & \multirow{2}{*}{$\begin{array}{l}\text { Relative effect } \\
\qquad(95 \% \mathrm{Cl})\end{array}$} & \multirow{2}{*}{$\begin{array}{l}\text { No of Participants } \\
\text { (studies) }\end{array}$} & \multirow{2}{*}{$\begin{array}{l}\text { Quality of the evidence } \\
\text { (GRADE) }\end{array}$} & \multirow{2}{*}{ Comments } \\
\hline & Assumed risk & Corresponding risk & & & & \\
\hline & CPAP & OAs & & & & \\
\hline AHI/RDI/REI & & $\begin{array}{l}\text { The mean AHI/RDI in the intervention groups was } \\
6.24 \text { higher } \\
\text { ( } 8.14 \text { to } 4.34 \text { higher) }\end{array}$ & & $\begin{array}{c}481 \\
\text { (15 studies) }\end{array}$ & $\begin{array}{c}\oplus \oplus \oplus \ominus \\
\text { moderate }^{1}\end{array}$ & \\
\hline Oxygen Saturation & & $\begin{array}{l}\text { The mean oxygen saturation in the intervention groups } \\
\text { was } \\
\text { 3.11 lower } \\
\text { (1.74 to } 4.48 \text { lower) }\end{array}$ & & $\begin{array}{c}354 \\
\text { (9 studies) }\end{array}$ & $\begin{array}{c}\oplus \oplus \oplus \ominus \\
\text { moderate }^{1}\end{array}$ & \\
\hline Arousal Index & & $\begin{array}{l}\text { The mean arousal index in the intervention groups was } \\
3.57 \text { higher } \\
\text { ( } 5.51 \text { to } 1.64 \text { higher) }\end{array}$ & & $\begin{array}{c}274 \\
\text { (6 studies) }\end{array}$ & $\begin{array}{c}\oplus \oplus \oplus \Theta \\
\text { moderate }^{1}\end{array}$ & \\
\hline Sleep Efficiency & & $\begin{array}{l}\text { The mean sleep efficiency in the intervention groups was } \\
0.37 \text { lower } \\
\text { ( } 0.47 \text { higher to } 1.21 \text { lower })\end{array}$ & & $\begin{array}{c}191 \\
\text { (5 studies) }\end{array}$ & $\begin{array}{c}\oplus \oplus \oplus \ominus \\
\text { moderate }^{2}\end{array}$ & \\
\hline \%REM & & $\begin{array}{l}\text { The mean \%REM in the intervention groups was } \\
0.72 \text { lower } \\
\text { (1.09 higher to } 2.52 \text { lower) }\end{array}$ & & $\begin{array}{c}244 \\
\text { (8 studies) }\end{array}$ & $\begin{array}{c}\oplus \oplus \ominus \ominus \\
\text { low }^{1,2}\end{array}$ & \\
\hline ODI & & $\begin{array}{l}\text { The mean ODI in the intervention groups was } \\
4.76 \text { higher } \\
(7.15 \text { to } 2.37 \text { higher) }\end{array}$ & & $\begin{array}{c}234 \\
\text { (3 studies) }\end{array}$ & $\begin{array}{c}\oplus \oplus \Theta \Theta \\
\text { low }^{1,2}\end{array}$ & \\
\hline \multicolumn{7}{|c|}{$\begin{array}{l}\text { "The basis for the assumed risk (e.g., the median control group risk across studies) is provided in footnotes. The corresponding risk (and its } 95 \% \text { confidence interval) is based on the } \\
\text { assumed risk in the comparison group and the relative effect of the intervention (and its } 95 \% \mathrm{Cl} \text { ). }\end{array}$} \\
\hline \multicolumn{7}{|c|}{ Cl: Confidence interval; } \\
\hline \multicolumn{7}{|c|}{$\begin{array}{l}\text { GRADE Working Group quality of evidence: } \\
\text { High quality: Further research is very unlikely to change our confidence in the estimate of effect. } \\
\text { Moderate quality: Further research is likely to have an important impact on our confidence in the estimate of effect and may change the estimate. } \\
\text { Low quality. Further research is very likely to have an important impact on our confidence in the estimate of effect and is likely to change the estimate. } \\
\text { Very low quality. We are very uncertain about the estimate. }\end{array}$} \\
\hline
\end{tabular}


Figure 46-OAs for OSA (Epworth Sleepiness Scale; ESS).

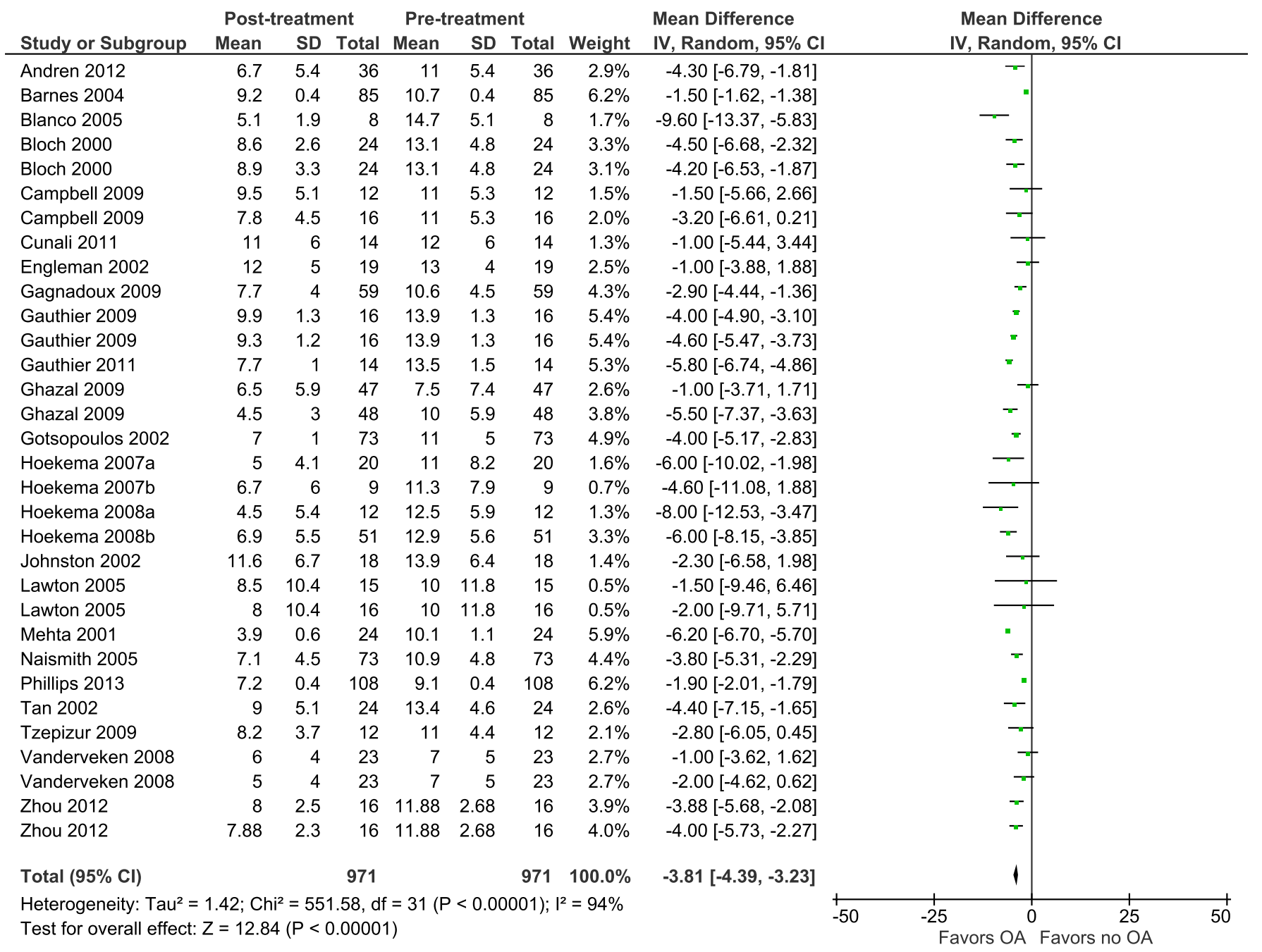


Figure 47-Custom OAs for OSA (ESS).

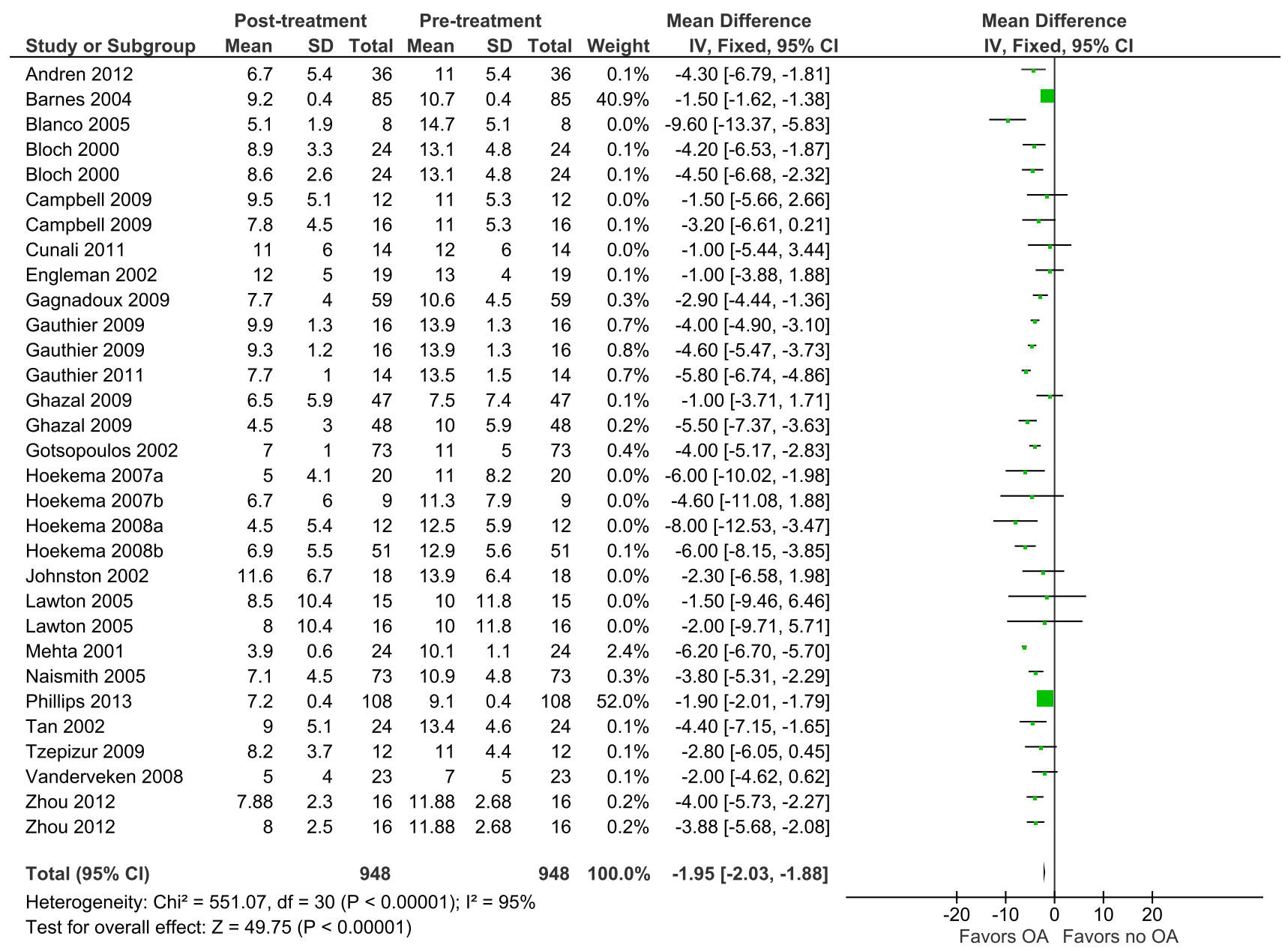

Figure 48-Custom, Titratable OAs for OSA (ESS).

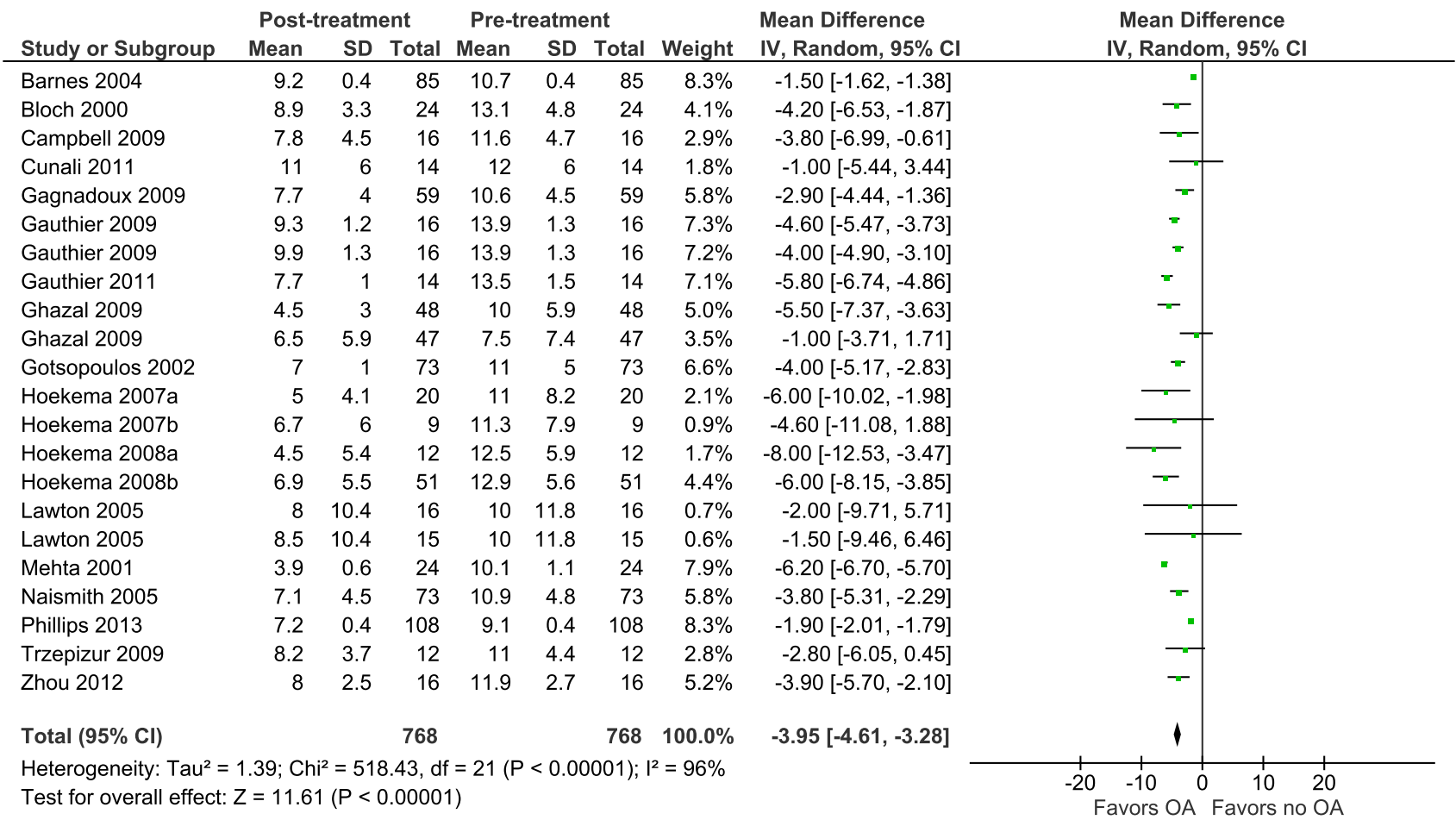


Figure 49—Custom, Non-Titratable OAs for OSA (ESS).

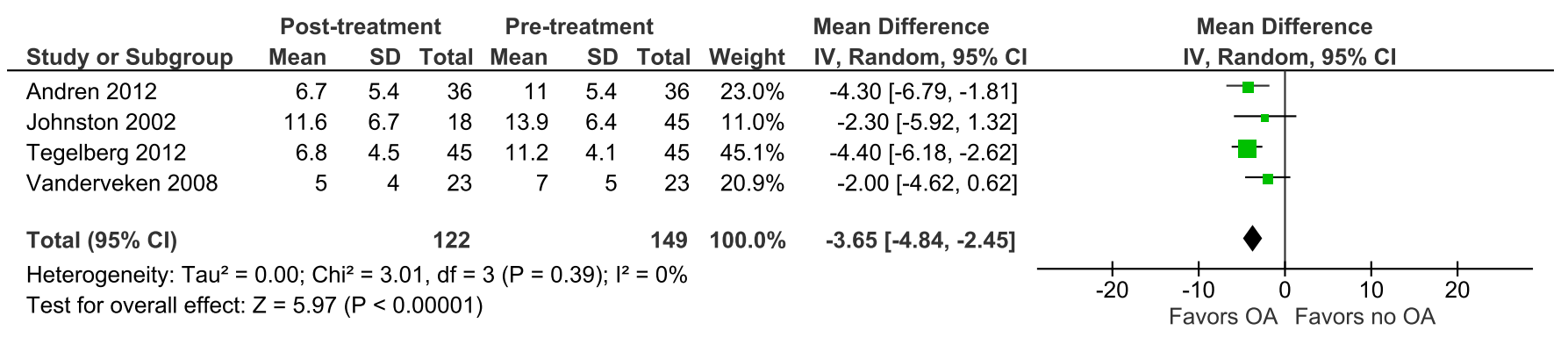

Figure 50-OAs vs. CPAP for OSA (ESS).

OA CPAP

Study or Subgroup Mean SD Total Mean SD Total Weight

Barnes 2004

Engleman 2002

Gagnadoux 2009

Hoekema 2007a

Hoekema 2008a

Hoekema 2008b

Phillips 2013

Tan 2002

Tzepizur 2009

Total $(95 \% \mathrm{Cl})$

$\begin{array}{rrrrrrr}9.2 & 0.4 & 85 & 9.2 & 0.4 & 89 & 44.1 \% \\ 12 & 5 & 19 & 8 & 5 & 29 & 1.0 \% \\ 7.7 & 4 & 59 & 8.2 & 3.9 & 59 & 4.0 \% \\ 5 & 4.1 & 20 & 5 & 6.7 & 27 & 0.9 \% \\ 6.7 & 6 & 9 & 5.5 & 4.1 & 10 & 0.4 \% \\ 4.5 & 5.4 & 12 & 5 & 5.2 & 13 & 0.5 \% \\ 6.9 & 5.5 & 49 & 5.9 & 4.8 & 50 & 2.1 \% \\ 7.2 & 0.4 & 108 & 7.5 & 0.4 & 108 & 44.7 \% \\ 9 & 5.1 & 24 & 8.1 & 4.1 & 24 & 1.3 \% \\ 8.2 & 3.7 & 12 & 8.8 & 3.7 & 12 & 1.0 \%\end{array}$

397

$421 \quad 100.0 \%$

Heterogeneity: $\mathrm{Tau}^{2}=0.05 ; \mathrm{Chi}^{2}=24.06, \mathrm{df}=9(\mathrm{P}=0.004) ; \mathrm{I}^{2}=63 \%$
Hoekema 2007b

Test for overall effect: $Z=0.55(P=0.58)$

Mean Difference Mean Difference

IV, Random, 95\% Cl

$0.00[-0.12,0.12]$

$4.00[1.11,6.89]$

$-0.50[-1.93,0.93]$

$0.00[-3.10,3.10]$

$1.20[-3.47,5.87]$

$-0.50[-4.66,3.66]$

$1.00[-1.04,3.04]$

$-0.30[-0.41,-0.19]$

$0.90[-1.72,3.52]$

$-0.60[-3.56,2.36]$

$-0.08[-0.38,0.21]$

IV, Random, $95 \% \mathrm{Cl}$

Figure 51-Summary of Findings: OAs Pre- vs. Post-Treatment for OSA (ESS). 
Figure 52-Summary of Findings: Custom OAs for OSA (ESS).

\section{Custom OAs for OSA}

Patient or population: Patients with OSA

Intervention: Custom OAs

\begin{tabular}{|c|c|c|c|c|c|c|}
\hline \multirow{2}{*}{ Outcomes } & \multicolumn{2}{|r|}{ Illustrative comparative risks* $(95 \% \mathrm{Cl})$} & \multirow{2}{*}{$\begin{array}{c}\text { Relative effect } \\
(95 \% \mathrm{Cl})\end{array}$} & \multirow{2}{*}{$\begin{array}{c}\text { No of Participants } \\
\text { (studies) }\end{array}$} & \multirow{2}{*}{$\begin{array}{l}\text { Quality of the evidence } \\
\text { (GRADE) }\end{array}$} & \multirow{2}{*}{ Comments } \\
\hline & Assumed risk & Corresponding risk & & & & \\
\hline & Control & Custom OAs & & & & \\
\hline $\begin{array}{l}\text { ESS } \\
\text { (Daytime sleepiness) }\end{array}$ & & $\begin{array}{l}\text { The mean ESS in the intervention groups was } \\
1.95 \text { lower } \\
(2.03 \text { to } 1.88 \text { lower) }\end{array}$ & & $\begin{array}{c}948 \\
\text { (25 studies) }\end{array}$ & $\begin{array}{c}\oplus \oplus \oplus \Theta \\
\text { moderate }^{1}\end{array}$ & \\
\hline
\end{tabular}

${ }^{\star}$ The basis for the assumed risk (e.g., the median control group risk across studies) is provided in footnotes. The corresponding risk (and its $95 \%$ confidence interval) is based on the assumed risk in the comparison group and the relative effect of the intervention (and its $95 \% \mathrm{Cl}$ ).

CI: Confidence interval

GRADE Working Group quality of evidence:

High quality: Further research is very unlikely to change our confidence in the estimate of effect.

Moderate quality: Further research is likely to have an important impact on our confidence in the estimate of effect and may change the estimate.

Low quality: Further research is very likely to have an important impact on our confidence in the estimate of effect and is likely to change the estimate.

Very low quality: We are very uncertain about the estimate.

${ }^{1}$ I squared is high

Figure 53-Summary of Findings: Non-Custom OAs for OSA (ESS).

\begin{tabular}{|c|c|c|c|c|c|c|}
\hline \multicolumn{7}{|c|}{ Non-custom OAs for OSA } \\
\hline \multicolumn{7}{|c|}{$\begin{array}{l}\text { Patient or population: Patients with OSA } \\
\text { Intervention: Non-custom OAs }\end{array}$} \\
\hline \multirow{3}{*}{ Outcomes } & \multicolumn{2}{|r|}{ Illustrative comparative risks* $(95 \% \mathrm{Cl})$} & \multirow{2}{*}{$\begin{array}{l}\text { Relative effect } \\
\qquad(95 \% \mathrm{Cl})\end{array}$} & \multirow{2}{*}{$\begin{array}{l}\text { No of Participants } \\
\text { (studies) }\end{array}$} & \multirow{2}{*}{$\begin{array}{l}\text { Quality of the evidence } \\
\text { (GRADE) }\end{array}$} & \multirow{2}{*}{ Comments } \\
\hline & Assumed risk & Corresponding risk & & & & \\
\hline & Control & Non-custom OAs & & & & \\
\hline $\begin{array}{l}\text { ESS } \\
\text { (Daytime sleepiness) }\end{array}$ & & $\begin{array}{l}\text { The mean ESS in the intervention groups was } \\
1.00 \text { lower } \\
\text { ( } 3.62 \text { lower to } 1.62 \text { higher) }\end{array}$ & & $\begin{array}{c}23 \\
\text { (1 study) }\end{array}$ & $\begin{array}{c}\oplus \oplus \oplus \ominus \\
\text { moderate }^{1}\end{array}$ & \\
\hline \multicolumn{7}{|c|}{$\begin{array}{l}\text { *The basis for the assumed risk (e.g., the median control group risk across studies) is provided in footnotes. The corresponding risk (and its } 95 \% \text { confidence interval) is based on the } \\
\text { assumed risk in the comparison group and the relative effect of the intervention (and its } 95 \% \mathrm{Cl} \text { ). }\end{array}$} \\
\hline \multicolumn{7}{|l|}{$\mathrm{Cl}$ : Confidence interval } \\
\hline \multicolumn{7}{|c|}{$\begin{array}{l}\text { GRADE Working Group quality of evidence: } \\
\text { High quality: Further research is very unlikely to change our confidence in the estimate of effect. } \\
\text { Moderate quality: Further research is likely to have an important impact on our confidence in the estimate of effect and may change the estimate. } \\
\text { Low quality: Further research is very likely to have an important impact on our confidence in the estimate of effect and is likely to change the estimate. } \\
\text { Very low quality: We are very uncertain about the estimate. }\end{array}$} \\
\hline
\end{tabular}

Figure 54-Summary of Findings: Custom, Titratable OAs for OSA (ESS).

\begin{tabular}{|c|c|c|c|c|c|c|}
\hline \multicolumn{7}{|c|}{ Custom, titratable OAs for OSA } \\
\hline \multicolumn{7}{|c|}{$\begin{array}{l}\text { Patient or population: Patients with OSA } \\
\text { Intervention: Custom, titratable OAs }\end{array}$} \\
\hline \multirow{2}{*}{ Outcomes } & \multicolumn{2}{|r|}{ Illustrative comparative risks ${ }^{*}(95 \% \mathrm{Cl})$} & $\begin{array}{l}\text { Relative effect } \\
(95 \% \mathrm{Cl})\end{array}$ & $\begin{array}{l}\text { No of Participants } \\
\text { (studies) }\end{array}$ & $\begin{array}{l}\text { Quality of the evidence } \\
\text { (GRADE) }\end{array}$ & Comments \\
\hline & Control & Custom, titratable OAs & & & & \\
\hline $\begin{array}{l}\text { ESS } \\
\text { (Daytime sleepiness) }\end{array}$ & & $\begin{array}{l}\text { The mean ESS in the intervention groups was } \\
3.95 \text { lower } \\
\text { ( } 4.61 \text { to } 3.28 \text { lower) }\end{array}$ & & $\begin{array}{c}768 \\
\text { (19 studies) }\end{array}$ & $\begin{array}{c}\oplus \oplus \oplus \ominus \\
\text { moderate }^{1}\end{array}$ & \\
\hline \multicolumn{7}{|l|}{$\mathrm{Cl}$ : Confidence interval } \\
\hline \multicolumn{7}{|c|}{$\begin{array}{l}\text { GRADE Working Group quality of evidence: } \\
\text { High quality: Further research is very unlikely to change our confidence in the estimate of effect. } \\
\text { Moderate quality. Further research is likely to have an important impact on our confidence in the estimate of effect and may change the estimate. } \\
\text { Low quality. Further research is very likely to have an important impact on our confidence in the estimate of effect and is likely to change the estimate. } \\
\text { Very low quality. We are very uncertain about the estimate. }\end{array}$} \\
\hline
\end{tabular}


Figure 55-Summary of Findings: Custom, Non-Titratable OAs for OSA (ESS).

\begin{tabular}{|c|c|c|c|c|c|c|}
\hline \multicolumn{7}{|c|}{ Custom, non-titratable OAs for OSA } \\
\hline \multicolumn{7}{|c|}{$\begin{array}{l}\text { Patient or population: Patients with OSA } \\
\text { Intervention: Custom, non-titratable OAs }\end{array}$} \\
\hline \multirow{2}{*}{ Outcomes } & \multicolumn{2}{|r|}{ Illustrative comparative risks* $(95 \% \mathrm{Cl})$} & $\begin{array}{l}\text { Relative effect } \\
(95 \% \mathrm{Cl})\end{array}$ & $\begin{array}{l}\text { No of Participants } \\
\text { (studies) }\end{array}$ & $\begin{array}{l}\text { Quality of the evidence } \\
\text { (GRADE) }\end{array}$ & Comments \\
\hline & Control & Custom, non-titratable OAs & & & & \\
\hline $\begin{array}{l}\text { ESS } \\
\text { (Daytime sleepiness) }\end{array}$ & & $\begin{array}{l}\text { The mean ESS in the intervention groups was } \\
\text { 3.65 lower } \\
\text { ( } 5.18 \text { to } 2.13 \text { lower) }\end{array}$ & & $\begin{array}{c}156 \\
\text { (8 studies) }\end{array}$ & 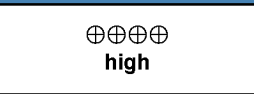 & \\
\hline \multicolumn{7}{|c|}{ Cl: Confidence interval } \\
\hline \multicolumn{7}{|c|}{$\begin{array}{l}\text { GRADE Working Group quality of evidence: } \\
\text { High quality. Further research is very unlikely to change our confidence in the estimate of effect. } \\
\text { Moderate quality: Further research is likely to have an important impact on our confidence in the estimate of effect and may change the estimate. } \\
\text { Low quality: Further research is very likely to have an important impact on our confidence in the estimate of effect and is likely to change the estimate. } \\
\text { Very low quality. We are very uncertain about the estimate. }\end{array}$} \\
\hline
\end{tabular}

\section{Figure 56-Summary of Findings: OAs vs. CPAP for OSA (ESS).}

\begin{tabular}{|c|c|c|c|c|c|c|}
\hline \multicolumn{7}{|c|}{ OAs compared to CPAP for OSA } \\
\hline \multicolumn{7}{|c|}{$\begin{array}{l}\text { Patient or population: patients with OSA } \\
\text { Intervention: OAs } \\
\text { Comparison: CPAP }\end{array}$} \\
\hline \multirow{3}{*}{ Outcomes } & \multicolumn{2}{|r|}{ Illustrative comparative risks* $(95 \% \mathrm{Cl})$} & \multirow{2}{*}{$\begin{array}{l}\text { Relative effect } \\
(95 \% \mathrm{Cl})\end{array}$} & \multirow{2}{*}{$\begin{array}{l}\text { No of Participants } \\
\text { (studies) }\end{array}$} & \multirow{2}{*}{$\begin{array}{l}\text { Quality of the evidence } \\
\text { (GRADE) }\end{array}$} & \multirow{2}{*}{ Comments } \\
\hline & Assumed risk & Corresponding risk & & & & \\
\hline & CPAP & \begin{tabular}{|c|} 
OAs \\
\end{tabular} & & & & \\
\hline $\begin{array}{l}\text { ESS } \\
\text { (Daytime sleepiness) }\end{array}$ & & $\begin{array}{l}\text { The mean ESS in the intervention groups was } \\
\text { 0.08 lower } \\
(0.21 \text { higher to } 0.38 \text { lower })\end{array}$ & & $\begin{array}{l}397 \\
\text { (10 studies) }\end{array}$ & $\begin{array}{l}\oplus \oplus \ominus \ominus \\
\text { low }^{1,2}\end{array}$ & \\
\hline \multicolumn{5}{|c|}{$\begin{array}{l}{ }^{*} \text { The basis for the assumed risk (e.g., the median control group risk across studies) is provided in footnotes. The corresponding risk (and its } 95 \% \text { confidence interval) is based on th } \\
\text { assumed risk in the comparison group and the relative effect of the intervention (and its } 95 \% \mathrm{Cl} \text { ). }\end{array}$} & its $95 \%$ confidence interval & is based on th \\
\hline \multicolumn{7}{|c|}{$\begin{array}{l}\text { GRADE Working Group quality of evidence: } \\
\text { High quality: Further research is very unlikely to change our confidence in the estimate of effect. } \\
\text { Moderate quality: Further research is likely to have an important impact on our confidence in the estimate of effect and may change the estimate. } \\
\text { Low quality: Further research is very likely to have an important impact on our confidence in the estimate of effect and is likely to change the estimate. } \\
\text { Very low quality: We are very uncertain about the estimate. }\end{array}$} \\
\hline
\end{tabular}


Figure 57-OAs for OSA (Quality of Life, QOL; Short Form-36, SF-36).

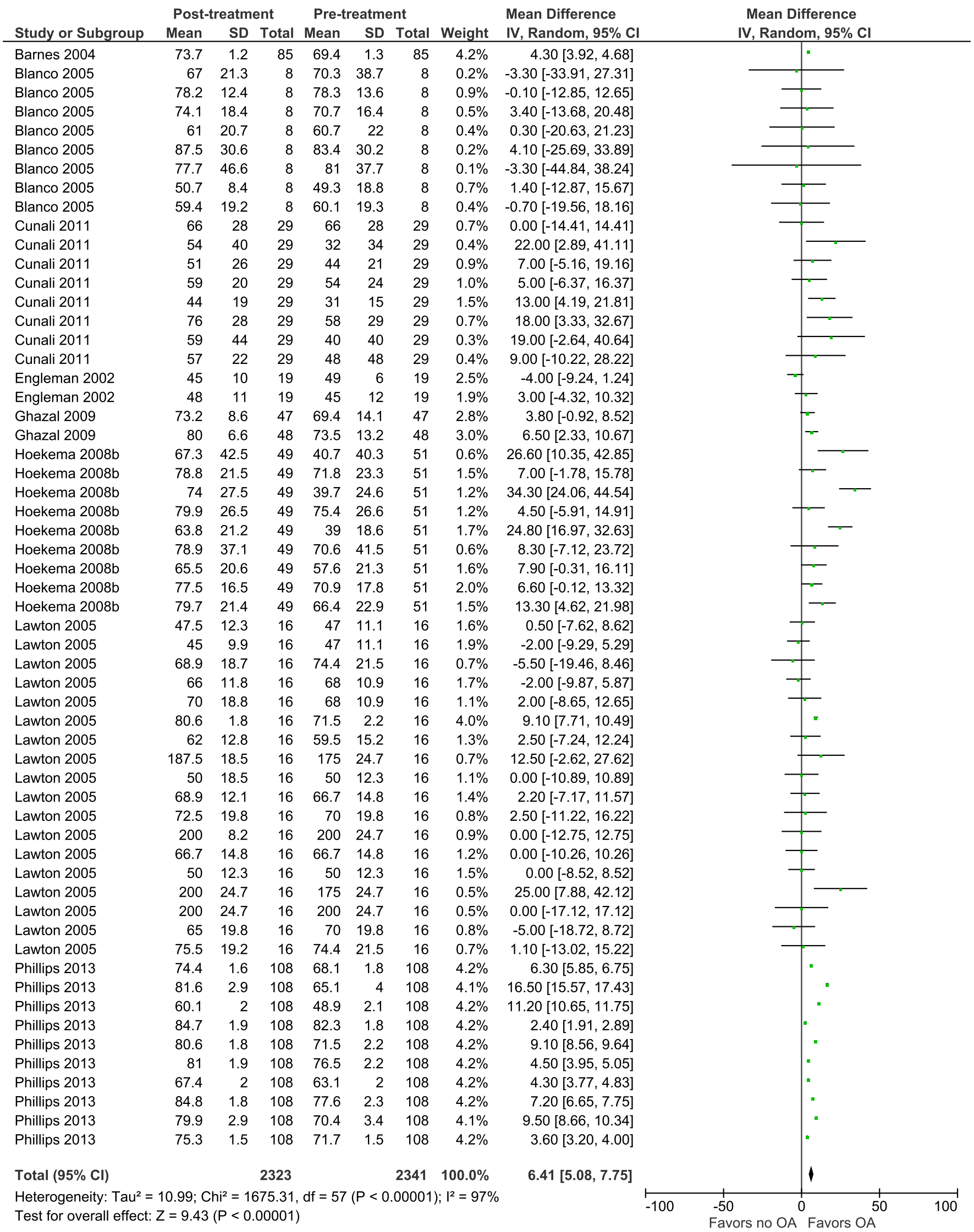


Figure 58-Custom, Titratable OAs for OSA (QOL; SF-36).

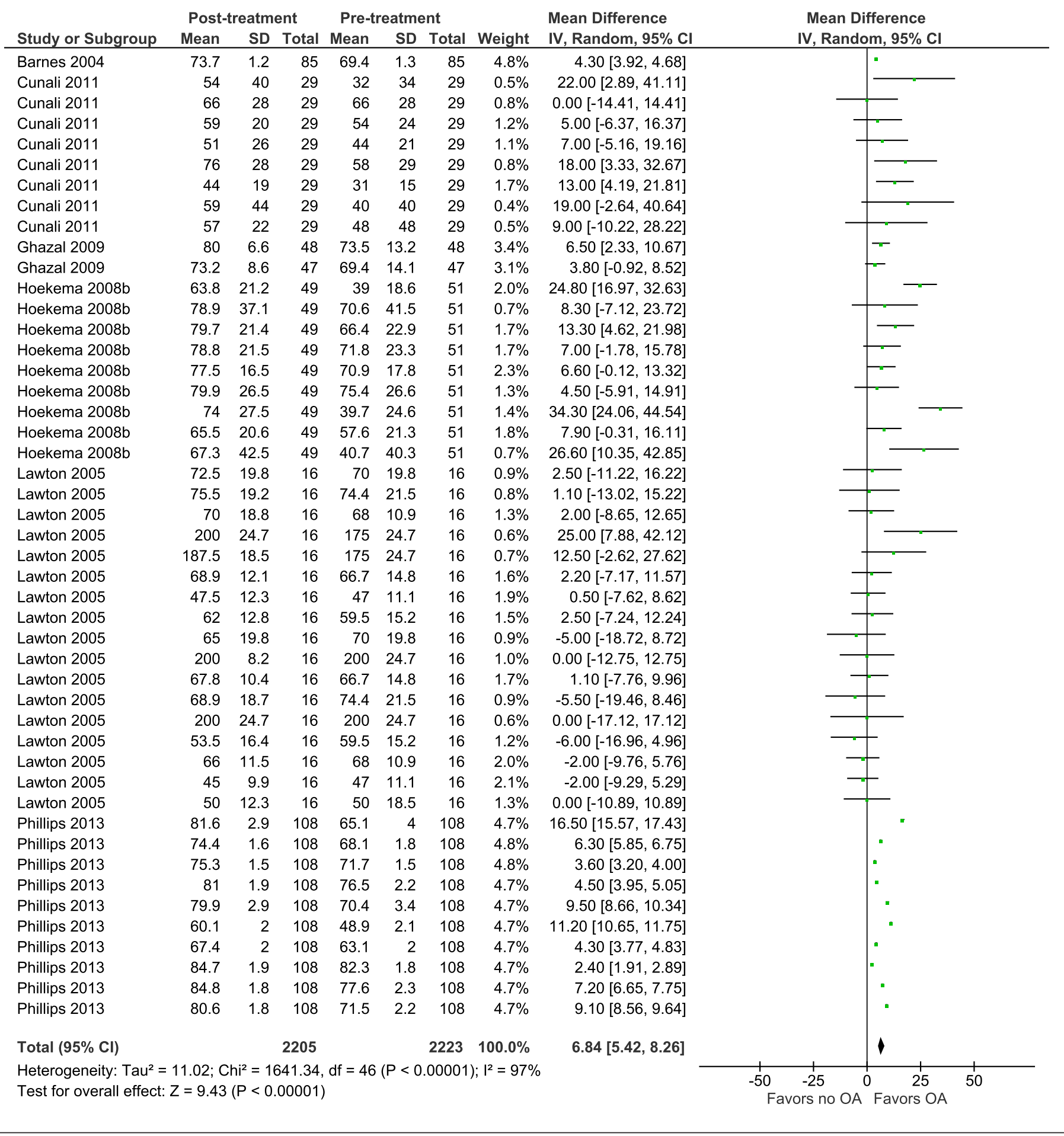


Figure 59—Custom, Non-Titratable OAs for OSA (QOL; SF-36).

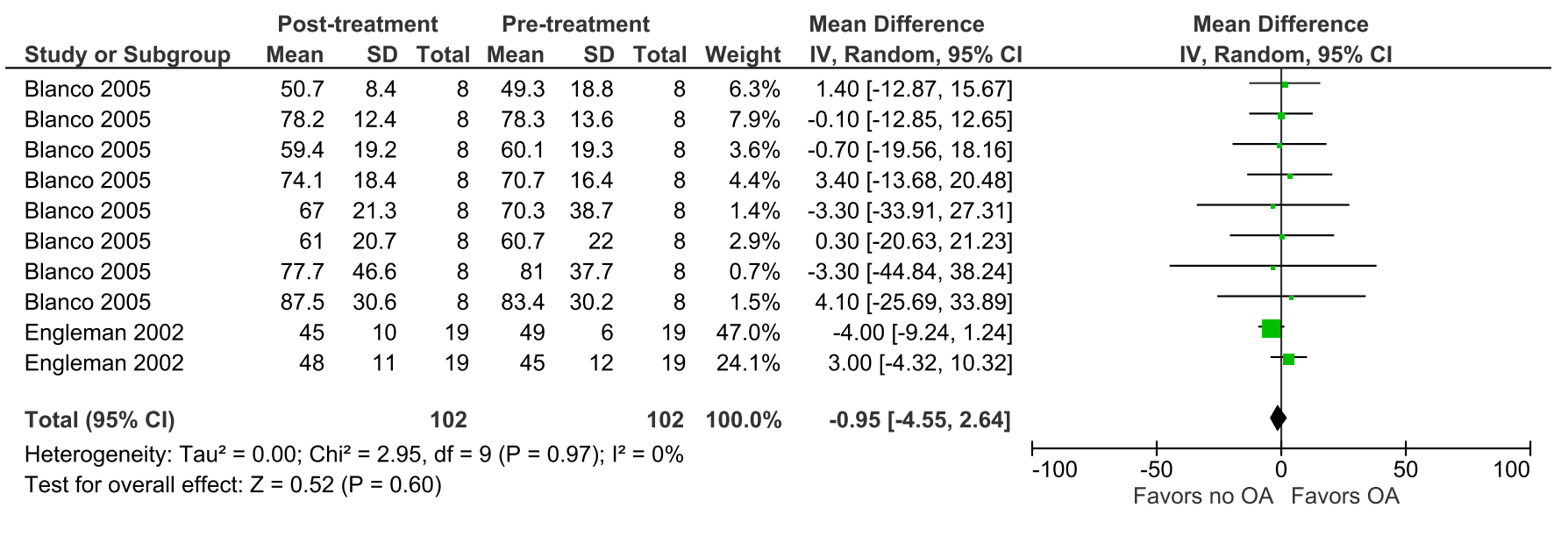

Figure 60-OAs vs. CPAP for OSA (QOL; SF-36).

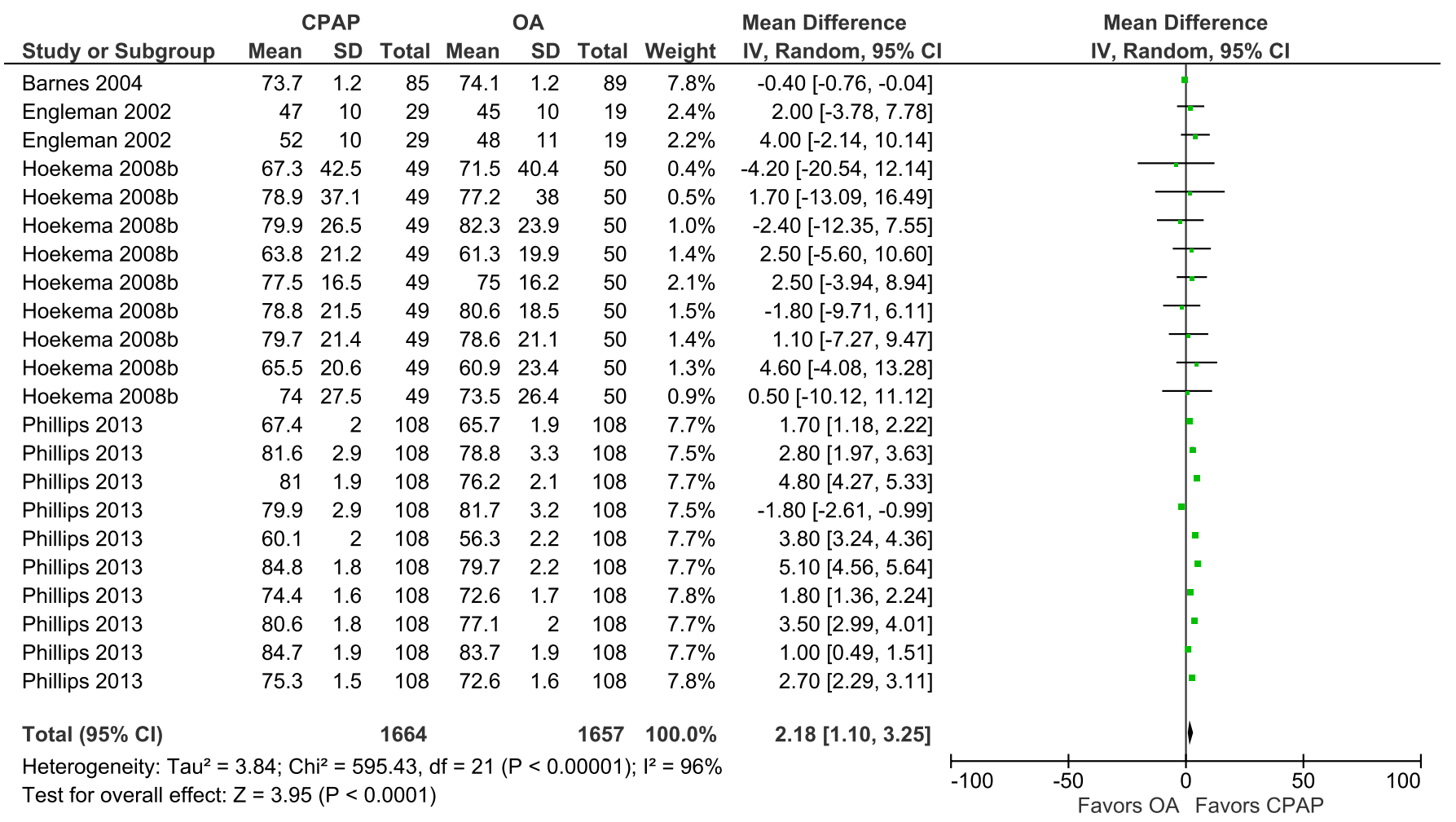


Figure 61-Summary of Findings: OAs Pre- vs. Post-Treatment for OSA (Quality of Life; QOL).

\begin{tabular}{|c|c|c|c|c|c|c|}
\hline OAs for O & & & & & & \\
\hline $\begin{array}{l}\text { Patient or } \\
\text { Interventio }\end{array}$ & tion: Patients & ith OSA & & & & \\
\hline Outcomes & & ustrative comparative risks* $(95 \% \mathrm{Cl})$ & Relative effect & No of Participants & Quality of the evidence & \\
\hline Uatconties & Assumed risk & \begin{tabular}{|c|} 
Corresponding risk \\
\end{tabular} & $(95 \% \mathrm{Cl})$ & (studies) & (GRADE) & Comments \\
\hline & Control & OAs & & & & \\
\hline QOL & & $\begin{array}{l}\text { The mean } Q O L \text { in the intervention groups was } \\
6.41 \text { higher } \\
\text { ( } 5.08 \text { to } 7.75 \text { higher) }\end{array}$ & & $\begin{array}{c}2323 \\
\text { (8 studies) }\end{array}$ & $\begin{array}{c}\oplus \oplus \oplus \ominus \\
\text { moderate }^{1}\end{array}$ & \\
\hline
\end{tabular}

*The basis for the assumed risk (e.g., the median control group risk across studies) is provided in footnotes. The corresponding risk (and its $95 \%$ confidence interval) is based on the assumed risk in the comparison group and the relative effect of the intervention (and its $95 \% \mathrm{Cl}$ ).

Cl: Confidence interval

GRADE Working Group quality of evidence:

High quality: Further research is very unlikely to change our confidence in the estimate of effect.

Moderate quality: Further research is likely to have an important impact on our confidence in the estimate of effect and may change the estimate.

Low quality: Further research is very likely to have an important impact on our confidence in the estimate of effect and is likely to change the estimate.

Very low quality: We are very uncertain about the estimate.

${ }^{1}$ s squared is high

Figure 62-Summary of Findings: Custom, Titratable OAs for OSA (QOL).

\begin{tabular}{|c|c|c|c|c|c|c|}
\hline \multicolumn{7}{|c|}{ Custom, titratable OAs for OSA } \\
\hline \multicolumn{7}{|c|}{$\begin{array}{l}\text { Patient or population: Patients with OSA } \\
\text { Intervention: Custom, titratable OAs }\end{array}$} \\
\hline \multirow{2}{*}{ Outcomes } & \multicolumn{2}{|c|}{ IIlustrative comparative risks* $(95 \% \mathrm{Cl})$} & \multirow{2}{*}{$\begin{array}{c}\text { Relative effect } \\
(95 \% \mathrm{Cl})\end{array}$} & \multirow{2}{*}{$\begin{array}{l}\text { No of Participants } \\
\text { (studies) }\end{array}$} & \multirow{2}{*}{$\begin{array}{l}\text { Quality of the evidence } \\
\text { (GRADE) }\end{array}$} & \multirow{2}{*}{ Comments } \\
\hline & Assumed risk & \begin{tabular}{|c|} 
Corresponding risk \\
\end{tabular} & & & & \\
\hline & Control & Custom, titratable OAs & & & & \\
\hline QOL & & $\begin{array}{l}\text { The mean QOL in the intervention groups was } \\
6.84 \text { higher } \\
(5.42 \text { to } 8.26 \text { higher) }\end{array}$ & & $\begin{array}{c}2205 \\
\text { (6 studies) }\end{array}$ & $\begin{array}{c}\oplus \oplus \oplus \Theta \\
\text { moderate }^{1}\end{array}$ & \\
\hline
\end{tabular}

"The basis for the assumed risk (e.g., the median control group risk across studies) is provided in footnotes. The corresponding risk (and its $95 \%$ confidence interval) is based on the assumed risk in the comparison group and the relative effect of the intervention (and its $95 \% \mathrm{Cl}$ )

Cl: Confidence interval

GRADE Working Group quality of evidence:

High quality. Further research is very unlikely to change our confidence in the estimate of effect.

Moderate quality: Further research is likely to have an important impact on our confidence in the estimate of effect and may change the estimate

Low quality. Further research is very likely to have an important impact on our confidence in the estimate of effect and is likely to change the estimate.

Very low quality: We are very uncertain about the estimate.

${ }^{1}$ I squared is high

Figure 63-Summary of Findings: Custom, Non-Titratable OAs for OSA (QOL).

\begin{tabular}{|c|c|c|c|c|c|c|}
\hline \multicolumn{7}{|c|}{ Custom, non-titratable OAs for OSA } \\
\hline \multicolumn{7}{|c|}{$\begin{array}{l}\text { Patient or population: Patients with OSA } \\
\text { Intervention: Custom, non-titratable OAs }\end{array}$} \\
\hline \multirow{2}{*}{ Outcomes } & \multicolumn{2}{|r|}{ Illustrative comparative risks* $(95 \% \mathrm{Cl})$} & \multirow{2}{*}{$\begin{array}{l}\text { Relative effect } \\
\qquad(95 \% \mathrm{Cl})\end{array}$} & \multirow{2}{*}{$\begin{array}{l}\text { No of Participants } \\
\text { (studies) }\end{array}$} & \multirow{2}{*}{$\begin{array}{l}\text { Quality of the evidence } \\
\text { (GRADE) }\end{array}$} & \multirow{2}{*}{ Comments } \\
\hline & Assumed risk & \begin{tabular}{|c|} 
Corresponding risk \\
\end{tabular} & & & & \\
\hline & Control & Custom, non-titratable OAs & & & & \\
\hline QOL & & $\begin{array}{l}\text { The mean } Q O L \text { in the intervention groups was } \\
0.95 \text { lower } \\
\text { ( } 4.55 \text { lower to } 2.64 \text { higher) }\end{array}$ & & $\begin{array}{c}102 \\
\text { (2 studies) }\end{array}$ & $\underset{\text { low }^{1,2}}{\oplus \oplus \ominus}$ & \\
\hline
\end{tabular}

*The basis for the assumed risk (e.g., the median control group risk across studies) is provided in footnotes. The corresponding risk (and its $95 \%$ confidence interval) is based on the assumed risk in the comparison group and the relative effect of the intervention (and its $95 \% \mathrm{Cl}$ ).

Cl: Confidence interval

GRADE Working Group quality of evidence:

High quality. Further research is very unlikely to change our confidence in the estimate of effect.

Moderate quality. Further research is likely to have an important impact on our confidence in the estimate of effect and may change the estimate.

Low quality. Further research is very likely to have an important impact on our confidence in the estimate of effect and is likely to change the estimate.

Very low quality. We are very uncertain about the estimate.

${ }^{1}$ I squared is high

${ }^{2} \mathrm{Cl}$ of absolute effect crosses clinical decision threshold 
Figure 64-Summary of Findings: OAs vs. CPAP for OSA (QOL).

\begin{tabular}{|c|c|c|c|c|c|c|}
\hline \multicolumn{7}{|c|}{ OAs compared to CPAP for OSA } \\
\hline \multicolumn{7}{|c|}{$\begin{array}{l}\text { Patient or population: patients with OSA } \\
\text { Intervention: OAs } \\
\text { Comparison: CPAP }\end{array}$} \\
\hline \multirow{2}{*}{ Outcomes } & \multicolumn{2}{|r|}{ Illustrative comparative risks $(95 \% \mathrm{Cl})$} & \multirow{2}{*}{$\begin{array}{l}\text { Relative effect } \\
\text { (95\% Cl) }\end{array}$} & \multirow{2}{*}{$\begin{array}{l}\text { No of Participants } \\
\text { (studies) }\end{array}$} & \multirow{2}{*}{$\begin{array}{l}\text { Quality of the evidence } \\
\text { (GRADE) }\end{array}$} & \multirow{2}{*}{ Comments } \\
\hline & Assumed risk & \begin{tabular}{|l|l} 
& Corresponding risk \\
\end{tabular} & & & & \\
\hline & CPAP & OAs & & & & \\
\hline QOL & & $\begin{array}{l}\text { The mean QOL in the intervention groups was } \\
2.18 \text { lower } \\
\text { (1.1 to } 3.25 \text { lower) }\end{array}$ & & $\begin{array}{c}1664 \\
\text { (4 studies) }\end{array}$ & $\underset{\text { low }^{1,2}}{\oplus \oplus \Theta}$ & \\
\hline \multirow{2}{*}{\multicolumn{7}{|c|}{$\begin{array}{l}{ }^{*} \text { The basis for the assumed risk (e.g., the median control group risk across studies) is provided in footnotes. The corresponding risk (and its } 95 \% \text { confidence interval) is based on th } \\
\text { assumed risk in the comparison group and the relative effect of the intervention (and its } 95 \% \mathrm{Cl} \text { ). } \\
\text { Cl: Confidence interval; }\end{array}$}} \\
\hline & & & & & & \\
\hline \multicolumn{7}{|c|}{$\begin{array}{l}\text { GRADE Working Group quality of evidence: } \\
\text { High quality: Further research is very unlikely to change our confidence in the estimate of effect. } \\
\text { Moderate quality: Further research is likely to have an important impact on our confidence in the estimate of effect and may change the estimate. } \\
\text { Low quality. Further research is very likely to have an important impact on our confidence in the estimate of effect and is likely to change the estimate. } \\
\text { Very low quality: We are very uncertain about the estimate. }\end{array}$} \\
\hline
\end{tabular}

Figure 65-OAs for OSA (Systolic blood pressure).

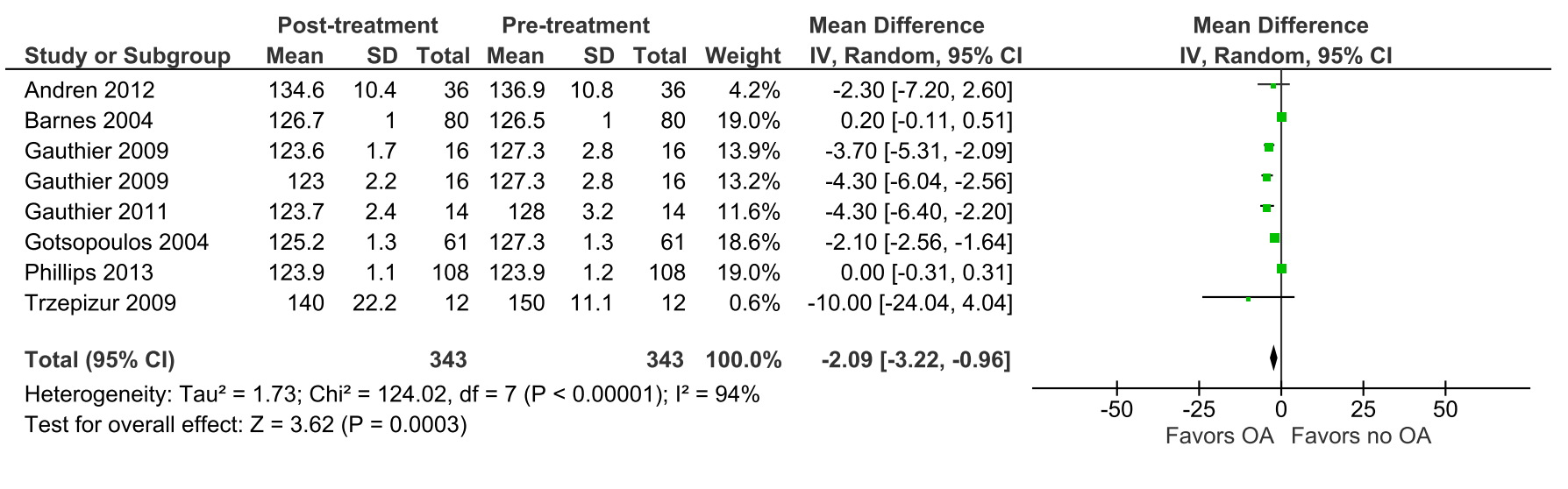

Figure 66-OAs for OSA (Diastolic blood pressure).

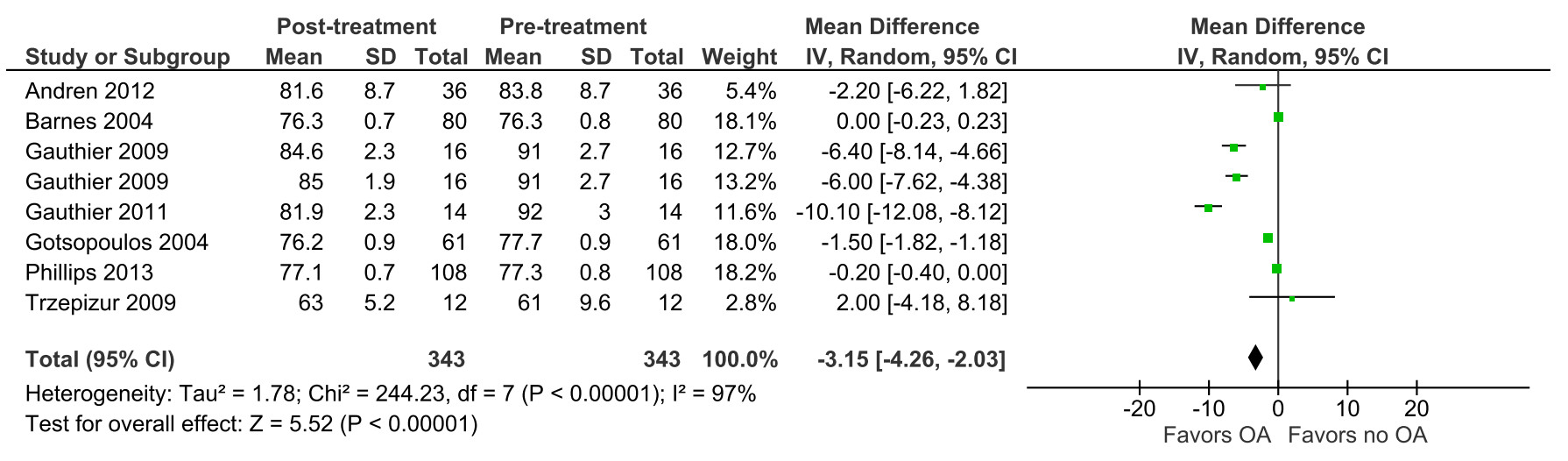


Figure 67-Custom, Titratable OAs for OSA (Systolic blood pressure).

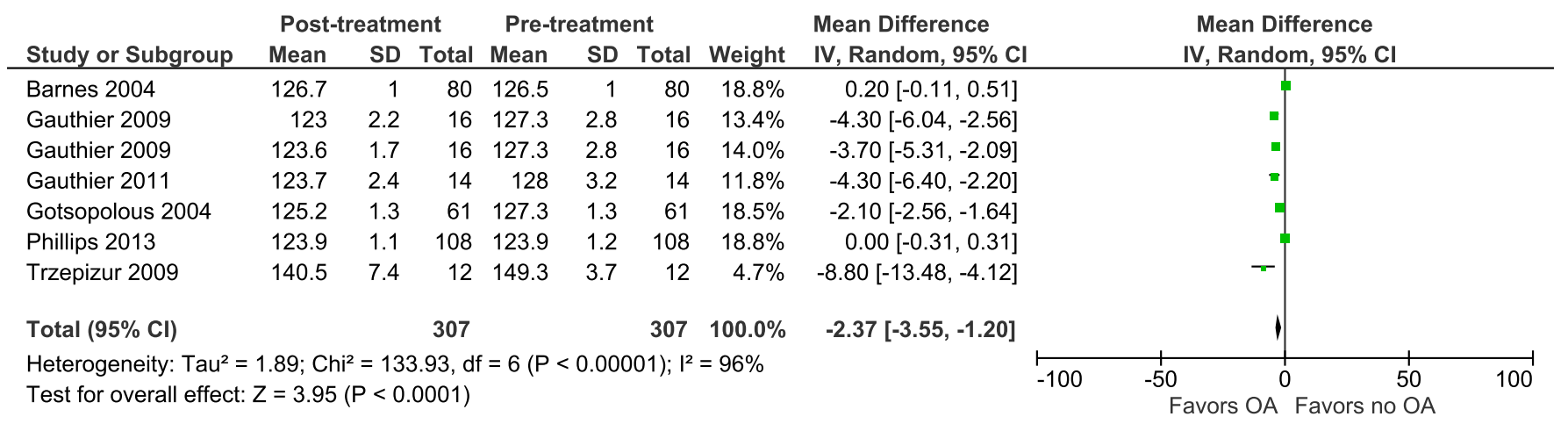

Figure 68-Custom, Titratable OAs for OSA (Diastolic blood pressure).

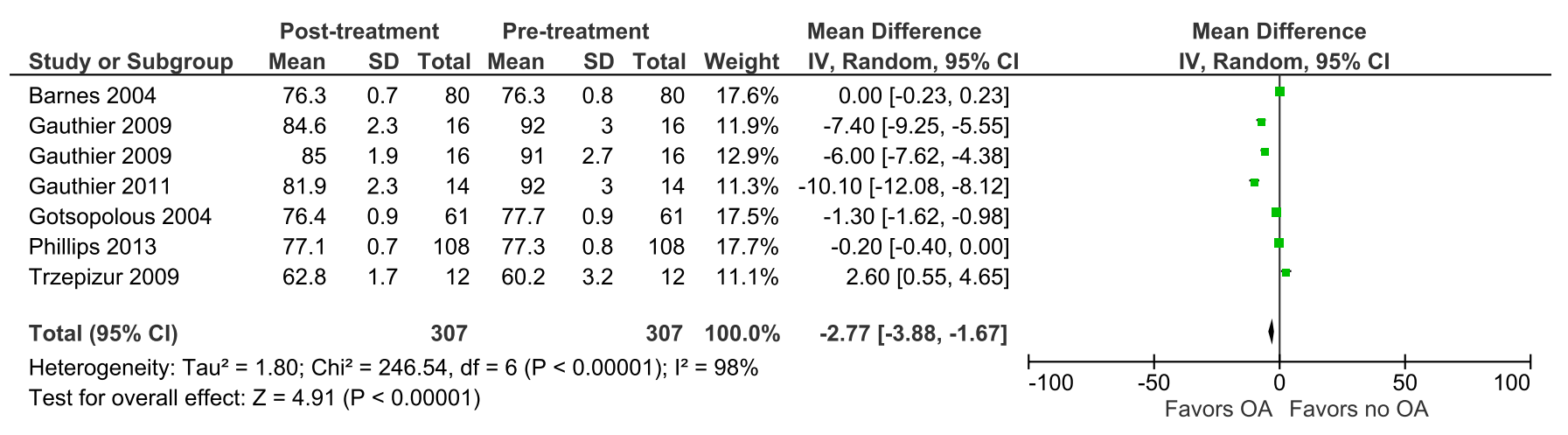

Figure 69-OAs vs. CPAP for OSA (Systolic blood pressure).

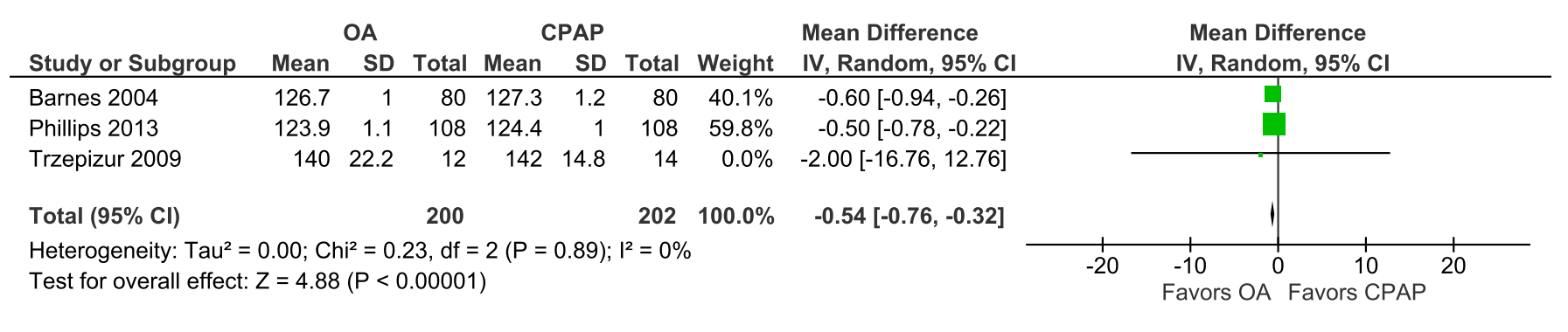

Figure 70-OAs vs. CPAP for OSA (Diastolic blood pressure).

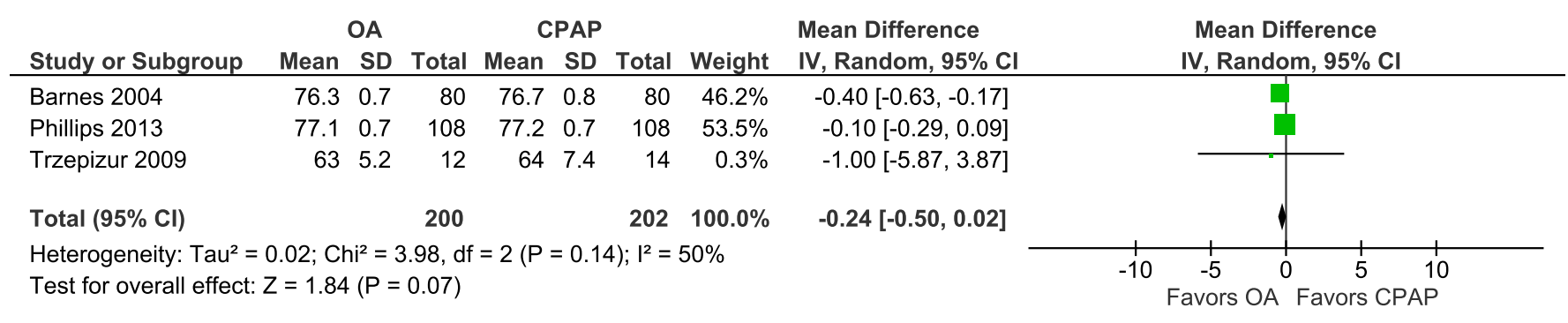


Figure 71-Summary of Findings: OAs for OSA (Hypertension).

\begin{tabular}{|c|c|c|c|c|c|c|}
\hline \multicolumn{7}{|l|}{ OAs for OSA } \\
\hline \multicolumn{7}{|c|}{$\begin{array}{l}\text { Patient or population: Patients with OSA } \\
\text { Intervention: OAs }\end{array}$} \\
\hline \multirow{2}{*}{ Outcomes } & \multicolumn{2}{|c|}{ Illustrative comparative risks* $(95 \% \mathrm{Cl})$} & \multirow{2}{*}{$\begin{array}{l}\text { Relative effect } \\
\quad(95 \% \mathrm{Cl})\end{array}$} & \multirow{2}{*}{$\begin{array}{l}\text { No of Participants } \\
\text { (studies) }\end{array}$} & \multirow{2}{*}{$\begin{array}{l}\text { Quality of the evidence } \\
\text { (GRADE) }\end{array}$} & \multirow{2}{*}{ Comments } \\
\hline & Assumed risk & Corresponding risk & & & & \\
\hline & Control & OAs & & & & \\
\hline Systolic blood pressure & & $\begin{array}{l}\text { The mean systolic blood pressure in the intervention } \\
\text { groups was } \\
\text { 2.09 lower } \\
\text { (3.22 to } 0.96 \text { lower) }\end{array}$ & & $\begin{array}{c}343 \\
(7 \text { studies })\end{array}$ & $\stackrel{\oplus \oplus \oplus \ominus}{\text { moderate }}$ & \\
\hline Diastolic blood pressure & & $\begin{array}{l}\text { The mean diastolic blood pressure in the intervention } \\
\text { groups was } \\
\text { 3.15 lower } \\
\text { (4.26 to } 2.03 \text { lower) }\end{array}$ & & $\begin{array}{c}343 \\
\text { (7 studies) }\end{array}$ & $\stackrel{\oplus \oplus \oplus \ominus}{\text { moderate }^{1}}$ & \\
\hline \multicolumn{7}{|c|}{$\begin{array}{l}\text { The basis for the assumed risk (e.g., the median control group risk across studies) is provided in footnotes. The corresponding risk (and its } 95 \% \text { confidence interval) is based on the } \\
\text { assumed risk in the comparison group and the relative effect of the intervention (and its } 95 \% \mathrm{Cl} \text { ). }\end{array}$} \\
\hline \multicolumn{7}{|c|}{ Cl: Confidence interval } \\
\hline \multicolumn{7}{|c|}{$\begin{array}{l}\text { GRADE Working Group quality of evidence: } \\
\text { High quality: Further research is very unlikely to change our confidence in the estimate of effect. } \\
\text { Moderate quality: Further research is likely to have an important impact on our confidence in the estimate of effect and may change the estimate. } \\
\text { Low quality. Further research is very likely to have an important impact on our confidence in the estimate of effect and is likely to change the estimate. } \\
\text { Very low quality: We are very uncertain about the estimate. }\end{array}$} \\
\hline
\end{tabular}

Figure 72-Summary of Findings: Custom, Titratable OAs for OSA (Hypertension).

\begin{tabular}{|c|c|c|c|c|c|c|}
\hline \multicolumn{7}{|c|}{ Custom, titratable OAs for OSA } \\
\hline \multicolumn{7}{|c|}{$\begin{array}{l}\text { Patient or population: Patients with OSA } \\
\text { Intervention: Custom, titratable OAs }\end{array}$} \\
\hline \multirow{2}{*}{ Outcomes } & \multicolumn{2}{|r|}{ Illustrative comparative risks ${ }^{\star}(95 \% \mathrm{Cl})$} & \multirow{2}{*}{\begin{tabular}{c|c|c|c|}
$\begin{array}{c}\text { Relative effect } \\
\text { (95\% Cl) }\end{array}$ &
\end{tabular}} & \multirow{2}{*}{$\begin{array}{l}\text { No of Participants } \\
\text { (studies) }\end{array}$} & \multirow{2}{*}{$\begin{array}{l}\begin{array}{l}\text { Quality of the evidence } \\
\text { (GRADE) }\end{array} \\
\text { (G) }\end{array}$} & \multirow{2}{*}{ Comments } \\
\hline & Assumed risk & Corresponding risk & & & & \\
\hline & Control & Custom, titratable OAs & & & & \\
\hline Systolic blood pressure & & $\begin{array}{l}\text { The mean systolic blood pressure in the intervention } \\
\text { groups was } \\
\text { 2.37 lower } \\
\text { (1.20 to } 3.55 \text { lower) }\end{array}$ & & $\begin{array}{c}307 \\
\text { (6 studies) }\end{array}$ & $\begin{array}{c}\oplus \oplus \oplus \ominus \\
\text { moderate }^{1}\end{array}$ & \\
\hline Diastolic blood pressure & & $\begin{array}{l}\text { The mean diastolic blood pressure in the intervention } \\
\text { groups was } \\
2.77 \text { lower } \\
\text { (1.67 to } 3.88 \text { lower) }\end{array}$ & & $\begin{array}{l}307 \\
\text { (6 studies) }\end{array}$ & $\begin{array}{c}\oplus \oplus \oplus \ominus \\
\text { moderate }\end{array}$ & \\
\hline \multicolumn{7}{|c|}{$\begin{array}{l}\text { *The basis for the assumed risk (e.g., the median control group risk across studies) is provided in footnotes. The corresponding risk (and its } 95 \% \text { confidence interval) is based on the } \\
\text { assumed risk in the comparison group and the relative effect of the intervention (and its } 95 \% \mathrm{Cl} \text { ). }\end{array}$} \\
\hline \multicolumn{7}{|c|}{ Cl: Confidence interval } \\
\hline \multicolumn{7}{|c|}{$\begin{array}{l}\text { GRADE Working Group quality of evidence: } \\
\text { High quality: Further research is very unlikely to change our confidence in the estimate of effect. } \\
\text { Moderate quality: Further research is likely to have an important impact on our confidence in the estimate of effect and may change the estimate. } \\
\text { Low quality: Further research is very likely to have an important impact on our confidence in the estimate of effect and is likely to change the estimate. } \\
\text { Very low quality: We are very uncertain about the estimate. }\end{array}$} \\
\hline I squared is high & & & & & & \\
\hline
\end{tabular}


Figure 73-Summary of Findings: Custom, Non-Titratable OAs for OSA (Hypertension).

\begin{tabular}{|c|c|c|c|c|c|c|}
\hline \multicolumn{7}{|c|}{ Custom, non-titratable OAs for OSA } \\
\hline \multicolumn{7}{|c|}{$\begin{array}{l}\text { Patient or population: Patients with OSA } \\
\text { Intervention: Custom, non-titratable OAs }\end{array}$} \\
\hline \multirow{2}{*}{ Outcomes } & \multicolumn{2}{|r|}{ Illustrative comparative risks* $(95 \% \mathrm{Cl})$} & \multirow{2}{*}{\begin{tabular}{|c|} 
Relative effect \\
$(95 \% \mathrm{Cl})$
\end{tabular}} & \multirow{2}{*}{\begin{tabular}{|c|}
$\begin{array}{c}\text { No of Participants } \\
\text { (studies) }\end{array}$ \\
\end{tabular}} & \multirow{2}{*}{$\begin{array}{c}\text { Quality of the evidence } \\
\text { (GRADE) }\end{array}$} & \multirow{2}{*}{ Comments } \\
\hline & Assumed risk & \begin{tabular}{|c|} 
Corresponding risk \\
\end{tabular} & & & & \\
\hline & Control & Custom, non-titratable OAs & & & & \\
\hline Systolic blood pressure & & $\begin{array}{l}\text { The mean systolic blood pressure in the intervention groups } \\
\text { was } \\
2.30 \text { lower } \\
\text { (7.2 to } 2.6 \text { lower) }\end{array}$ & & $\begin{array}{l}36 \\
(1 \text { study })\end{array}$ & $\begin{array}{l}\oplus \oplus \oplus \oplus \\
\text { high }\end{array}$ & \\
\hline Diastolic blood pressure & & $\begin{array}{l}\text { The mean diastolic blood pressure in the intervention } \\
\text { groups was } \\
2.2 \text { lower } \\
\text { (6.22 to } 1.82 \text { lower) }\end{array}$ & & $\begin{array}{l}36 \\
(1 \text { study })\end{array}$ & $\underset{\text { high }}{\oplus \oplus \oplus}$ & \\
\hline \multicolumn{7}{|c|}{$\begin{array}{l}{ }^{*} \text { The basis for the assumed risk (e.g., the median control group risk across studies) is provided in footnotes. The corresponding risk (and its } 95 \% \text { confidence interval) is based on the } \\
\text { assumed risk in the comparison group and the relative effect of the intervention (and its } 95 \% \mathrm{Cl} \text { ). }\end{array}$} \\
\hline \multicolumn{7}{|l|}{ Cl: Confidence interval } \\
\hline \multicolumn{7}{|c|}{$\begin{array}{l}\text { GRADE Working Group quality of evidence: } \\
\text { High quality. Further research is very unlikely to change our confidence in the estimate of effect. } \\
\text { Moderate quality: Further research is likely to have an important impact on our confidence in the estimate of effect and may change the estimate. } \\
\text { Low quality. Further research is very likely to have an important impact on our confidence in the estimate of effect and is likely to change the estimate. } \\
\text { Very low quality: We are very uncertain about the estimate. }\end{array}$} \\
\hline
\end{tabular}

Figure 74-Summary of Findings: OAs vs. CPAP for OSA (Hypertension).

\begin{tabular}{|c|c|c|c|c|c|c|}
\hline \multicolumn{7}{|c|}{ OAs compared to CPAP for OSA } \\
\hline \multicolumn{7}{|c|}{$\begin{array}{l}\text { Patient or population: Patients with OSA } \\
\text { Intervention: OAs } \\
\text { Comparison: CPAP }\end{array}$} \\
\hline \multirow{2}{*}{ Outcomes } & \multicolumn{2}{|r|}{ Illustrative comparative risks* $(95 \% \mathrm{Cl})$} & \multirow{2}{*}{$\begin{array}{c}\begin{array}{c}\text { Relative effect } \\
(95 \% \mathrm{Cl})\end{array} \\
\end{array}$} & \multirow{2}{*}{$\begin{array}{l}\text { No of Participants } \\
\text { (studies) }\end{array}$} & \multirow{2}{*}{$\begin{array}{l}\text { Quality of the evidence } \\
\text { (GRADE) }\end{array}$} & \multirow{2}{*}{ Comments } \\
\hline & Assumed risk & Corresponding risk & & & & \\
\hline & CPAP & OAs & & & & \\
\hline Systolic blood pressure & & \begin{tabular}{|l|} 
The mean systolic blood pressure in the intervention groups \\
was \\
0.54 lower \\
(0.76 to 0.32 lower)
\end{tabular} & & $\begin{array}{c}202 \\
\text { (3 studies) }\end{array}$ & $\begin{array}{l}\oplus \oplus \Theta \Theta \\
\text { low }^{1,2}\end{array}$ & \\
\hline Diastolic blood pressure & & $\begin{array}{l}\text { The mean diastolic blood pressure in the intervention } \\
\text { groups was } \\
0.24 \text { lower } \\
\text { ( } 0.5 \text { lower to } 0.02 \text { higher) }\end{array}$ & & $\begin{array}{c}202 \\
\text { (3 studies) }\end{array}$ & $\begin{array}{l}\oplus \oplus \Theta \Theta \\
\text { low }^{1.2}\end{array}$ & \\
\hline \multicolumn{7}{|c|}{$\begin{array}{l}\text { "The basis for the assumed risk (e.g., the median control group risk across studies) is provided in footnotes. The corresponding risk (and its } 95 \% \text { confidence interval) is based on the } \\
\text { assumed risk in the comparison group and the relative effect of the intervention (and its } 95 \% \mathrm{Cl} \text { ). }\end{array}$} \\
\hline \multicolumn{7}{|l|}{ Cl: Confidence interval } \\
\hline \multicolumn{7}{|c|}{$\begin{array}{l}\text { GRADE Working Group quality of evidence: } \\
\text { High quality: Further research is very unlikely to change our confidence in the estimate of effect. } \\
\text { Moderate quality: Further research is likely to have an important impact on our confidence in the estimate of effect and may change the estimate. } \\
\text { Low quality. Further research is very likely to have an important impact on our confidence in the estimate of effect and is likely to change the estimate. } \\
\text { Very low quality: We are very uncertain about the estimate. }\end{array}$} \\
\hline
\end{tabular}


Figure 75-OAs vs. CPAP for OSA (Adherence).

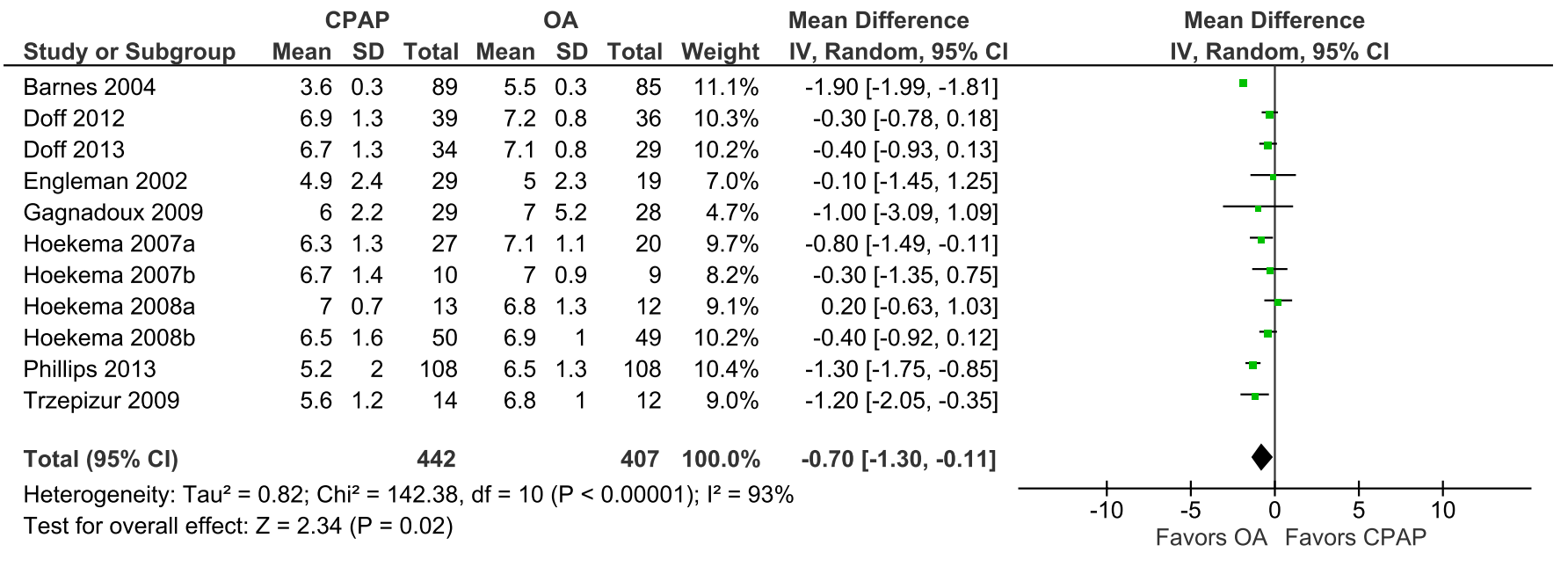

Figure 76-Summary of Findings: OAs vs. CPAP for OSA (Adherence).

\begin{tabular}{|c|c|c|c|c|c|c|}
\hline \multicolumn{7}{|c|}{ OAs compared to CPAP for OSA } \\
\hline \multicolumn{7}{|c|}{$\begin{array}{l}\text { Patient or population: Patients with OSA } \\
\text { Intervention: OAs } \\
\text { Comparison: CPAP }\end{array}$} \\
\hline \multirow{2}{*}{ Outcomes } & \multicolumn{2}{|r|}{ Illustrative comparative risks* $(95 \% \mathrm{Cl})$} & \multirow{2}{*}{$\begin{array}{l}\text { Relative effect } \\
(95 \% \mathrm{Cl})\end{array}$} & \multirow{2}{*}{$\begin{array}{l}\text { No of Participants } \\
\text { (studies) }\end{array}$} & \multirow{2}{*}{$\begin{array}{l}\text { Quality of the evidence } \\
\text { (GRADE) }\end{array}$} & \multirow{2}{*}{ Comments } \\
\hline & Assumed risk & Corresponding risk & & & & \\
\hline & CPAP & OAs & & & & \\
\hline Adherence (hrs./night) & & $\begin{array}{l}\text { The mean adherence ( } h / \text { night }) \text { in the intervention groups } \\
\text { was } \\
0.70 \text { higher } \\
(0.11 \text { to } 1.30 \text { higher })\end{array}$ & & $\begin{array}{l}442 \\
\text { (11 studies) }\end{array}$ & $\begin{array}{l}\oplus \oplus \ominus \ominus \\
\text { low }^{1,2}\end{array}$ & \\
\hline \multicolumn{7}{|c|}{$\begin{array}{l}\text { *The basis for the assumed risk (e.g., the median control group risk across studies) is provided in footnotes. The corresponding risk (and its } 95 \% \text { confidence interval) is based on th } \\
\text { assumed risk in the comparison group and the relative effect of the intervention (and its } 95 \% \mathrm{Cl} \text { ). }\end{array}$} \\
\hline \multicolumn{7}{|l|}{ Cl: Confidence interval } \\
\hline \multicolumn{7}{|c|}{$\begin{array}{l}\text { GRADE Working Group quality of evidence: } \\
\text { High quality: Further research is very unlikely to change our confidence in the estimate of effect. } \\
\text { Moderate quality. Further research is likely to have an important impact on our confidence in the estimate of effect and may change the estimate. } \\
\text { Low quality: Further research is very likely to have an important impact on our confidence in the estimate of effect and is likely to change the estimate. } \\
\text { Very low quality. We are very uncertain about the estimate. }\end{array}$} \\
\hline
\end{tabular}

Figure 77-OAs for OSA (Side Effects).

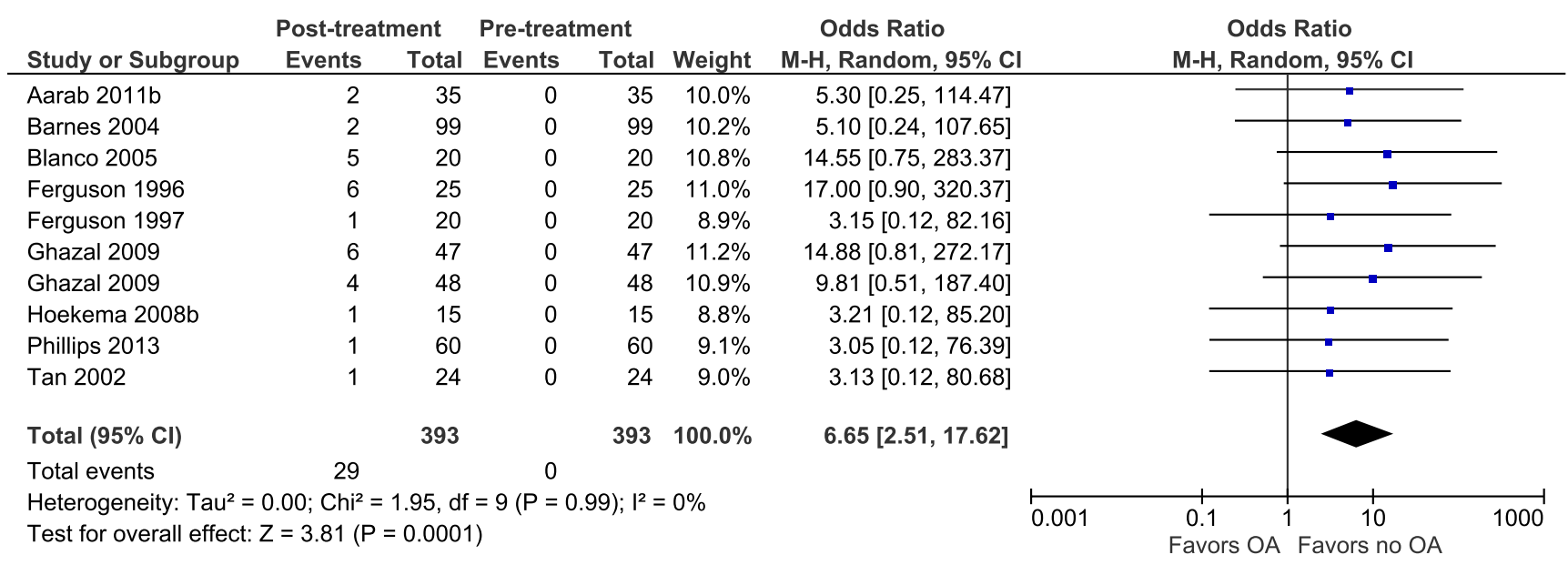


Figure 78-OAs vs. CPAP for OSA (Side Effects).

OA CPAP

Study or Subgroup

Aarab 2011a

Aarab 2011b

Barnes 2004

Ferguson 1996

Ferguson 1997

Hoekema 2008b

Phillips 2013

Tan 2002

Total $(95 \% \mathrm{Cl})$

Total events

Heterogeneity: $\mathrm{Tau}^{2}=0.00 ; \mathrm{Chi}^{2}=3.82, \mathrm{df}=7(\mathrm{P}=0.80) ; \mathrm{I}^{2}=0 \%$

Test for overall effect: $Z=1.65(P=0.10)$
Odds Ratio

M-H, Random, 95\% Cl

$0.13[0.01,2.67]$

$0.29[0.05,1.57]$

$1.98[0.18,22.19]$

$0.67[0.19,2.33]$

$0.30[0.03,3.15]$

$2.79[0.10,74.63]$

$0.51[0.04,5.76]$

$0.48[0.04,5.66]$

$0.54[0.26,1.12]$

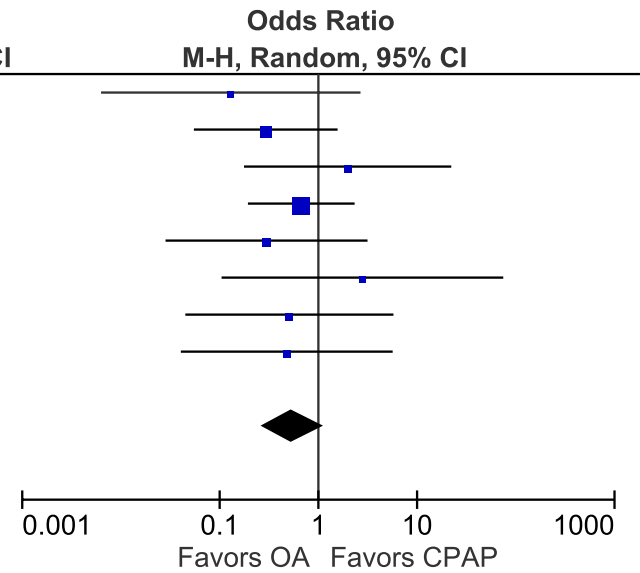

Figure 79-Summary of Findings: OAs for OSA (Side Effects).

\section{OAs for OSA}

Patient or population: Patients with OSA

Intervention: OAs

\begin{tabular}{|c|c|c|c|c|c|c|}
\hline \multirow[t]{2}{*}{ Outcomes } & \multicolumn{2}{|c|}{$\begin{array}{l}\text { Illustrative comparative risks }{ }^{*} \\
\qquad(95 \% \mathrm{Cl})\end{array}$} & \multirow{2}{*}{$\begin{array}{l}\text { Relative } \\
\text { effect } \\
(95 \% \text { Cl) }\end{array}$} & \multirow{2}{*}{$\begin{array}{c}\text { No of } \\
\text { Participants } \\
\text { (studies) }\end{array}$} & \multirow{2}{*}{$\begin{array}{l}\text { Quality of the } \\
\text { evidence } \\
\text { (GRADE) }\end{array}$} & \multirow[t]{2}{*}{ Comments } \\
\hline & Assumed risk & Corresponding risk & & & & \\
\hline & Control & OAs & & & & \\
\hline $\begin{array}{l}\text { Discontinuation of therapy } \\
\text { from side effects }\end{array}$ & & & $\begin{array}{c}\text { RR 6.65 } \\
(2.51 \text { to } \\
17.62)\end{array}$ & $\begin{array}{c}786 \\
\text { (9 studies) }\end{array}$ & $\underset{\text { high }}{\oplus \oplus \oplus \oplus}$ & \\
\hline
\end{tabular}

*The basis for the assumed risk (e.g., the median control group risk across studies) is provided in footnotes. The corresponding risk (and its $95 \%$ confidence interval) is based on the assumed risk in the comparison group and the relative effect of the intervention (and its $95 \% \mathrm{Cl}$ ).

CI: Confidence interval; RR: Risk ratio

GRADE Working Group quality of evidence:

High quality: Further research is very unlikely to change our confidence in the estimate of effect.

Moderate quality: Further research is likely to have an important impact on our confidence in the estimate of effect and may change the estimate.

Low quality: Further research is very likely to have an important impact on our confidence in the estimate of effect and is likely to change the estimate.

Very low quality: We are very uncertain about the estimate. 
Figure 80-Summary of Findings: OAs vs. CPAP for OSA (Side Effects).

OAs compared to CPAP for OSA

Patient or population: Patients with OSA

Intervention: OAs

Comparison: CPAP

\begin{tabular}{|c|c|c|c|c|c|c|}
\hline \multirow[t]{2}{*}{ Outcomes } & \multicolumn{2}{|c|}{$\begin{array}{l}\text { Illustrative comparative risks* } \\
\qquad(95 \% \mathrm{CI})\end{array}$} & \multirow{2}{*}{$\begin{array}{c}\text { Relative } \\
\text { effect } \\
(95 \% \mathrm{Cl})\end{array}$} & \multirow{2}{*}{$\begin{array}{c}\text { No of } \\
\text { Participants } \\
\text { (studies) }\end{array}$} & \multirow{2}{*}{$\begin{array}{l}\text { Quality of the } \\
\text { evidence } \\
\text { (GRADE) }\end{array}$} & \multirow[t]{2}{*}{ Comments } \\
\hline & Assumed risk & Corresponding risk & & & & \\
\hline & CPAP & OAs & & & & \\
\hline $\begin{array}{l}\text { Discontinuation of therapy } \\
\text { from side effects }\end{array}$ & 84 per 1000 & $\begin{array}{l}45 \text { per } 1000 \\
(22 \text { to } 94)\end{array}$ & $\begin{array}{c}\text { RR } 0.54 \\
(0.26 \text { to } \\
1.12)\end{array}$ & $\begin{array}{c}597 \\
\text { (8 studies) }\end{array}$ & $\begin{array}{c}\oplus \oplus \oplus \ominus \\
\text { moderate }^{1}\end{array}$ & \\
\hline
\end{tabular}

*The basis for the assumed risk (e.g., the median control group risk across studies) is provided in footnotes. The corresponding risk (and its $95 \%$ confidence interval) is based on the assumed risk in the comparison group and the relative effect of the intervention (and its $95 \% \mathrm{Cl}$ ).

Cl: Confidence interval; RR: Risk ratio

GRADE Working Group quality of evidence:

High quality: Further research is very unlikely to change our confidence in the estimate of effect.

Moderate quality: Further research is likely to have an important impact on our confidence in the estimate of effect and may change the estimate.

Low quality: Further research is very likely to have an important impact on our confidence in the estimate of effect and is likely to change the estimate.

Very low quality: We are very uncertain about the estimate.

${ }^{1} \mathrm{Cl}$ of absolute effect crosses the clinical decision threshold 